\title{
1 Prenatal exposure to EDCs dis-integrates and reconstitutes neuromolecular- behavioral relationships in adult rats
}

3

4 Morgan E. Hernandez Scudder ${ }^{1}$, Rebecca L. Young ${ }^{2 @}$, Lindsay M. Thompson ${ }^{3}$, Pragati Kore²,

5 David Crews ${ }^{2}$, Hans A. Hofmann ${ }^{1,2}$, Andrea C. Gore ${ }^{1,3, *}$

6

$7{ }^{\circledR}$ Co-first authors

8

9 Institute for Neuroscience ${ }^{1}$; Department of Integrative Biology ${ }^{2}$; Division of Pharmacology \&

10 Toxicology ${ }^{3}$; The University of Texas at Austin, Austin, TX, 78712

$12 *$ Correspondence:

13 Andrea C. Gore

14 University of Texas at Austin

Email: andrea.gore@austin.utexas.edu

15107 W. Dean Keeton St., Box C0875

16 Austin, TX, 78712, USA

17

18 Grant support: NIH 1RO1 ES023254 (ACG, DC), 1RO1 ES029464 (ACG); T32 DA018926

19 (MEHS)

20

21 Acknowledgments: The authors thank Dr. Krittika Krishnan and Dr. Michael Reilly for their

22 assistance collecting behavioral data and for their input on the selection of target genes.

23

24 Keywords: endocrine-disrupting chemicals (EDCs), polychlorinated biphenyls (PCBs),

25 vinclozolin, ventromedial nucleus, preoptic area, medial amygdala, mate preference, gene

26 networks 
AbSTRACT

Exposure to endocrine-disrupting chemicals (EDCs) is ubiquitous in all species, including

29 humans. Previous studies have shown behavioral deficits caused by EDCs that have implications

30 for social competence and sexual selection. The neuromolecular mechanisms for these behavioral

31 changes induced by EDCs have not been thoroughly explored. Here, we tested the hypothesis that

32 EDCs administered to rats during a critical period of embryonic brain development would lead to

33 disruption of normal social preference behavior, and that this involves a network of underlying

34 gene pathways in brain regions that regulate these behaviors. Rats were exposed prenatally to

35 human-relevant concentrations of EDCs [polychlorinated biphenyls (PCB), an industrial chemical

36 mixture; vinclozolin (VIN), a fungicide], or vehicle. In adulthood, a sociosexual preference test

37 (choice between hormone-primed and hormone-depleted opposite-sex rats) was administered. We

38 profiled gene expression of in three brain regions involved in these behaviors [preoptic area (POA),

39 medial amygdala (MeA), ventromedial nucleus (VMN)]. Prenatal PCBs impaired sociosexual

40 preference in both sexes, and VIN disrupted this behavior in males. Each brain region (POA, MeA,

41 VMN) had unique sets of genes altered in a sex- and EDC-specific manner. Sexually dimorphic

42 gene expression disruption was particularly prominent for gene modules pertaining to sex steroid

43 hormones and nonapeptides in the MeA. EDC exposure also changed the relationships between

44 gene expression and behavior in the mate preference test, a pattern we refer to as dis-integration

45 and reconstitution. These findings underscore the profound effects that developmental exposure to

46 EDCs can have on adult social behavior, highlight sex-specific and individual variation in

47 responses, and provide a foundation for further work on the disruption of mate preference behavior

48 after prenatal exposure to EDCs. 
INTRODUCTION

Environmental contamination with endocrine-disrupting chemicals (EDCs) perturbs

51 hormones and their actions in virtually all species and ecosystems (Gore et al., 2015). Prenatal

52 EDC exposures pose a particular risk due to the exquisite sensitivity of the developing brain to

53 gonadal hormones, which are required for sex-typical differentiation and development of neural

54 circuits, and the manifestation of behaviors. In the hypothalamus of male rodents and other

55 mammals, prenatal and early postnatal testicular hormones masculinize and defeminize circuits.

56 In females, the relative quiescence of the ovary and concomitantly lower gonadal hormone

57 production, together with alpha-fetoprotein that prevents estrogens' crossing the blood-brain-

58 barrier, is responsible for brain feminization and demasculinization (Bakker et al., 2006; Nugent

59 et al., 2015; Schwarz \& McCarthy, 2008; Wright, Schwarz, Dean, \& McCarthy, 2010).

60 The effects of developmental EDC exposure on sexually dimorphic social behaviors and

61 gene expression patterns in different brain regions have been described for several classes of

62 chemicals. Although individual EDCs are not pure hormone agonists or antagonists, some [such

63 as certain polychlorinated biphenyls (PCBs) and bisphenol A (BPA)] mimic or disrupt estrogen

64 signaling (Dickerson \& Gore, 2007), and others [vinclozolin (VIN) and phthalates] are anti65 androgenic (Euling et al., 2002; Stroheker et al., 2005). PCBs, widespread industrial chemical

66 contaminants, alter gene expression in the hypothalamus (Dickerson, Cunningham, \& Gore, 2011;

67 Faass, Ceccatelli, Schlumpf, \& Lichtensteiger, 2013; Topper et al., 2019) and change interactions

68 of adult rats with conspecifics (Hernandez Scudder et al., 2020; Bell, Hart, \& Gore, 2016; Colciago

69 et al., 2009; Cummings, Clemens, \& Nunez, 2008; Steinberg, Juenger, \& Gore, 2007). Bisphenol

70 A (BPA) from plastic, and the fungicide VIN also change brain gene expression (BPA:

71 Wolstenholme et al., 2012, VIN: Skinner, Savenkova, Zhang, Gore, \& Crews, 2014; Faass et al.,

72 2013; Lichtensteiger et al., 2015) and sociosexual behavior (BPA: Jones, Shimell, \& Watson,

73 2011; Monje, Varayoud, Muñoz-de-Toro, Luque, \& Ramos, 2009; Porrini et al., 2005, VIN:

74 Colbert et al., 2005; Krishnan et al., 2018). Prenatal exposure to phthalates causes long-lasting 
75 changes to gene expression in the hypothalamus and beyond (Gao et al., 2018; Lin et al., 2015).

76 Phthalate exposure early in life also cause deficits in cognitive and social behaviors (Lin et al.,

77 2015; R. Wang, $\mathrm{Xu}, \& \mathrm{Zhu}, 2016)$. In most cases, outcomes are dependent on the dose, timing,

78 and length of exposure, as well as the sex of the animal. This is not surprising considering the

79 dynamic nature of endogenous hormone signaling as the brain develops, and the vulnerability of

80 estrogenic and androgenic pathways to EDCs.

81 Reproductive success is contingent upon sex-appropriate differentiation of the brain during

82 early life. For an individual to reproduce successfully, appropriate dyadic interactions with another

83 sexually mature potential mate of the opposite sex are required. This process involves assessment

84 of an opposite-sex animal's fitness through a variety of physical and behavioral cues, including

85 hormonal status, as well-documented in rats (Drewett, 1973; Edwards \& Einhorn, 1986; Eliasson

$86 \&$ Meyerson, 1975). There is plasticity in this behavior, with the decision-making process affected

87 by prior sexual experience of both individuals, estrous cycle stage, hormone levels, and other

88 factors. Within the brain, a complex social decision-making network (O'Connell \& Hofmann,

89 2012) comprising hypothalamic [e.g., ventromedial nucleus (VMN), preoptic area (POA)] and

90 extra-hypothalamic [e.g., medial amygdala (MeA)] regions expresses specific genes and proteins

91 that modulate these behaviors (Spiteri et al., 2010).

92 Here, we tested the hypothesis that prenatal EDC exposures would cause disruptions to the

93 pattern of expression of a suite of genes in three brain regions in the social decision-making

94 network (VMN, POA, MeA) and that this underlies functional deficits in an ethologically-relevant

95 sociosexual behavioral task. Previous work has not considered the complex inter-relationships of

96 these phenotypes, a gap we intended to fill in current work. The goal was to determine whether

97 these relationships would break down (become "dis-organized") and/or become reconstituted into

98 novel patterns. To do this, we combined an integrative analysis of behavioral and hormonal

99 phenotypes and gene co-expression patterns to characterize relationships between multiple 
measures of motivated behavior, gene expression patterns, and circulating hormone levels in response to prenatal EDC exposure in both male and female rats.

\section{METHODS AND MATERIALS}

\section{Experimental design}

All rat procedures were conducted in compliance with protocols approved by IACUC at The University of Texas at Austin. Sprague-Dawley rats purchased from Envigo (Houston) were housed in colony rooms with consistent temperature $\left(22^{\circ} \mathrm{C}\right)$ and light cycle $(14: 10$ dark:light, lights

108 off at 1100). All rats had ad libitum access to water and were fed a low phytoestrogen rat chow 109 (Teklad 2019, Envigo).

To generate experimental rats, virgin females were mated with sexually experienced males.

111 Successful mating was indicated by the presence of sperm in a vaginal smear. The day after mating 112 overnight was termed embryonic day 1 (E1). Pregnant rats received intraperitoneal (i.p.) injections

113 of one of three treatments daily from E8-E18: (1) Vehicle (6\% DMSO in sesame oil), (2) A1221

$114(1 \mathrm{mg} / \mathrm{kg})$, or (3) VIN (1mg/kg). Each dam was exposed to the same treatment daily and received 115 a total of 11 injections. The route, timing of treatment and the dosages were selected to match prior 116 work, based on ecological relevance, and to span the period of hypothalamic neurogenesis, fetal 117 gonadal development and the early stages of brain sexual differentiation (Arnold \& Gorski, 1984; 118 Krishnan, Hasbum, et al., 2019; Krishnan et al., 2018; Krishnan, Rahman, et al., 2019; Rodier, 119 1980). A subset of offspring (30 male and 29 female) from 9 DMSO, 10 A1221 (PCB), and 10 120 VIN dams were included in this study. No more than 2 same sex rats per litter were used. We 121 measured body weight and anogenital distance (AGD) on days P7 and P14 to calculate the 122 Anogenital Index $(A G I=A G D / \sqrt[3]{\text { bodyweight }})$. The 5 males and 5 females with the median 123 intrasex AGI measurements were used for the subsequent experiments. The pups were weaned at 
124 P21 and re-housed in same-sex groups of 2-3. Beginning on the day of vaginal opening, daily 125 vaginal smears were collected from females and cell cytology was examined as an indication of 126 estrous cyclicity. Timing of pubertal development did not vary across treatment groups (ANOVA; 127 Male age at preputial separation: DMSO 43.50 \pm 0.5, PCB $44.22 \pm 0.70$, VIN $44.10 \pm 0.66$. Female 128 age at vaginal opening: DMSO $36.44 \pm 0.65$, PCB $35.30 \pm 0.92$, VIN $34.60 \pm 0.56$ ). Rats were 129 euthanized at $\sim \mathrm{P} 120$, with females in proestrus, by rapid decapitation and brains removed and 130 processed as described below.

131 Stimulus Sprague-Dawley rats for the mate preference test were purchased as virgin adults.

132 Males were castrated (GDX) and females ovariectomized (OVX) under isoflurane anesthesia in 133 aseptic conditions (Garcia, Bezner, Depena, Yin, \& Gore, 2017; Wu \& Gore, 2010). During the

134 surgery, stimulus animals assigned to the hormone-replaced group also had a $1.5 \mathrm{~cm}$ Silastic 135 capsule containing testosterone (males: 100\% T; GDX+T) or a 1.0cm silastic capsule containing $13617 \beta$-estradiol (females: 5\% E2/95\% cholesterol; OVX+E2) implanted subcutaneously into the 137 nape of the neck (Garcia et al., 2017). All rats recovered from surgery for at least one week prior 138 to use in behavioral tests. 32 GDX males (no hormone replacement), 32 GDX+T males, 32 OVX 139 females (no hormone replacement), and $32 \mathrm{OVX}+\mathrm{E} 2$ females were used as stimuli throughout the 140 study. For the latter group, on the day of use these E2-treated females were primed for sexual 141 receptivity by a subcutaneous injection of progesterone $(\mathrm{P} 4,0.6 \mathrm{mg})$ in sesame oil four hours 142 before experiments started.

\section{Sociosexual preference behavior}

A $1 \mathrm{~m} \times 1 \mathrm{~m}$ three-chambered apparatus (Stoelting, Wood Dale, IL) was used as the testing 145 arena (Bell et al., 2016; Reilly et al., 2015). Testing was conducted under dim red light 146 approximately two hours into the dark phase of the light-dark cycle. Each test utilized an 147 experimental (EDC or vehicle exposed) rat at $\sim 3$ months of age. Two opposite-sex stimulus rats, 148 one with and one without hormone replacement, were used, with each one placed inside $7 \mathrm{~cm} \times 15$ 

spaced vertical bars, allowing for limited tactile interactions between rats. The position of stimulus

151 rats was randomized between trials and with respect to hormone status. The bars of the stimulus

152 cage allowed for visual, olfactory, auditory, and minimal tactile interaction between the confined

153 stimulus rat and the freely-moving experimental rat. Each trial began with the two stimulus rats

154 already in position in their cylindrical cages. An experimental rat was placed in the center chamber

155 of the apparatus with closed doors preventing entry into either side chamber for a five-minute

156 habituation period. After habituation, the doors were removed and the experimental rat was

157 allowed to freely explore the entire arena for 10 minutes. Each test was recorded by overhead

158 video. ANY-Maze (Stoelting, Wood Dale, IL) was used to track the position, speed, and distance

159 traveled of the experimental rat in each compartment of the chamber (Hernandez Scudder et al.,

160 2020; Garcia et al., 2017; Reilly et al., 2015). Recordings of the tests were scored by a trained

161 investigator blinded to treatment for the following behaviors: nose touching (direct nose-to-nose

162 contact between the experimental rat and a stimulus rat) and stimulus investigation (all other

163 investigation by the experimental rat of a stimulus rat or stimulus cage). The time the experimental

164 animal spent within one body length of either stimulus cage without engaging with the stimulus

165 animal or cage [time within one body length - (time nose touching + time investigating)] was

166 defined as "time near". To avoid testing fatigue, stimulus rats were used for no more than three

167 rounds of testing per day and had 10 minutes of rest with access to food and water between each

168 round. Stimulus rats had two days of rest between each day of testing. The entire apparatus was 169 cleaned using $70 \%$ ethanol between each test subject.

\section{Hormone radioimmunoassay}

171 Serum levels of testosterone and corticosterone (CORT) were measured in duplicate 172 samples, and estradiol (E2) in single samples (due to larger serum volume needed for this assay) 173 using radioimmunoassays (Testosterone: MP Biomedicals \#07189102, CORT: MP Biomedicals 
$174 \quad \# 07120102$; E2: Beckman Coulter \#DSL-4800). Assay parameters were: CORT, limit of detection

$1757.7 \mathrm{ng} / \mathrm{ml}$, intra-assay CV 2.5\%; testosterone, limit of detection $30 \mathrm{pg} / \mathrm{ml}$, intra-assay CV $3.7 \%$;

176 E2: limit of detection $2.2 \mathrm{pg} / \mathrm{ml}$, intra-assay CV $16.8 \%$.

\section{TaqMan Low Density qPCR Array}

178 Brains from experimental rats were rapidly removed, chilled on ice, and then coronally

179 sliced at $1 \mathrm{~mm}$ using a chilled brain matrix. These slices were placed on slides and stored at -80

180 until all samples were collected. Bilateral punches were taken of the POA, MeA and VMN using

181 a $1 \mathrm{~mm}$ Palkovits punch (Gillette et al., 2014). RNA from frozen POA, MeA, and VMN punches

182 was extracted using AllPrep RNA/DNA Mini Kit (Qiagen, 80204) according to the manufacturer's

183 protocol. To determine the integrity and purity, a subset of samples was run on a Bioanalyzer 2100

184 (Agilent, RNA Pico Kit 5067-1513). All samples had a RIN of 8.4 or above. RNA (200 ng) was

185 then converted to single stranded cDNA using high-capacity cDNA reverse transcriptase kit (Life

186 Technologies, 4374966) according to the manufacturer's protocol. cDNA was run on a custom 48-

187 gene TaqMan Low Density Array Card (ThermoFisher Scientific) with target genes selected based

188 on a priori hypotheses and their role in neuroendocrine function and sensitivity to EDCs reported

189 in the literature. Run parameters were: $95{ }^{\circ} \mathrm{C}$ for $10 \mathrm{~min}, 50$ cycles of $95{ }^{\circ} \mathrm{C}$ for $15 \mathrm{sec}$, and $60{ }^{\circ} \mathrm{C}$

190 for $1 \mathrm{~min}$ (Topper et al., 2019). Gene expression cycle threshold (Ct) values were normalized using

191 the $\Delta \Delta \mathrm{Ct}$ method. First, each target gene value was normalized to the expression level of the

192 reference gene Gapdh within each subject to generate $\Delta \mathrm{Ct}$. To standardize between subjects, the

$193 \Delta \mathrm{Ct}$ of each gene was normalized to the median value of a control group (DMSO females) to 194 generate $\Delta \Delta C \mathrm{Ct}$. Data are reported as $2^{-\Delta \Delta C t}$. Two genes (Cypl1al \& Hsd3b1) did not amplify and 195 were excluded, leaving 44 target genes and 2 housekeeping genes (Gapdh, 18s). In all cases, 196 significance was set at $\mathrm{p}<0.05$ after appropriate corrections for multiple comparisons. 


\section{Behaviors and hormones}

For behaviors, analyses were performed separately for each sex. Those behaviors involving

199 choice based on the hormone status of the stimulus rat were analyzed by a two-way ANOVA

200 (treatment $\mathrm{x}$ stimulus hormone status). Other behaviors (e.g. center time, distance traveled of

201 experimental rat) were analyzed by one-way ANOVA. To explore sex differences, a two-way

202 ANOVA for treatment $\mathrm{x}$ sex was used for stimulus-independent behaviors between the sexes.

203 Hormone concentrations, body weight, and puberty timing within each sex were analyzed by one-

204 way ANOVA. Reported p-values of multiple comparisons were adjusted using Sidak's multiple 205 comparisons test.

207 preference was calculated as a ratio of time within one body length of both stimulus animals out

208 of the total test time: $\frac{\text { time within one body length }}{\text { total test time }}$. Linear regressions were used to determine 209 correlations with significantly non-zero slopes.

\section{$210 \quad$ Principal components analysis}

211 To characterize coordinated phenotypic response to EDC exposure, we performed a

212 Principal Components Analysis (PCA) on morphological, physiological, and behavioral measures

213 including body weight, CORT, E2, T (males only), activity, social preference, hormone preference,

214 and social activity (time spent investigating and interacting with stimulus rats) using the prcomp

215 function in R. Behavioral variables included in the PCA are provided in Table 1. All variables

216 were centered and scaled prior to PCA. 
Table 1. Behavioral variables analyzed in the sociosexual preference test

\begin{tabular}{|c|c|c|c|c|c|c|c|c|c|c|}
\hline \multirow[t]{2}{*}{ Behavior } & \multirow[t]{2}{*}{$\begin{array}{l}\text { Abbreviation } \\
\text { in PCA }\end{array}$} & \multicolumn{3}{|c|}{ DMSO } & \multicolumn{3}{|c|}{ PCB } & \multicolumn{3}{|c|}{ VIN } \\
\hline & & Mean & SEM & $\mathrm{N}$ & Mean & SEM & $\mathrm{N}$ & Mean & SEM & $\mathrm{N}$ \\
\hline \multicolumn{11}{|l|}{ Females } \\
\hline Total distance (m) & Dist & 46 & 3 & 9 & 43 & 3 & 10 & 43 & 4 & 10 \\
\hline Center time (s) & CentTime & 102 & 14 & 9 & 101 & 11 & 10 & 118 & 16 & 10 \\
\hline Total social time (s) & SocTime & 335 & 19 & 9 & 332 & 22 & 10 & 343 & 21 & 10 \\
\hline $\begin{array}{l}\text { Total time near } \\
\text { stimulus (s) }\end{array}$ & NearTime & 158 & 11 & 9 & 157 & 13 & 10 & 163 & 16 & 10 \\
\hline $\begin{array}{l}\text { Total nose touch time } \\
\text { (s) }\end{array}$ & NoseTouch & 8.1 & 2.5 & 9 & 8.6 & 4.4 & 10 & 13.8 & 4.2 & 10 \\
\hline $\begin{array}{l}\text { Total stimulus explore } \\
\text { time (s) }\end{array}$ & StimExpl & 169 & 14 & 9 & 166 & 28 & 10 & 167 & 15 & 10 \\
\hline Hormone preference & HormPref & 0.64 & 0.05 & 9 & 0.52 & 0.04 & 10 & 0.66 & 0.06 & 10 \\
\hline Social preference & SocPref & 0.56 & 0.03 & 9 & 0.56 & 0.04 & 10 & 0.57 & 0.03 & 10 \\
\hline \multicolumn{11}{|l|}{ Males } \\
\hline Total distance (m) & Dist & 25 & 2 & 10 & 22 & 4 & 9 & 23 & 4 & 10 \\
\hline Center time (s) & CentTime & 171 & 34 & 10 & 285 & 65 & 9 & 317 & 59 & 10 \\
\hline Total social time (s) & SocTime & 256 & 46 & 10 & 219 & 52 & 9 & 143 & 37 & 10 \\
\hline $\begin{array}{l}\text { Total time near } \\
\text { stimulus (s) }\end{array}$ & NearTime & 142 & 37 & 10 & 95 & 25 & 9 & 68 & 17 & 10 \\
\hline $\begin{array}{l}\text { Total nose touch time } \\
\text { (s) }\end{array}$ & NoseTouch & 9.7 & 5.0 & 10 & 3.9 & 1.6 & 9 & 5.2 & 1.8 & 10 \\
\hline $\begin{array}{l}\text { Total stimulus explore } \\
\text { time (s) }\end{array}$ & StimExpl & 105 & 32 & 10 & 121 & 38 & 9 & 70 & 20 & 10 \\
\hline Hormone preference & HormPref & 0.41 & 0.12 & 10 & 0.23 & 0.08 & 9 & 0.45 & 0.11 & 10 \\
\hline Social preference & SocPref & 0.43 & 0.08 & 10 & 0.37 & 0.09 & 9 & 0.24 & 0.06 & 10 \\
\hline
\end{tabular}

Sociosexual preference behaviors are shown as mean \pm SEM, with n's indicated. Total behaviors are times for the two stimulus rats combined. Bolded numbers are significantly different from the same-sex DMSO control. 

and three brain regions with a minimum module size of five genes. Expression values of each

223 module were summarized as module eigengenes (i.e., the first principal component of each gene

224 co-expression module). Thus, each eigengene is the linear combination of gene expression values 225 that explains the most variation in the expression levels of the genes contained in the module. We 226 assessed coordinated changes in phenotypes and gene expression across treatments using general

227 linear models. Specifically, we tested the hypotheses that the relationship between behavioral 228 measures associated with preference and social interactions and gene co-expression modules 229 describing coordinated nonapeptide gene expression patterns would differ across the treatments in 230 both sexes (Co-expression module $\sim$ Treatment + Behavioral PC + TreatmentXBehavioral PC).

\section{Co-variance patterns between neural gene expression, physiology, behavior, and morphology}

To assess systems-level response to EDC treatment and the potential dis-integration and/or 233 reconstitution, defined as loss or change of correlations by EDCs, respectively, we examined co234 variance patterns among all neural gene expression, physiological, behavioral, and morphological 235 measures for each control and treatment conditions separately and visualized changes in the 236 correlation structure across treatments. We calculated Spearman's rank correlations between all 237 pairwise variables. Variables were clustered using 1-correlation scores as distance variables. To 238 visually assess the extent of integration or re-organization (or lack thereof) for each EDC treatment 239 across levels of biological organization, neural gene expression and phenotype clustering of the 240 control condition was maintained for treatment animals for each sex and brain region.

241 Sexually dimorphic neural expression of nonapeptide and sex steroid hormone signaling 242 genes

To characterize changes to sexually dimorphic gene expression and any potential 244 demasculinizing/feminizing or defeminizing/masculinizing effects of EDC treatment, we 245 quantified gene expression distances of all pairwise treatments and sexes for genes from two 
candidate functional categories, nonapeptides and sex steroid hormone signaling (Fig. 5, yellow and orange functional group, respectively). Nonapeptide genes included Oxt, Oxtr, Avp, Avprla,

248 Kiss1, and Kiss 1r for all 3 brain regions, with Gnrh1 and Tac3 also included in the POA. Sex

249 steroid hormone signaling genes included Esrl, Esr2, Ar, Pgr, Nr3c1, Cyp19a1, Srd5al, and

$250 H s d 17 b 1$ for all three brain regions. Euclidean distances for each pairwise sex, treatment

251 comparison were calculated using the expression levels of each gene in these functional categories.

252 We then used a permutation analysis to test for significant modifications in sexually dimorphic 253 expression of functional categories. Specifically, to test the hypothesis that sex or treatment were 254 closer in any pairwise comparison than expected by chance, we shuffled sample treatment 255 assignment within sex and recalculated the Euclidean distances for all pairwise comparisons. We 256 repeated this process for 1000 iterations and compared the observed distance to the distribution of 257 permutated distances to obtain a p-value. Distance networks were plotted for both functional 258 categories and all three brain regions.

\section{RESULTS}

\section{Embryonic exposure to EDCs affected sociosexual behavior in a sex-dependent manner} to investigate both of the stimulus rat options during the allotted 10 minutes. We refer to these 265 males as "non-responders" in all subsequent analyses. All males were included regardless of 266 responder status in analyses of sex differences, PCA analysis, and gene expression analysis. 267 However, Figure 1 shows analyses of only the responder males (6 DMSO, $6 \mathrm{PCB}$, and $6 \mathrm{VIN}$ ), as 268 that test required rats to interact with both opposite-sex stimulus animals to calculate a score. Other 269 figures are inclusive of the entire cohort of males, regardless of responder status. 
271 females spent associating (within one body length) with the stimulus rats $\left(\mathrm{F}_{(1,52)}=18.77 ; \mathrm{p}<\right.$ 272 0.0001). Females prenatally exposed to DMSO or VIN preferred the hormone-replaced male.
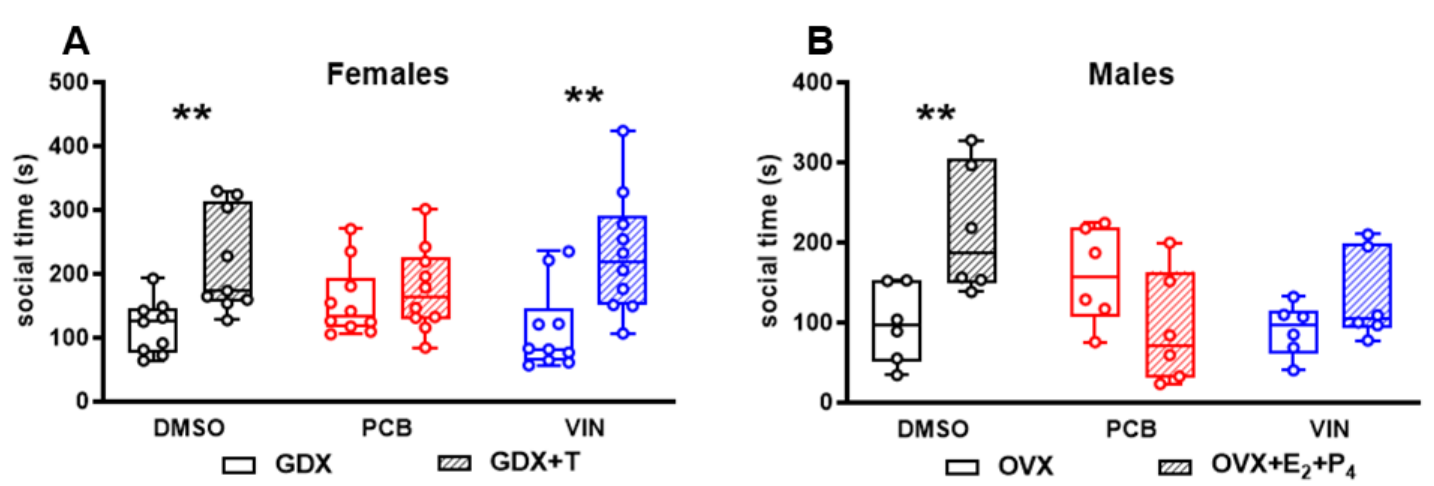

Figure 1: Time spent with each stimulus rat (social time) during mate preference is shown for females (A) and males (B) as median (bar within the box), quartiles (upper and lower limits of the box), and range (whisker) for the 10-minute mate preference test. The same graphing conventions are used for other box-and-whisker graphs. Data for males include responders only. Asterisks indicate a significant difference between the social time spent with the two stimulus options. Two-way ANOVA, main effect of stimulus hormone, followed by Sidak's multiple comparisons test. GDX, gonadectomized male; OVX, ovariectomized female. ** $\mathrm{p}<$

273 Prenatal exposure to PCB, however, abolished this preference in females (Fig 1A). There was no

274 effect of treatment on the total time that the experimental rats spent investigating both stimulus 275 rats (Social Time; Table 1).

In males, there was a significant interaction between treatment and hormone status of the

277 stimulus rat on the time spent associating with the stimulus rats $\left(\mathrm{F}_{(2,30)}=7.113 ; \mathrm{p}<0.01\right)$. Males

278 exposed prenatally to DMSO spent more time investigating the stimulus female with hormone 279 replacement over the one without. However, the time males exposed prenatally to PCB or VIN 280 spent near the two stimulus rat options did not differ significantly (Fig 1B). These findings 281 replicated those in our recent publication (Hernandez Scudder et al., 2020). 
284 the test duration, females traveled significantly farther than males (Fig 2A; $\mathrm{F}_{(1,52)}=55.94 ; \mathrm{p}<$ 285 0.0001). Females spent more time in close proximity to but not interacting with both stimulus rats $286\left(\right.$ Fig $\left.2 \mathrm{~B} ; \mathrm{F}_{(1,52)}=10.49 ; \mathrm{p}<0.01\right)$. Females spent more time directly investigating the stimulus rats

287 than males $\left(\right.$ Fig $\left.2 \mathrm{C} ; \mathrm{F}_{(1,52)}=10.43 ; \mathrm{p}<0.01\right)$. For hormone preference score, females preferred the 288 hormone-replaced stimulus animals more strongly than males did (Fig $2 \mathrm{D} ; \mathrm{F}_{(1,52)}=13.21 ; \mathrm{p}<$ 289 0.001). VIN males spent less time in close proximity to the stimulus rats without interacting than 290 DMSO males, shown in Figure $2 \mathrm{E}$ as the social preference score $\left(\mathrm{F}_{(1,52)}=20.66 ; \mathrm{p}<0.0001\right)$. 291 These and all other behavior measures included in further analyses are summarized in Table 1. 

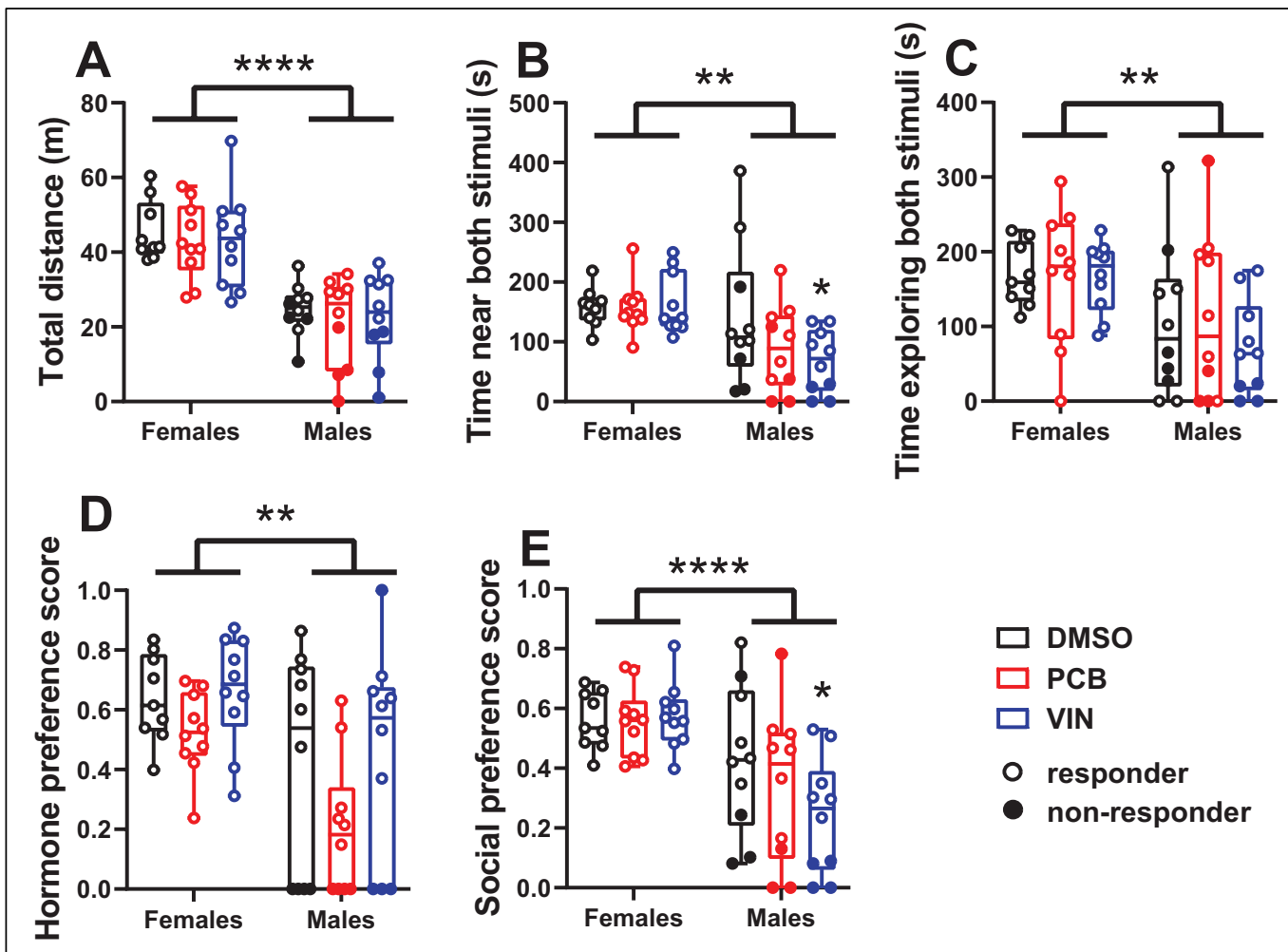

Figure 2: Sex differences during the 10-minute mate preference test are shown. (A) Total distance traveled during the test duration. (B) Total time the experimental rat spent near (within one body length) both stimulus cages without interacting with the stimulus rats. (C) Total time the experimental rat spent exploring (sniffing, touching, etc.) the stimulus cages and stimulus rats (but not nose-touching). (D) Hormone preference score (social time with hormone-replaced stimulus rat/social time with both stimulus rats). (E) Social preference score (social time with both stimulus rats/time in the remote portions of the side chambers [further than one body length away from the stimulus cage]). For males, non-responders (rats who failed to venture near one or both stimulus options) are indicated with solid black circles, here and in subsequent figures. Asterisks indicate a significant sex difference. Twoway ANOVA, main effect of sex followed by Sidak's multiple comparisons test. ${ }^{* *} \mathrm{p}<$ $0.01, * * * * \mathrm{p}<0.0001, * \mathrm{VIN}<\mathrm{DMSO} \mathrm{p}<0.05$. 
EDCs did not affect circulating steroid hormone levels, but PCBs resulted in reduced body weight in males and females

297 behaviorally characterized rats on the day of euthanasia (Fig 3). PCB exposure significantly

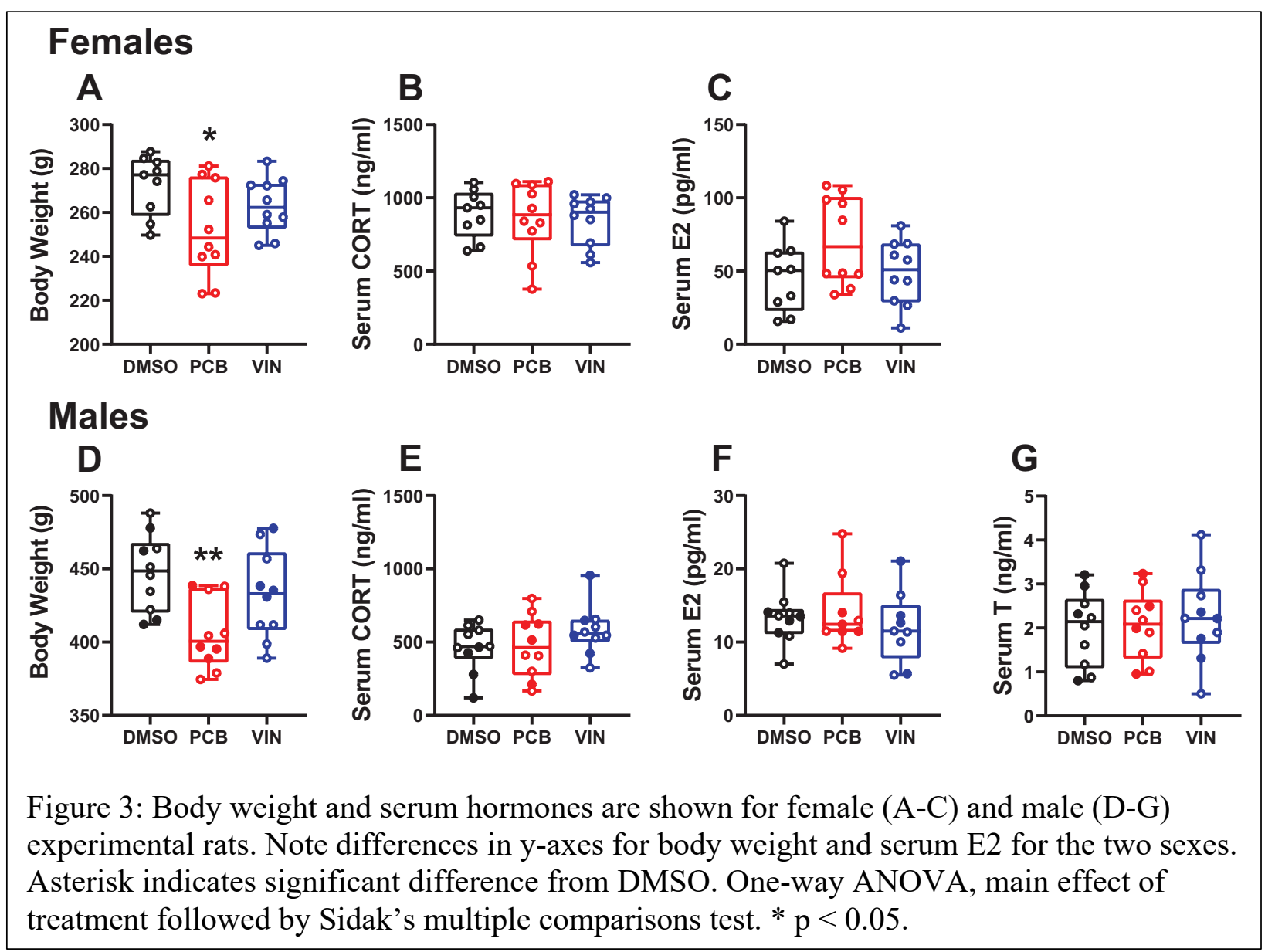
reduced the body weight of both female $\left(\mathrm{F}_{(2,26)}=3.506 ; \mathrm{p}<0.05 ;\right.$ Fig $\left.3 \mathrm{~A}\right)$ and male $\left(\mathrm{F}_{(2,27)}=\right.$

299 6.080; $\mathrm{p}<0.01 ;$ Fig 3D) rats. There were no significant effects of treatment on hormone

300 concentrations within males or females [Fig 3B, C (females), E-G (males)]. In females, there was

301 a non-significant trend for PCB exposure to increase E2 levels $\left(\mathrm{F}_{(2,26)}=2.916 ; \mathrm{p}=0.07\right.$; Fig 3C). 


\section{Integration across levels of biological organization revealed high levels of individual} variation with treatment groups measures) revealed variation between the sexes in coordinated phenotypic response to EDC treatment, as the PCs characterized different aspects of the phenotype (Fig 4). Eigenvectors describing the loadings, or contribution, of phenotypes to PC variation revealed patterns of coordinated phenotypic variation that differed in strength (absolute value of the eigenvector) and directionality (positive or negative). The results indicate that relationships differed for each

310 treatment group (Fig. 4C and 4D).

In females, the first four PCs described $78 \%$ of the total variation in morphology, behavior,

312 and physiology within and across treatments (Fig. 4A). Social Time, Social Preference, and

313 Stimulus Explore loaded strongly and concordantly on PC1 (35\%), indicating that PC1 primarily

314 represents variation in time spent engaging in sociosexual behavior. With strong and concordant

315 loadings of Hormone Preference and Near Time, PC2 (20\%) represents Social Preference and

316 Social Interaction. PC3 (12\%) is strongly loaded by sex steroid (E2) levels and time spent near a

317 stimulus rat with opposing effects. Finally, with strong and opposing loadings of CORT and body

318 weight, PC4 (11\% of the variation) may be an indicator of condition. Within treatment, females

319 varied in their integrated response to EDC treatment; however, there were no significant 320 differences across treatments for the first four PCs (Fig. 4E; Supplementary Fig. 1A-F).

321 In males, the first four PCs described $75 \%$ of the total variation in morphology, behavior, 322 and physiology within and across treatments (Fig. 4B). PC1 (38\%) primarily described variation 323 among males in the time they spent in the center of the apparatus (Fig. 4D), and, thus, represents 
324 differences between responder and non-responder males (Supplementary Fig. 1G. 4F). PC2 (15\% 325 of the variation) primarily represented, in opposing fashion, CORT levels and time spent engaging

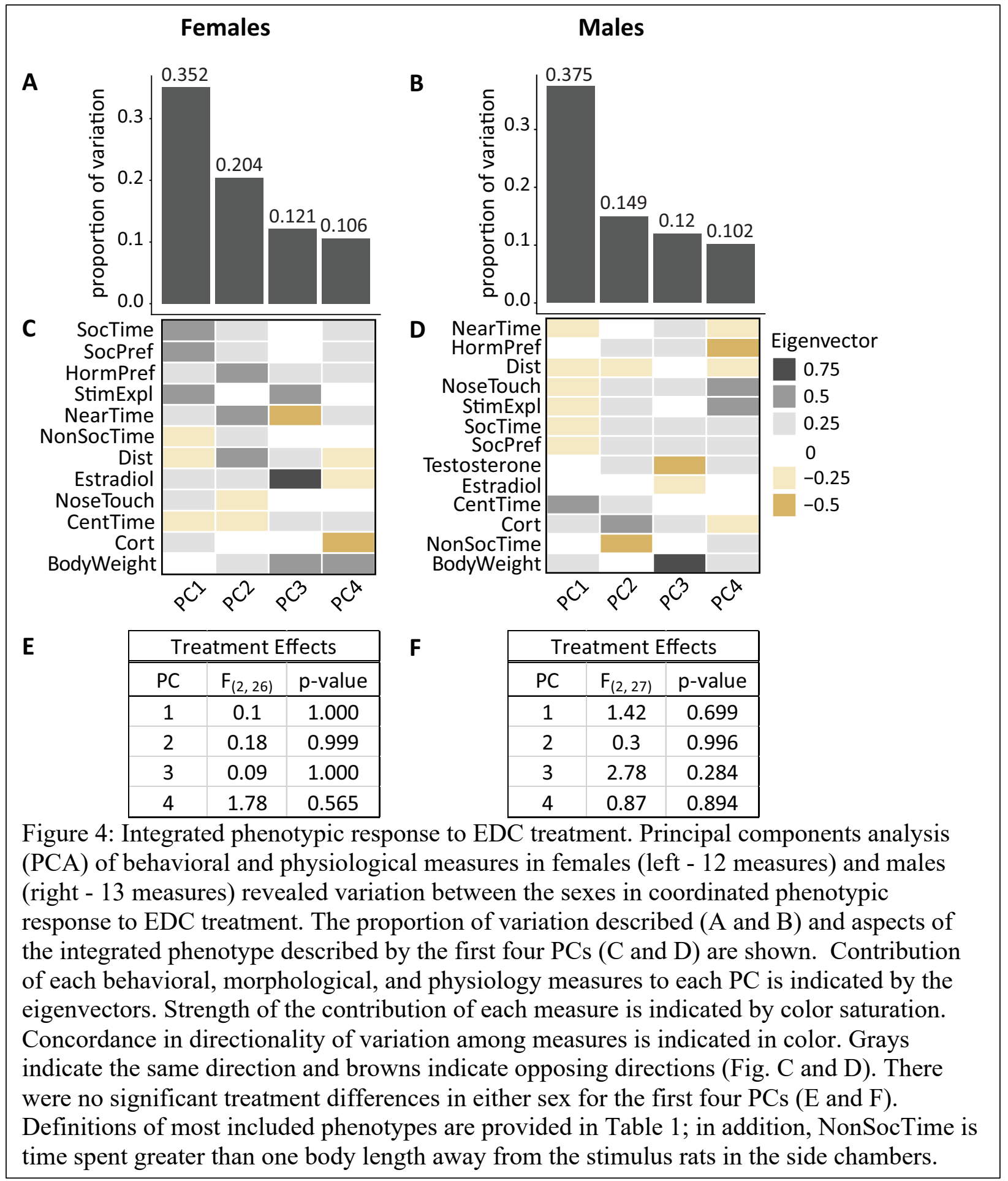


in non-social activity. PC3 (12\% of the variation) characterized opposing variation in body weight

327 and $\mathrm{T}$ among males. With strong loadings of nose touch, stimulus explore, and hormone

328 preference, PC4 (10\% of the variation) characterized variation in preference and social interaction.

329 Because non-responders failed to approach one or both of the stimulus rat options during the

330 allotted 10 minutes biasing their hormone preference and other sociosexual behavioral scores,

331 responder and non-responder males differed across PC4 (Supplementary Fig. 1K).

332 Embryonic EDC exposure had sex-specific effects on candidate gene expression in VMN,

333 POA, and MeA

The effect of EDC treatment and sex on the expression of the 44 detectable candidate genes

335 in three brain regions was examined (all results shown in Supplementary Table 1). The expression

336 levels of only a small number of genes were significantly affected by treatment after correction for

337 multiple comparisons. In the VMN of females, PCB-exposed rats had higher expression of 338 Cyp19a1, Oxt, Avp, and Kiss1 than DMSO females. In VIN females, Hsd17b1 and Oxt were higher

339 than levels in DMSO females. The expression level of only one gene in the female POA, Grin $2 b$,

340 was changed significantly by EDCs: it was over-expressed in the POA of females exposed to PCBs

341 and VIN compared to DMSO. Two genes were affected in the female MeA: Kiss I was more highly

342 expressed by PCBs, and Oxt expression was lower in PCB treatment and higher in VIN treatment

343 compared to the DMSO control females.

344 In the male VMN, Cyp19al was lower in both PCB and VIN treatment. In the male POA, 345 only Grin $2 b$ expression was affected: it was higher in VIN compared to DMSO males. One gene 346 in the male MeA, Kiss 1, was expressed at lower levels in the VIN treatment group compared to 347 DMSO. 
348 Several sex differences in the gene expression of DMSO rats were identified 349 (Supplementary Table 2). In the VMN, males had significantly higher expression of Cyp19al 350 compared to females. In the POA, females had significantly higher Kiss 1 expression, while males 351 had higher Grin2b expression. In the MeA, males had significantly higher Kiss 1 expression than 352 females. 
bioRxiv preprint doi: https://doi.org/10.1101/2020.10.12.335984; this version posted October 12, 2020. The copyright holder for this preprint

(which was not certified by peer review) is the author/funder. All rights reserved. No reuse allowed without permission.

Gene co-expression modules displayed treatment-specific relationships with preference and

The 44 candidate genes assessed were selected based on a priori hypotheses and their roles in

356 neuroendocrine function and sensitivity to EDCs reported in the literature, as described in greater

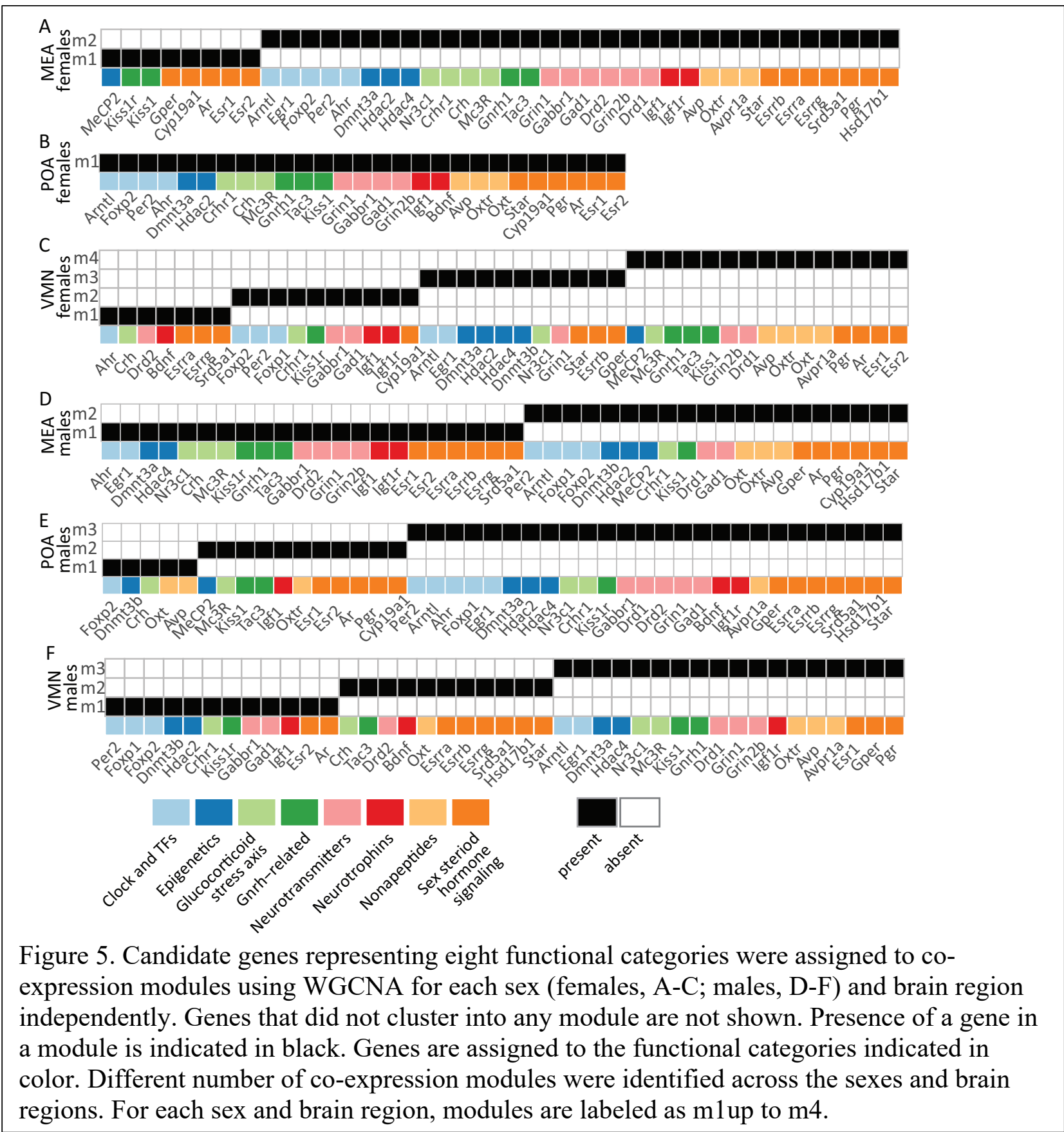


357 detail in the Discussion. These genes belong to functional categories that include sex steroid 358 hormone signaling, glucocorticoid stress axis, nonapeptides, GnRH-related genes, neurotrophins, 359 neurotransmission, epigenetics, and clock genes and other transcription factors (Suppl. Table 1;

360 Fig 5). Co-expression modules generated using WGCNA spanned functional gene groups and 361 varied across brain regions and sexes. Treatments did not differ in eigengene expression for either 362 sex or brain region after adjusting for multiple hypothesis testing (Suppl. Fig. 2).

363 An example of how these data can be used in hypothesis-testing is provided for the 364 nonapeptides. To test the hypothesis that coordinated expression of nonapeptides varies with 365 preference and other social interactions we first identified gene co-expression modules integrating 366 expression of the majority of the nonapeptides including: MeA module 2, POA module 1, and 367 VMN module 4 in females, and MeA module 2 and VMN module 3 in males (Fig. 5). Second, we 368 identified PC2 in females and PC4 in males as representing variation in preference and social 369 interaction across individuals. For PC4 in males, linear models revealed significant treatment and 370 interaction effects in the relationship between module eigengene expression and preference and 371 social interaction in the VMN and a trend in the MeA in males (Fig. 6; Supplementary Table 3). 


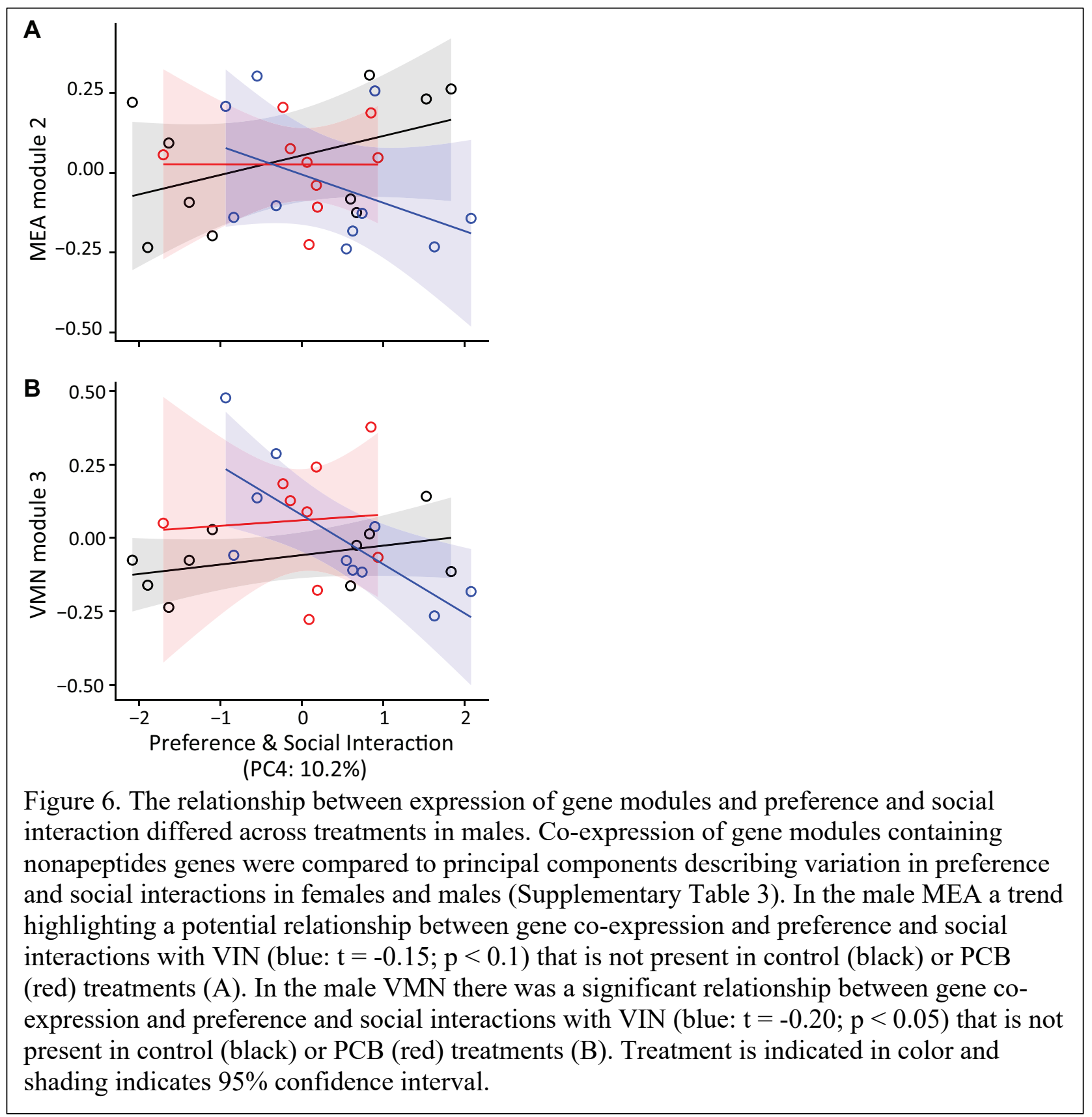


Embryonic exposure to EDCs caused dis-integration and reconstitution across levels of

378 in both behavior and gene expression. This allowed us to examine co-variance patterns between

379 phenotypic measures (behavior, body weight, hormones) and gene expression to identify any

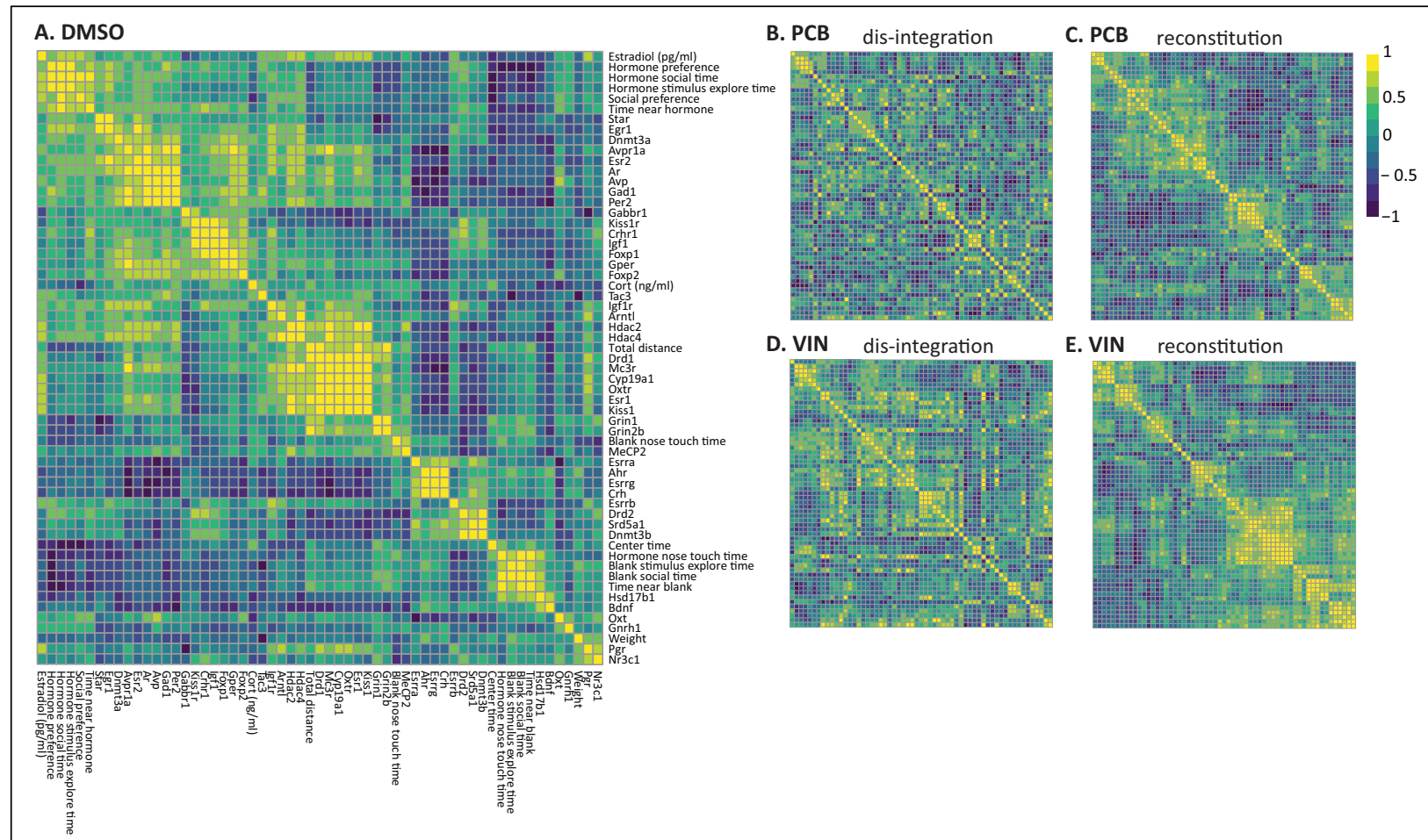

Figure 7: Representative correlation heatmap from the VMN of females, illustrating the disintegration and reconsolidation of behavioral, hormonal, and neuromolecular phenotypes caused by EDC treatment. Gene expression, behavioral, and physiological measures were clustered using Spearman's rank correlations for the DMSO control samples (A). The same ordering of phenotypes in the control group was applied to both the PCB (B) and VIN (D) treatment groups to illustrate dis-integration associated with EDC treatment. To illustrate reorganization of phenotypes, behavioral, hormonal, and neuromolecular phenotypes were clustered for using Spearman's rank correlations for PCB (C) and VIN (E) females. Correlation strength is indicated by intensity of color with yellow indicating positive correlations and indigo indicating negative correlations. Correlations of remaining brain regions and sexes including the order of phenotypes in the reorganized heatmaps above are provided in Supplementary Fig. 3. 
systems-level effects of EDC treatment and ask if behavioral, physiological, and neuromolecular correlations are maintained across treatments. Correlation strengths and phenotypic clustering are

382 illustrated as heatmaps in Figure 7 (in this case for gene expression in the VMN of females).

383 Heatmaps for the POA and MeA in females, and for all three regions in males, are shown in

384 Supplementary Fig. 3). In all cases, we observed that correlations between gene expression levels 385 are stronger (females: median $r=0.3$ to 0.43 ; males: median $r=0.28$ to 0.43 ) than between genes 386 and behavior (females: median $r=0.2$ to 0.28 ; males: median $r=0.2$ to 0.32 ). Importantly, for 387 both sexes and all brain regions the co-variance structure was strongly integrated in control animals 388 (in terms of number and size of robust clusters), whereas with EDC treatment these patterns 389 appeared to "dis-integrate" and/or reorganize. In other words, many genes and phenotypes that 390 were strongly correlated in the control group (indicated as clusters of yellow cells in the heatmap) 391 were uncorrelated or only weakly correlated in treatment groups. To illustrate dis-integration of 392 correlations in the female VMN, the identical order of phenotypes generated by clustering of the 393 DMSO control group (Fig. 7A) was maintained and applied to generate a heatmap for PCB and 394 VIN females (Fig. 7B and 7D), clearly showing few if any robust clusters. If instead the heatmap 395 for PCB and VIN was generated by unbiased clustering, a completely different reconstituted 396 correlation structure emerged (Fig. 7C and 7E), albeit less robust. Importantly, a subset of 397 phenotypes (e.g., Ahr, Esrrg, and Crh expression are positively correlated in the female VMN 398 across treatments, Fig. 7) maintained strong correlations across all treatment groups indicating 399 their robust relationships. While the present study is underpowered to perform a quantitative 400 analysis of this "dis-integration hypothesis," the pattern of correlation loss and reorganization in 401 both sexes and in all three brain regions reveals striking qualitative differences between the DMSO 402 and EDC-treated rats.

403 One set of factors that demonstrates this dis-integration effect particularly well is the total 404 distance traveled during the mate preference test and VMN Grin2b expression in females (Fig 8). 
405 A robust correlation between these factors was found for the DMSO group $\left(\mathrm{F}_{(1,7)}=19.60 ; \mathrm{p}<0.01\right.$; $406 \mathrm{R}^{2}=0.74$; Fig 8A) but not the PCB $\left(\mathrm{R}^{2}=0.005\right.$; Fig 8B) or VIN $\left(\mathrm{R}^{2}=0.0008\right.$; Fig 8C) females. 407 Conversely, we found strong evidence of reconstitution in males, where the direction of 408 correlations present in the DMSO group were reversed by EDC treatment. Fig 8D shows one such 409 example: the negative correlation between hormone preference score and $H s d 17 b 1$ expression in 410 the POA of DMSO males $\left(\mathrm{F}_{(1,8)}=13.56 ; \mathrm{p}<0.01 ; \mathrm{R}^{2}=0.63\right)$. The direction of this correlation was 411 reversed by PCB treatment $\left(\mathrm{F}_{(1,7)}=17.68 ; \mathrm{p}<0.01 ; \mathrm{R}^{2}=0.72 ;\right.$ Fig $\left.8 \mathrm{E}\right)$ and abolished by VIN 412 treatment $\left(\mathrm{R}^{2}=0.03\right.$; Fig $\left.8 \mathrm{~F}\right)$. Furthermore, there was considerable individual variation in both 413 gene expression and behavior, and the correlation heatmaps demonstrate that there are many 414 stronger correlations between genes than between genes and behavior. 


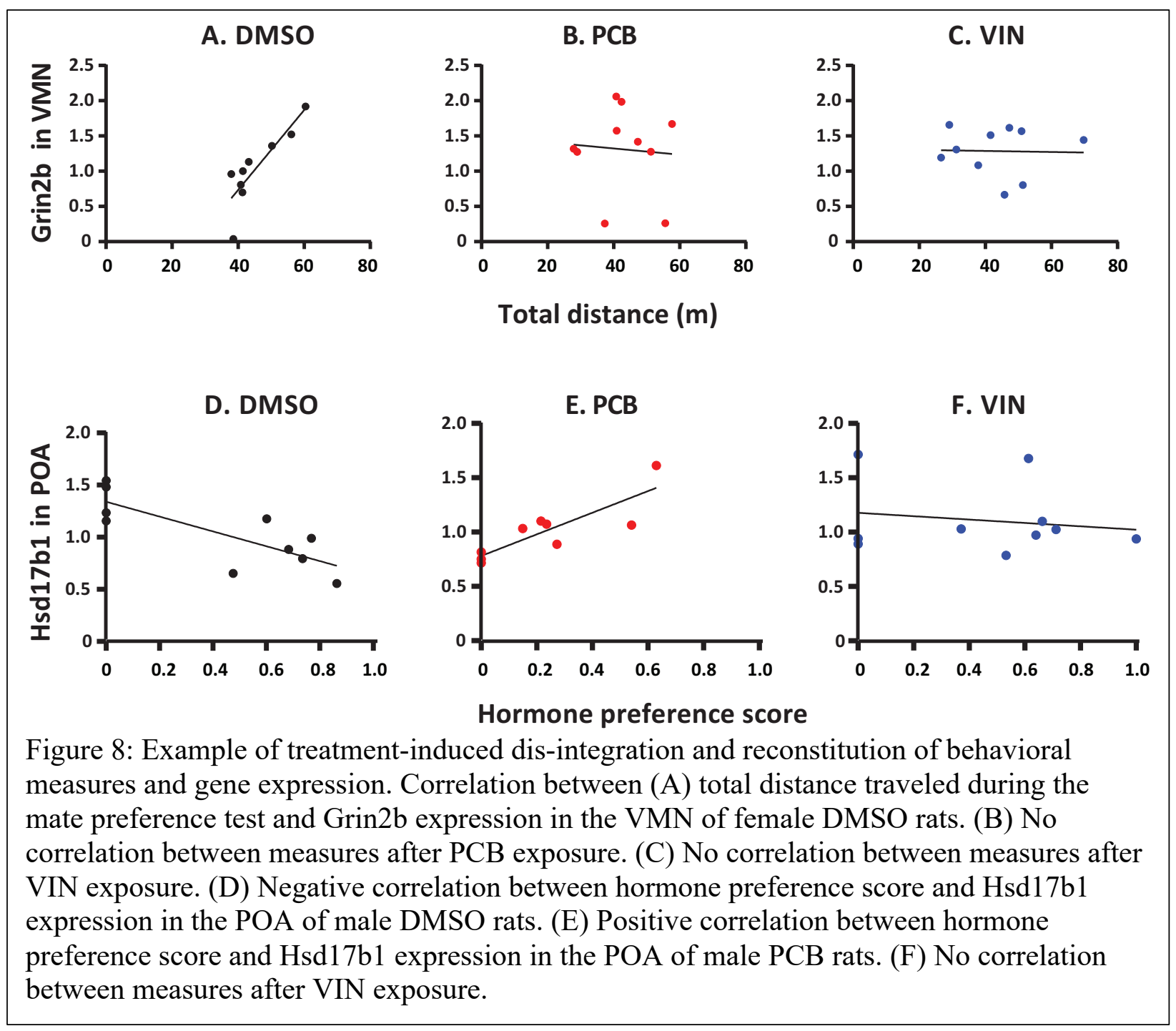

416 EDC exposure disrupts sexually dimorphic expression of nonapeptides and sex steroid 417 hormone signaling genes

418 To test the hypothesis that EDC treatment interferes with sexually dimorphic gene 419 expression patterns, or, based on the behavioral phenotype, specifically, demasculinizes (VIN, 420 PCB in males) or defeminizes (PCB in females) neural gene expression patterns of our 421 experimental rats, for each brain region, we calculated the Euclidean distance in expression for all 422 pairwise sex, treatment comparisons for genes from two functional categories, nonapeptide and 423 sex steroid hormone signaling genes (from Fig. 5, yellow and orange groups, respectively). While 
424 no generalized demasculinizing or defeminizing effects of EDC treatment was evident across all 425 brain regions (Suppl. Figure 4), several interesting patterns emerged. In the MeA, modification of 426 sexually dimorphic nonapeptide and sex steroid hormone signaling gene expression in response to 427 EDC treatment was quite similar (Fig. 9). For both nonapeptides and sex steroid hormone 428 signaling genes, males treated with VIN and females treated with PCB were significantly more 429 similar to each other than expected by chance (Fig. 9 - line between red circle and blue triangle). 430 This finding indicates that EDC treatment shifted both sexes away from their respective control 431 groups and toward an intermediate defeminized (females) and demasculinized (males) phenotype.

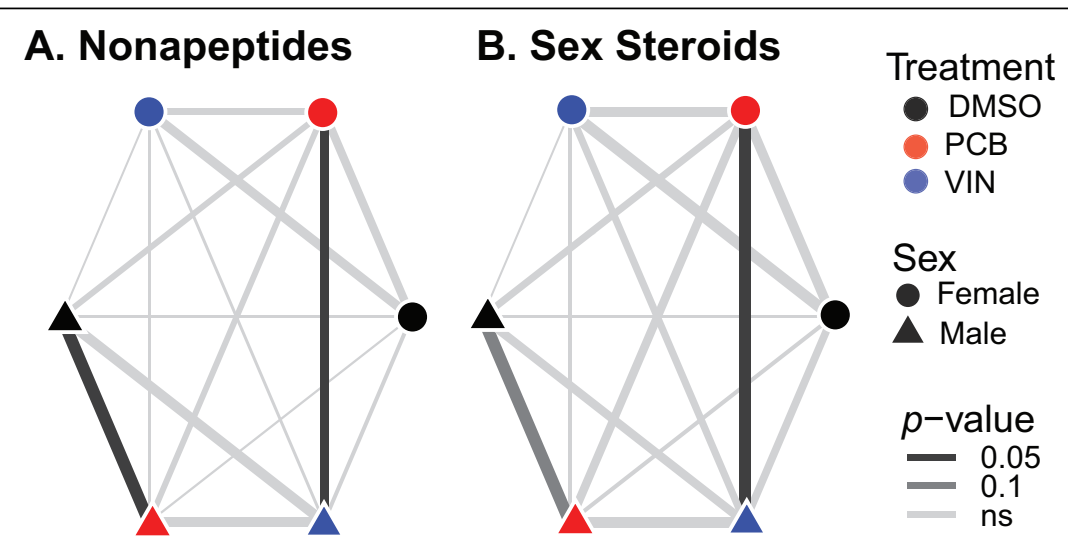

Figure 9. MeA distance networks indicate gene expression distance for all pairwise sex and treatment comparisons for nonapeptide (A) and sex steroid hormone signaling genes (B). Nodes (circles, female; triangles, male) represent each sex and treatment. Edge width is defined as $-z$-score of all pairwise Euclidean distance in the network such that thick edges represent nodes that are more similar in gene expression. Darker edge colors indicate that nodes are closer than would be expected by chance. Distance networks of remaining brain regions are provided in Supplementary Fig. 4.
In addition, males treated with $\quad$ PCB were significantly more similar to control males than expected, indicating a muted response of nonapeptide and sex steroid signaling in the $\mathrm{MeA}$ to this treatment (Fig. 9).

\section{DISCUSSION}

The current study a novel analysis of the changing

445 phenotypic relationships among neural gene expression and behavior, and the dis-integration and

446 reconstitution among related sociosexual behavioral measures and neuromolecular networks, in

447 rats exposed prenatally to EDCs. More specifically, sociosexual preference behaviors were 
impaired by PCBs in both sexes, and by VIN in males. This difference between the EDCs is

449 interesting and may reflect the different modes of action by which the PCB mixture, A1221, acts

450 [mainly weakly estrogenic (Dickerson \& Gore, 2007)] vs. that of VIN [anti-androgenic (Euling

451 et al., 2002; Stroheker et al., 2005)]. These results are also consistent with the literature showing

452 that phenotypes induced by EDCs are compound-specific, likely reflecting different mechanisms

453 by which a compound can disrupt the endocrine system. In line with the current finding, Crews

454 et al. (Crews et al., 2012) demonstrated the utility of using an approach to combines levels of

455 biological organization to produce the 'functioning phenotype' in a model of transgenerational

456 exposures using VIN. Here, each of the EDCs (PCBs, VIN) resulted in a unique dis-

457 integration/reconstitution of the behavioral and molecular relationships within each sex. As a

458 whole, the perturbations by EDCs of conspecific interactions have implications for social

459 preference and sexual selection (Gore, Holley, \& Crews, 2018).

\section{Prenatal EDCs changed mate preference in a treatment- and sex-specific manner}

Female mammals have an incentive to seek out mates with the best likelihood of producing

462 fertile offspring due to this sex's high investment in reproduction. For example, males with the

463 typical adult range of concentrations of testosterone (Spiteri et al., 2010), and odors from a male

464 with higher testosterone levels, are preferred by sexually active female rats over their low- or no-

465 testosterone counterparts (Osada, Kashiwayanagi, \& Izumi, 2009; Taylor et al., 1982). Here we

466 showed that prenatal exposure to PCBs abolished the females' preference for a stimulus male with

467 testosterone replacement over a male without testosterone, replicating results from a recently 468 published study (Hernandez Scudder et al., 2020). This outcome could translate into compromised 469 reproductive success if a female were unable to discriminate between optimal and sub-optimal 470 males in more naturalistic conditions. Interestingly, VIN treatment had no effect in the females. 
471 The difference between the EDCs may be attributable to differential hormonal mechanisms acted upon by the different classes of EDCs (Nugent et al., 2015; Schwarz \& McCarthy, 2008).

While males tend to be less choosy about mates, the process of mating involves mutual

474 interactions and coordination between both members of the dyad. Females exhibit proceptive 475 behaviors to solicit the sexual attention of males, and males are also able to discriminate the odor 476 of urine from receptive females (Edwards \& Einhorn, 1986; Hurtazo, Paredes, \& Ågmo, 2008; 477 Lydell \& Doty, 1972; Xiao, Kondo, \& Sakuma, 2004). In the current study, and unlike females, 478 exposure of experimental males to both classes of EDCs (PCB or VIN) abolished the preference 479 for the hormone-primed female over the female without hormone-replacement. The male rat brain 480 develops under the influence of relatively high concentrations of both androgens and estrogens 481 (Bakker et al., 2006; Nugent et al., 2015; Schwarz \& McCarthy, 2008; Wright et al., 2010), perhaps 482 conferring greater sensitivity to disruption of these pathways by both VIN and PCBs, respectively. 483 Previous work on prenatal A1221 exposure showed disrupted sex behavior in female rats, 484 and decreased sexual motivation in male rats (Steinberg et al., 2007; Topper et al., 2019). Exposure 485 to other PCBs caused reduced sexual motivation and receptivity in females and altered sexual 486 behavior in males (Colciago et al., 2009; Cummings et al., 2008; Faass et al., 2013; Faqi, Dalsenter, 487 Merker, \& Chahoud, 2016; X. Q. Wang, Fang, Nunez, \& Clemens, 2002). Exposure to VIN during 488 the prenatal period and during postnatal life (E14 to adulthood) resulted in a lack of sexual 489 motivation and deficits in sexual performance (reduced erections and ejaculations) in male rabbits 490 (Veeramachaneni, Palmer, Amann, \& Pau, 2007; Veeramachaneni et al., 2006). Our current 491 finding adds to this literature on sex-specific effects of EDCs on sociosexual behaviors. 492 Subsequent integrative and systems-level analyses provide novel insights into patterns of dis493 organization and reconstitution into novel phenotypes. 


\section{Prenatal EDCs altered the neuromolecular phenotype in the hypothalamus and amygdala}

Prenatal EDCs affected the expression of a small number of genes in the VMN, POA, and MeA. It is notable that genes for kisspeptin (Kiss1), nonapeptides (Avp, Oxt), steroidogenic enzymes (Cyp19al, Hsd17bl), and the glutamatergic NMDA receptor subunit 2b (Grin2b) were those affected, as these same genes have previously been shown to be disrupted by EDCs and are involved in sexually-dimorphic behaviors. For example, the hypothalamic kisspeptin system is highly estrogen sensitive (Jenny Clarkson, Boon, Simpson, \& Herbison, 2009; Navarro \& TenaSempere, 2008), making it an obvious target for estrogenic EDCs. Other studies have shown that PCBs and other estrogenic EDCs affect kisspeptin protein and gene expression (Cao, Mickens, McCaffrey, Leyrer, \& Patisaul, 2012; Dickerson, Cunningham, Patisaul, Woller, \& Gore, 2011; Ruiz-Pino et al., 2019), consistent with the current results. Our finding that VIN affects Kiss1 in males is also consistent with this neuropeptide's regulation by androgens (Cernea, Phillips, Padmanabhan, Coolen, \& Lehman, 2016; Clarkson, Shamas, Mallinson, \& Herbison, 2012).

Oxytocin gene expression was decreased in the MeA of PCB females; this was the same group of rats that showed deficits in the mate preference test. The MeA has been characterized as an important target of oxytocin in mate and odor preference behaviors (Yao, Bergan, Lanjuin, \&

511 Dulac, 2017), but, although it has relatively sparse oxytocin fibers, there is evidence for a role of 512 oxytocin expression in the amygdala in social behavior (Smith, DiBenedictis, \& Veenema, 2019).

513 Oxytocin knockout mice have deficits in social recognition associated with reduced activity in the

514 MeA and its projection targets (Ferguson, Aldag, Insel, \& Young, 2001). By contrast, Oxt was

515 increased by both PCBs and VIN in the female VMN in the current study, and vasopressin by 516 PCBs in the female VMN. Other labs have reported effects of EDCs on the nonapeptides 517 vasopressin, oxytocin, and their receptors in several brain regions (Arambula, Jima, \& Patisaul, 518 2018; Sullivan et al., 2014; Witchey, Fuchs, \& Patisaul, 2019), implicating these as targets for 519 perinatal endocrine disruption. 
Both PCB and VIN males had lower Cyp19al (aromatase) expression in the VMN compared to DMSO control males. This region exhibits some of the highest levels of aromatase in

522 the brains of rats along with the POA and the bed nucleus of the stria terminalis (BNST) (Wagner

$523 \&$ Morrell, 1996). In the hypothalamus, aromatase expression and activity is sexually dimorphic

524 with males having denser expression and higher activity (Roselli, Klosterman, \& Fasasi, 1996).

525 Prenatal exposure to a similar PCB, Aroclor 1254, reduced aromatase activity in the hypothalamus

526 of neonatal male rats (Hany et al., 1999). Prenatal exposure to another EDC, the phthalate DEHP, 527 reduced Cyp19al expression in the hypothalamus of neonatal rats (Gao et al., 2018).

The N-methyl-D-aspartate (NMDA) glutamate receptor subunit $2 \mathrm{~b}($ Grin $2 b)$ is expressed

529 widely throughout the rat hypothalamus (Eyigor, Centers, \& Jennes, 2001) and its presence and

530 abundance affects functional properties of NMDA receptors. In the POA, PCBs resulted in the

531 over-expression of Grin2b in both sexes, and VIN also increased Grin2b in the female POA.

532 Hypothalamic Grin2b expression is sensitive to circulating estradiol levels, and naturally decreases

533 during reproductive senescence (Maffucci, Noel, Gillette, Wu, \& Gore, 2009). The activation of

534 gonadotropin-releasing hormone $(\mathrm{GnRH})$ neurons in the POA by glutamate is necessary for

535 reproductive function, and administration of a specific antagonist of the NMDAR2b subunit

536 altered GnRH and downstream luteinizing hormone (LH) release in rats (Maffucci, Walker,

537 Ikegami, Woller, \& Gore, 2008). Limited work also suggests that EDCs may change Grin2b

538 expression (Alavian-Ghavanini et al., 2018; Dickerson, Cunningham, Patisaul, et al., 2011). Our

539 finding suggests that glutamatergic neurotransmission may be altered by prenatal EDC exposure.

540 While we found no evidence for globally demasculinizing or defeminizing effects of EDC

541 treatment on gene expression, the typically sexually dimorphic expression of nonapeptide and sex

542 steroid signaling genes was significantly disrupted in the MeA. Specifically, we found that EDC

543 treatment (VIN males and PCB females) shifted both sexes away from their respective control

544 groups and toward an intermediate defeminized (females) and demasculinized (males) phenotype 
545 (Fig. 9). Further work using global gene expression profiling, something we are in the midst of 546 undertaking, will enable us to better test this hypothesis. Some evidence is provided by a previous 547 study from our lab (Walker, Goetz, \& Gore, 2014) in which a shorter-term (2 day) prenatal

548 exposure to PCBs changed gene expression patterns in the anteroventral periventricular nucleus of 549 the hypothalamus (AVPV) in female rats such that developmental profiles were masculinized. 550 Furthermore, hierarchical clustering analysis of genes in the AVPV and the arcuate nucleus 551 revealed changes in relationships among gene expression profiles, with males and females each 552 being affected in a sex-specific manner. That prior study's results presaged those of the 553 comprehensive analyses of the current one and its finding of dis-integration and reconstitution, as 554 discussed next.

EDC treatment can dis-integrate and/or reconstitute the relationships of behavior and gene expression phenotypes

Gene co-expression patterns revealed sex, brain region, and treatment-specific effects of EDCs. Genes clustered into distinct modules between males and females across all brain regions

560 suggesting sex-specificity of neuromolecular phenotypes. In VIN males there was a relationship

561 between gene co-expression of modules containing nonapeptides and the behavioral PC describing

562 variation in social interaction and preference in the VMN (and a trend in the MeA) that was not

563 present in DMSO or PCB males. This finding indicates that a reorganization of the neuromolecular 564 and behavioral phenotypes occurs in males in response to prenatal VIN exposure. Previous studies

565 have reported effects of EDCs on the nonapeptides vasopressin, oxytocin, and their receptors in 566 several brain regions (Arambula et al., 2018; Sullivan et al., 2014; Witchey et al., 2019), 
567 implicating these as targets for perinatal endocrine disruption. Interestingly, gene co-expression

568 modules clustered genes across functional categories and often clustered genes from the same

569 functional category into distinct modules (see Fig. 5). This finding illustrates the importance of a

570 systems-level approach that describes the neuromolecular phenotype beyond typical candidate

571 pathways to identify gene expression mechanisms of complex behavior.

572 Furthermore, there were many more correlations among the expression of genes rather than 573 between genes and behavior. The correlation heatmaps showed a striking pattern of EDC influence 574 on these relationships. In both males and females, we observed an EDC-induced qualitative dis575 integration of gene-gene and gene-behavior interactions in all three brain regions.

\section{Conclusions}

Overall, this present study presents evidence that prenatal exposure to two classes of EDCs

579 abolished the innate preference of males and females for an opposite-sex mate, and identified

580 several gene targets modified by EDC treatment both independent of and related to specific

581 behavioral measures. More importantly, the relationships across the different levels of phenotypic

582 analysis underwent considerable dis-organization and reorganization, indicating that beyond

583 effects on individual genes and behaviors, EDCs disrupt the integration across these levels or

584 organization. Because there were stronger correlations between genes than there were between

585 genes and behavior, a broader analysis of more genes and brain regions is merited. These findings

586 provide a foundation for further work on the disruption of complex behaviors after prenatal 587 exposure to EDCs. 


\section{REFERENCES}

Alavian-Ghavanini, A., Lin, P. I., Lind, P. M., Risén Rimfors, S., Halin Lejonklou, M., Dunder, L., ... Rüegg, J. (2018). Prenatal Bisphenol A Exposure is Linked to Epigenetic Changes in Glutamate Receptor Subunit Gene Grin2b in Female Rats and Humans. Scientific Reports, 8(1). https://doi.org/10.1038/s41598-018-29732-9

Arambula, S. E., Jima, D., \& Patisaul, H. B. (2018). Prenatal bisphenol A (BPA) exposure alters the transcriptome of the neonate rat amygdala in a sex-specific manner: a CLARITY-BPA consortium study. NeuroToxicology, 65, 207-220. https://doi.org/10.1016/j.neuro.2017.10.005

Arnold, A. P., \& Gorski, R. A. (1984). Gonadal Steroid Induction of Structural Sex Differences in the Central Nervous System. Annual Review of Neuroscience, 7(1), 413-442. https://doi.org/10.1146/annurev.ne.07.030184.002213

Bakker, J., De Mees, C., Douhard, Q., Balthazart, J., Gabant, P., Szpirer, J., \& Szpirer, C. (2006). Alpha-fetoprotein protects the developing female mouse brain from masculinization and defeminization by estrogens. Nature Neuroscience, 9(2), 220-226. https://doi.org/10.1038/nn1624

Bell, M. R., Hart, B. G., \& Gore, A. C. (2016). Two-hit exposure to polychlorinated biphenyls at gestational and juvenile life stages: 2. Sex-specific neuromolecular effects in the brain. Molecular and Cellular Endocrinology, 420, 125-137. https://doi.org/10.1016/j.mce.2015.11.024

Cao, J., Mickens, J. A., McCaffrey, K. A., Leyrer, S. M., \& Patisaul, H. B. (2012). Neonatal Bisphenol A exposure alters sexually dimorphic gene expression in the postnatal rat hypothalamus. NeuroToxicology, 33(1), 23-36. https://doi.org/10.1016/j.neuro.2011.11.002

Cernea, M., Phillips, R., Padmanabhan, V., Coolen, L. M., \& Lehman, M. N. (2016). Prenatal testosterone exposure decreases colocalization of insulin receptors in kisspeptin/neurokinin B/dynorphin and agouti-related peptide neurons of the adult ewe. European Journal of Neuroscience, 44(8), 2557-2568. https://doi.org/10.1111/ejn.13373

Clarkson, J., Shamas, S., Mallinson, S., \& Herbison, A. E. (2012). Gonadal Steroid Induction of Kisspeptin Peptide Expression in the Rostral Periventricular Area of the Third Ventricle During Postnatal Development in the Male Mouse. Journal of Neuroendocrinology, 24(6), 907-915. https://doi.org/10.1111/j.1365-2826.2012.02294.x

Clarkson, Jenny, Boon, W. C., Simpson, E. R., \& Herbison, A. E. (2009). Postnatal development of an estradiol-kisspeptin positive feedback mechanism implicated in puberty onset. Endocrinology, 150(7), 3214-3220. https://doi.org/10.1210/en.2008-1733

Colbert, N. K. W., Pelletier, N. C., Cote, J. M., Concannon, J. B., Jurdak, N. A., Minott, S. B., \& Markowski, V. P. (2005). Perinatal exposure to low levels of the environmental antiandrogen vinclozolin alters sex-differentiated social play and sexual behaviors in the rat. Environmental Health Perspectives, 113(6), 700-707. https://doi.org/10.1289/ehp.7509

Colciago, A., Casati, L., Mornati, O., Vergoni, A. V., Santagostino, A., Celotti, F., \& Negri-Cesi, P. (2009). Chronic treatment with polychlorinated biphenyls (PCB) during pregnancy and 
lactation in the rat. Part 2: Effects on reproductive parameters, on sex behavior, on memory retention and on hypothalamic expression of aromatase and 5alpha-reductases in the off. Toxicology and Applied Pharmacology, 239(1), 46-54. https://doi.org/10.1016/j.taap.2009.04.023

Crews, D., Gillette, R., Scarpino, S. V., Manikkam, M., Savenkova, M. I., \& Skinner, M. K. (2012). Epigenetic transgenerational inheritance of altered stress responses. Proceedings of the National Academy of Sciences of the United States of America, 109(23), 9143-9148. https://doi.org/10.1073/pnas.1118514109

Cummings, J. A., Clemens, L. G., \& Nunez, A. A. (2008). Exposure to PCB 77 affects partner preference but not sexual behavior in the female rat. Physiology and Behavior, 95(3), 471475. https://doi.org/10.1016/j.physbeh.2008.07.016

Dickerson, S. M., Cunningham, S. L., \& Gore, A. C. (2011). Prenatal PCBs disrupt early neuroendocrine development of the rat hypothalamus. Toxicology and Applied Pharmacology, 252(1), 36-46. https://doi.org/10.1016/j.taap.2011.01.012

Dickerson, S. M., Cunningham, S. L., Patisaul, H. B., Woller, M. J., \& Gore, A. C. (2011). Endocrine disruption of brain sexual differentiation by developmental PCB exposure. Endocrinology, 152(2), 581-594. https://doi.org/10.1210/en.2010-1103

Dickerson, S. M., \& Gore, A. C. (2007). Estrogenic environmental endocrine-disrupting chemical effects on reproductive neuroendocrine function and dysfunction across the life cycle. Reviews in Endocrine and Metabolic Disorders, 8(2), 143-159. https://doi.org/10.1007/s11154-007-9048-y

Drewett. (1973). Sexual Behaviour and Sexual Motivation and in the Female Rat. Nature, 243, 232.

Edwards, D. A., \& Einhorn, L. C. (1986). Preoptic and midbrain control of sexual motivation. Physiology and Behavior, 37(2), 329-335. https://doi.org/10.1016/0031-9384(86)90242-8

Eliasson, M., \& Meyerson, B. J. (1975). Sexual preference in female rats during estrous cycle, pregnancy and lactation. Physiology \& Behavior, 14(6), 705-710. https://doi.org/10.1016/0031-9384(75)90061-X

Euling, S. Y., Gennings, C., Wilson, E. M., Kemppainen, J. A., Kelce, W. R., \& Kimmel, C. A. (2002). Response-Surface Modeling of the Effect of 5-Dihydrotestosterone and Androgen Receptor Levels on the Response to the Androgen Antagonist Vinclozolin.

Eyigor, O., Centers, A., \& Jennes, L. (2001). Distribution of ionotropic glutamate receptor subunit mRNAs in the rat hypothalamus. Journal of Comparative Neurology, 434(1), 101124. https://doi.org/10.1002/cne.1167

Faass, O., Ceccatelli, R., Schlumpf, M., \& Lichtensteiger, W. (2013). Developmental effects of perinatal exposure to PBDE and PCB on gene expression in sexually dimorphic rat brain regions and female sexual behavior. General and Comparative Endocrinology, 188(1), 232-241. https://doi.org/10.1016/j.ygcen.2013.04.008

Faqi, A. S., Dalsenter, P. R., Merker, H.-J., \& Chahoud, I. (2016). Effects on developmental 
landmarks and reproductive capability of $3,3^{\prime}, 4,4^{\prime}, 5$ - Pentacholorobiphenyl in offspring of Http://Dx.Doi.Org/10.1177/096032719801700702. https://doi.org/10.1177/096032719801700702
3,3',4,4'-Tetrachlorobiphenyl and rats exposed during pregnancy:

Ferguson, J. N., Aldag, J. M., Insel, T. R., \& Young, L. J. (2001). Oxytocin in the medial amygdala is essential for social recognition in the mouse. Journal of Neuroscience, 21(20), 8278-8285. https://doi.org/10.1523/jneurosci.21-20-08278.2001

Gao, N., Hu, R., Huang, Y., Dao, L., Zhang, C., Liu, Y., ... Sun, Z. (2018). Specific effects of prenatal DEHP exposure on neuroendocrine gene expression in the developing hypothalamus of male rats. Archives of Toxicology, 92(1), 501-512. https://doi.org/10.1007/s00204-017-2049-z

Garcia, A. N., Bezner, K., Depena, C., Yin, W., \& Gore, A. C. (2017). The effects of long-term estradiol treatment on social behavior and gene expression in adult female rats. Hormones and Behavior, 87, 145-154. https://doi.org/10.1016/j.yhbeh.2016.11.011

Gillette, R., Miller-Crews, I., Nilsson, E.E., Skinner, M.K., Gore, A.C., \& Crews, D. (2014). Sexually dimorphic effects of ancestral exposure to vinclozolin on stress reactivity in rats. Endocrinology, 155(10, 3853-3866. doi: 10.1210/en.2014-1253.

Gore, A. C., Chappell, V. A., Fenton, S. E., Flaws, J. A., Nadal, A., Prins, G. S., ... Zoeller, R. T. (2015). EDC-2: The Endocrine Society's Second Scientific Statement on EndocrineDisrupting Chemicals. Endocrine Reviews, 36(6), E1-E150. https://doi.org/10.1210/er.2015-1010

Gore, A. C., Holley, A. M., \& Crews, D. (2018). Mate choice, sexual selection, and endocrinedisrupting chemicals. Hormones and Behavior, 101, 3-12. doi: 10.1016/j.yhbeh.2017.09.001

Hany, H, L., A, S., A, R.-H., A, F., L, D., ... G, W. (1999). Developmental Exposure of Rats to a Reconstituted PCB Mixture or Aroclor 1254: Effects on Organ Weights, Aromatase Activity, Sex Hormone Levels, and Sweet Preference Behavior. Toxicology and Applied Pharmacology, 158(3). https://doi.org/10.1006/TAAP.1999.8710

Hernandez Scudder, M.E., Weinberg, A., Thompson, L., Crews, D., \& Gore, A.C. (2020). Prenatal EDCs impair mate and odor preference and activation of the VMN in male and female rats. Endocrinology, 161(9), bqaa124. doi: 10.1210/endocr/bqaa124

Hurtazo, H. A., Paredes, R. G., \& Ågmo, A. (2008). Inactivation of the medial preoptic area/anterior hypothalamus by lidocaine reduces male sexual behavior and sexual incentive motivation in male rats. Neuroscience, 152(2), 331-337. https://doi.org/10.1016/j.neuroscience.2007.10.063

Jones, B. A., Shimell, J. J., \& Watson, N. V. (2011). Pre- and postnatal bisphenol A treatment results in persistent deficits in the sexual behavior of male rats, but not female rats, in adulthood. Hormones and Behavior. https://doi.org/10.1016/j.yhbeh.2010.12.006

Krishnan, K., Hasbum, A., Morales, D., Thompson, L. M., Crews, D., \& Gore, A. C. (2019). Endocrine-disrupting chemicals alter the neuromolecular phenotype in F2 generation adult 
male rats. Physiology \& Behavior, 211, 112674.

https://doi.org/10.1016/j.physbeh.2019.112674

Krishnan, K., Mittal, N., Thompson, L. M., Rodriguez-Santiago, M., Duvauchelle, C. L., Crews, D., \& Gore, A. C. (2018). Effects of the endocrine-disrupting chemicals, vinclozolin and polychlorinated biphenyls, on physiological and sociosexual phenotypes in F2 generation sprague-dawley rats. Environmental Health Perspectives, 126(9). https://doi.org/10.1289/EHP3550

Krishnan, K., Rahman, S., Hasbum, A., Morales, D., Thompson, L. M., Crews, D., \& Gore, A. C. (2019). Maternal care modulates transgenerational effects of endocrine-disrupting chemicals on offspring pup vocalizations and adult behaviors. Hormones and Behavior, 107, 96-109. https://doi.org/10.1016/j.yhbeh.2018.12.009

Langfelder, P., \& Horvath, S. (2008). WGCNA: An R package for weighted correlation network analysis. BMC Bioinformatics, 9. https://doi.org/10.1186/1471-2105-9-559

Lichtensteiger, W., Bassetti-Gaille, C., Faass, O., Axelstad, M., Boberg, J., Christiansen, S., ... Schlumpf, M. (2015). Differential gene expression patterns in developing sexually dimorphic rat brain regions exposed to antiandrogenic, estrogenic, or complex endocrine disruptor mixtures: Glutamatergic synapses as target. Endocrinology, 156(4), 1477-1493. https://doi.org/10.1210/en.2014-1504

Lin, H., Yuan, K., Li, L., Liu, S., Li, S., Hu, G., ... Ge, R. S. (2015). In utero exposure to diethylhexyl phthalate affects rat brain development: A behavioral and genomic approach. International Journal of Environmental Research and Public Health, 12(11), 13696-13710. https://doi.org/10.3390/ijerph121113696

Lydell, K., \& Doty, R. L. (1972). Male rat odor preferences for female urine as a function of sexual experience, urine age, and urine source. Hormones and Behavior, 3(3), 205-212. https://doi.org/10.1016/0018-506X(72)90033-5

Maffucci, J. A., Noel, M. L., Gillette, R., Wu, D., \& Gore, A. C. (2009). Age- and hormoneregulation of $\mathrm{N}$-methyl-d-aspartate receptor subunit $\mathrm{NR} 2 \mathrm{~b}$ in the anteroventral periventricular nucleus of the female rat: Implications for reproductive senescence. Journal of Neuroendocrinology, 21(5), 506-517. https://doi.org/10.1111/j.1365-2826.2009.01860.x

Maffucci, Jacqueline A., Walker, D. M., Ikegami, A., Woller, M. J., \& Gore, A. C. (2008). NMDA receptor subunit NR2b: Effects on LH release and GnRH gene expression in young and middle-aged female rats, with modulation by estradiol. Neuroendocrinology, 87(3), 129-141. https://doi.org/10.1159/000111136

Monje, L., Varayoud, J., Muñoz-de-Toro, M., Luque, E. H., \& Ramos, J. G. (2009). Neonatal exposure to bisphenol A alters estrogen-dependent mechanisms governing sexual behavior in the adult female rat. Reproductive Toxicology, 28(4), 435-442. https://doi.org/10.1016/j.reprotox.2009.06.012

Navarro, V. M., \& Tena-Sempere, M. (2008). The KiSS-1/GPR54 system: Putative target for endocrine disruption of reproduction at hypothalamic-pituitary unit? In International Journal of Andrology (Vol. 31, pp. 224-232). Int J Androl. https://doi.org/10.1111/j.1365- 
Nugent, B. M., Wright, C. L., Shetty, A. C., Hodes, G. E., Lenz, K. M., Mahurkar, A., ... McCarthy, M. M. (2015). Brain feminization requires active repression of masculinization via DNA methylation. Nature Neuroscience, 18(5), 690-697. https://doi.org/10.1038/nn.3988

O’Connell, L. A., \& Hofmann, H. A. (2012). Evolution of a vertebrate social decision-making network. Science, 336(6085), 1154-1157. https://doi.org/10.1126/science.1218889

754

755

756

757

758

759

760

761

762

763

764

765

766

767

768

769

770

771

772

773

774

775

776

777

778

779

780

781

782

783

784

785

Porrini, S., Belloni, V., Seta, D. Della, Farabollini, F., Giannelli, G., \& Dessì-Fulgheri, F. (2005). Early exposure to a low dose of bisphenol A affects socio-sexual behavior of juvenile female rats. Brain Research Bulletin, 65(3), 261-266. https://doi.org/10.1016/j.brainresbull.2004.11.014

Reilly, M. P., Weeks, C. D., Topper, V. Y., Thompson, L. M., Crews, D., \& Gore, A. C. (2015). Hormones and Behavior The effects of prenatal PCBs on adult social behavior in rats. Hormones and Behavior, 73, 47-55. https://doi.org/10.1016/j.yhbeh.2015.06.002

Rodier, P. M. (1980). Chronology of Neuron Development: Animal Studies and their Clinical Implications. Developmental Medicine \& Child Neurology. Dev Med Child Neurol. https://doi.org/10.1111/j.1469-8749.1980.tb04363.x

Roselli, C. E., Klosterman, S. A., \& Fasasi, T. A. (1996). Sex Differences in Androgen Responsiveness in the Rat Brain: Regional Differences in the Induction of Aromatase Activity. Neuroendocrinology, 64(2), 139-145. https://doi.org/10.1159/000127111

Ruiz-Pino, F., Miceli, D., Franssen, D., Vazquez, M. J., Farinetti, A., Castellano, J. M., ... TenaSempere, M. (2019). Environmentally relevant perinatal exposures to bisphenol a disrupt postnatal Kiss1/NKB neuronal maturation and puberty onset in female mice. Environmental Health Perspectives, 127(10). https://doi.org/10.1289/EHP5570

Schwarz, J. M., \& McCarthy, M. M. (2008, June). Steroid-induced sexual differentiation of the developing brain: Multiple pathways, one goal. Journal of Neurochemistry. J Neurochem. https://doi.org/10.1111/j.1471-4159.2008.05384.x

Skinner, M. K., Savenkova, M. I., Zhang, B., Gore, A. C., \& Crews, D. (2014). Gene bionetworks involved in the epigenetic transgenerational inheritance of altered mate preference: Environmental epigenetics and evolutionary biology. BMC Genomics, 15(1). https://doi.org/10.1186/1471-2164-15-377

Smith, C. J. W., DiBenedictis, B. T., \& Veenema, A. H. (2019, April 1). Comparing vasopressin and oxytocin fiber and receptor density patterns in the social behavior neural network: Implications for cross-system signaling. Frontiers in Neuroendocrinology. Academic Press Inc. https://doi.org/10.1016/j.yfrne.2019.02.001

Spiteri, T., Musatov, S., Ogawa, S., Ribeiro, A., Pfaff, D. W., \& Ågmo, A. (2010). Estrogeninduced sexual incentive motivation, proceptivity and receptivity depend on a functional estrogen receptor ?? in the ventromedial nucleus of the hypothalamus but not in the amygdala. Neuroendocrinology, 91(2), 142-154. https://doi.org/10.1159/000255766 
Steinberg, R. M., Juenger, T. E., \& Gore, A. C. (2007). The effects of prenatal PCBs on adult female paced mating reproductive behaviors in rats. Hormones and Behavior, 51(3), 364372. https://doi.org/10.1016/j.yhbeh.2006.12.004

Stroheker, T., Cabaton, N., Nourdin, G., Régnier, J. F., Lhuguenot, J. C., \& Chagnon, M. C. (2005). Evaluation of anti-androgenic activity of di-(2-ethylhexyl)phthalate. Toxicology, 208(1), 115-121. https://doi.org/10.1016/j.tox.2004.11.013

Sullivan, A. W., Beach, E. C., Stetzik, L. A., Perry, A., D’Addezio, A. S., Cushing, B. S., \& Patisaul, H. B. (2014). A novel model for neuroendocrine toxicology: Neurobehavioral effects of BPA exposure in a prosocial species, the prairie vole (Microtus ochrogaster). Endocrinology, 155(10), 3867-3881. https://doi.org/10.1210/en.2014-1379

Topper, V. Y., Reilly, M. P., Wagner, L. M., Thompson, L. M., Gillette, R., Crews, D., \& Gore, A. C. (2019). Social and neuromolecular phenotypes are programmed by prenatal exposures to endocrine-disrupting chemicals. Molecular and Cellular Endocrinology, 479(October 2018), 133-146. https://doi.org/10.1016/j.mce.2018.09.010

Veeramachaneni, D. N. R., Palmer, J. S., Amann, R. P., Kane, C. M., Higuchi, T. T., \& Pau, K. Y. F. (2006). Disruption of sexual function, FSH secretion, and spermiogenesis in rabbits following developmental exposure to vinclozolin, a fungicide. Reproduction, 131(4), 805816. https://doi.org/10.1530/rep.1.01048

Veeramachaneni, D. N. R., Palmer, J. S., Amann, R. P., \& Pau, K. Y. F. (2007). Sequelae in male rabbits following developmental exposure to $\mathrm{p}, \mathrm{p}^{\prime}$-DDT or a mixture of $\mathrm{p}, \mathrm{p}^{\prime}$-DDT and vinclozolin: Cryptorchidism, germ cell atypia, and sexual dysfunction. Reproductive Toxicology, 23(3), 353-365. https://doi.org/10.1016/j.reprotox.2007.01.001

Wagner, \& Morrell. (1996). Distribution and Steroid Hormone Regulation of Aromatase mRNA Expression in the Forebrain of Adult Male and Female Rats: A Cellular-Level Analysis Using in Situ Hybridization. The Journal of Comparative Neurology, 370(1). https://doi.org/10.1002/(SICI)1096-9861(19960617)370:1<71::AID-CNE7>3.0.CO;2-I

Walker, D. M., Goetz, B. M., \& Gore, A. C. (2014). Dynamic postnatal developmental and sexspecific neuroendocrine effects of prenatal polychlorinated biphenyls in rats. Molecular Endocrinology, 28(1), 99-115. https://doi.org/10.1210/me.2013-1270

Wang, R., Xu, X., \& Zhu, Q. (2016). Pubertal exposure to di-(2-ethylhexyl) phthalate influences social behavior and dopamine receptor D2 of adult female mice. Chemosphere. https://doi.org/10.1016/j.chemosphere.2015.10.062

Wang, X. Q., Fang, J., Nunez, A. A., \& Clemens, L. G. (2002). Developmental exposure to polychlorinated biphenyls affects sexual behavior of rats. Physiology and Behavior. https://doi.org/10.1016/S0031-9384(02)00673-X

Witchey, S. K., Fuchs, J., \& Patisaul, H. B. (2019). Perinatal bisphenol A (BPA) exposure alters brain oxytocin receptor (OTR) expression in a sex- and region- specific manner: A CLARITY-BPA consortium follow-up study. NeuroToxicology, 74, 139-148. https://doi.org/10.1016/j.neuro.2019.06.007

Wolstenholme, J. T., Edwards, M., Shetty, S. R. J., Gatewood, J. D., Taylor, J. A., Rissman, E. 
F., \& Connelly, J. J. (2012). Gestational exposure to bisphenol a produces transgenerational changes in behaviors and gene expression. Endocrinology, 153(8), 3828-3838. https://doi.org/10.1210/en.2012-1195

Wright, C. L., Schwarz, J. S., Dean, S. L., \& McCarthy, M. M. (2010). Cellular mechanisms of estradiol-mediated sexual differentiation of the brain. Trends in Endocrinology and Metabolism, 21(9), 553-561. https://doi.org/10.1016/j.tem.2010.05.004

Wu, D., \& Gore, A. C. (2010). Changes in androgen receptor, estrogen receptor alpha, and sexual behavior with aging and testosterone in male rats. Hormones and Behavior, 58(2), 306-316. https://doi.org/10.1016/j.yhbeh.2010.03.001

Xiao, K., Kondo, Y., \& Sakuma, Y. (2004). Sex-specific effects of gonadal steroids on conspecific odor preference in the rat. Hormones and Behavior, 46(3), 356-361. https://doi.org/10.1016/j.yhbeh.2004.05.008

Yao, S., Bergan, J., Lanjuin, A., \& Dulac, C. (2017). Oxytocin signaling in the medial amygdala is required for sex discrimination of social cues. ELife, 6 . 


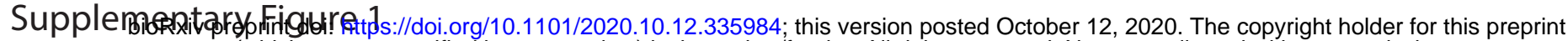
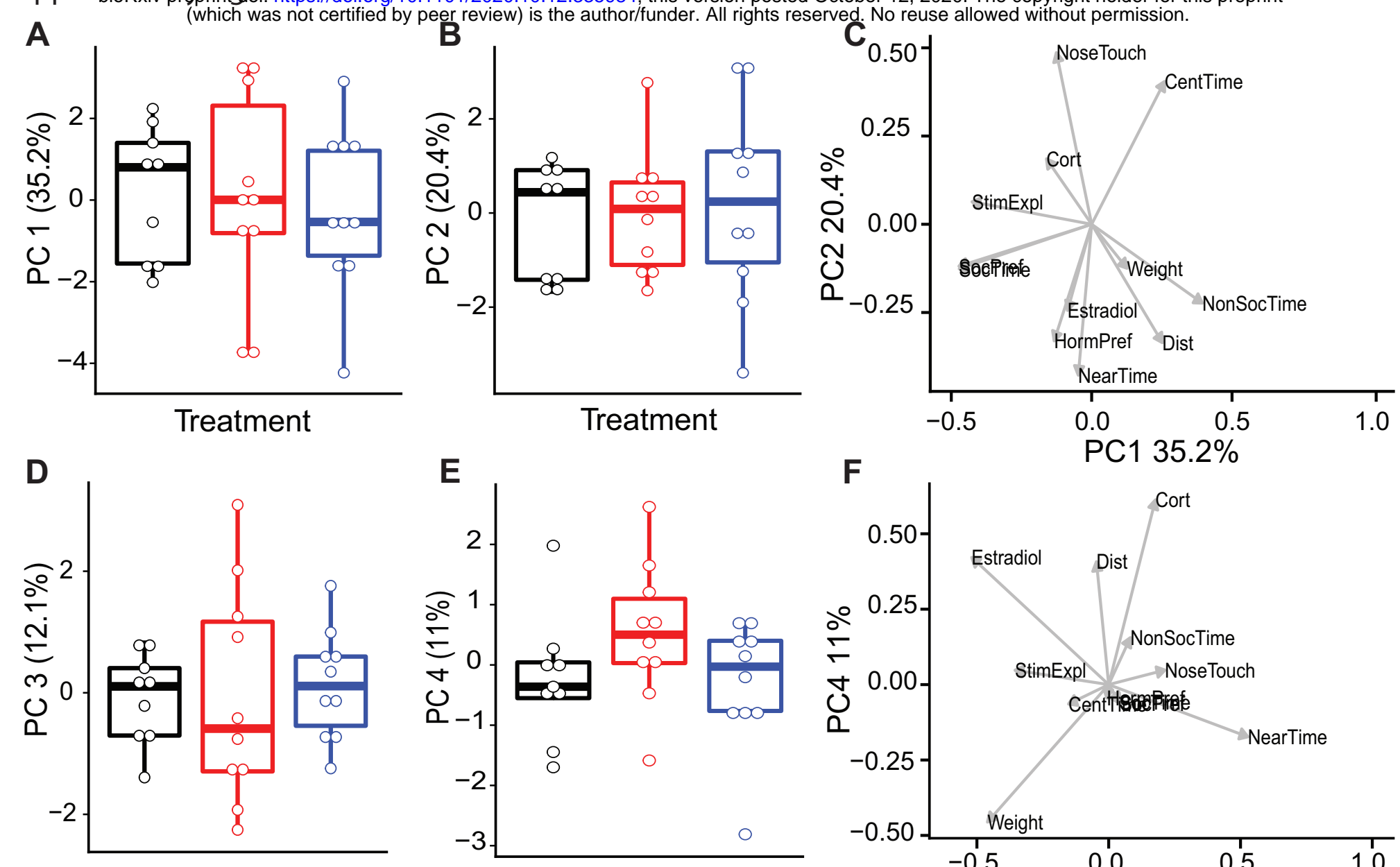

F

PC1 35.2\%
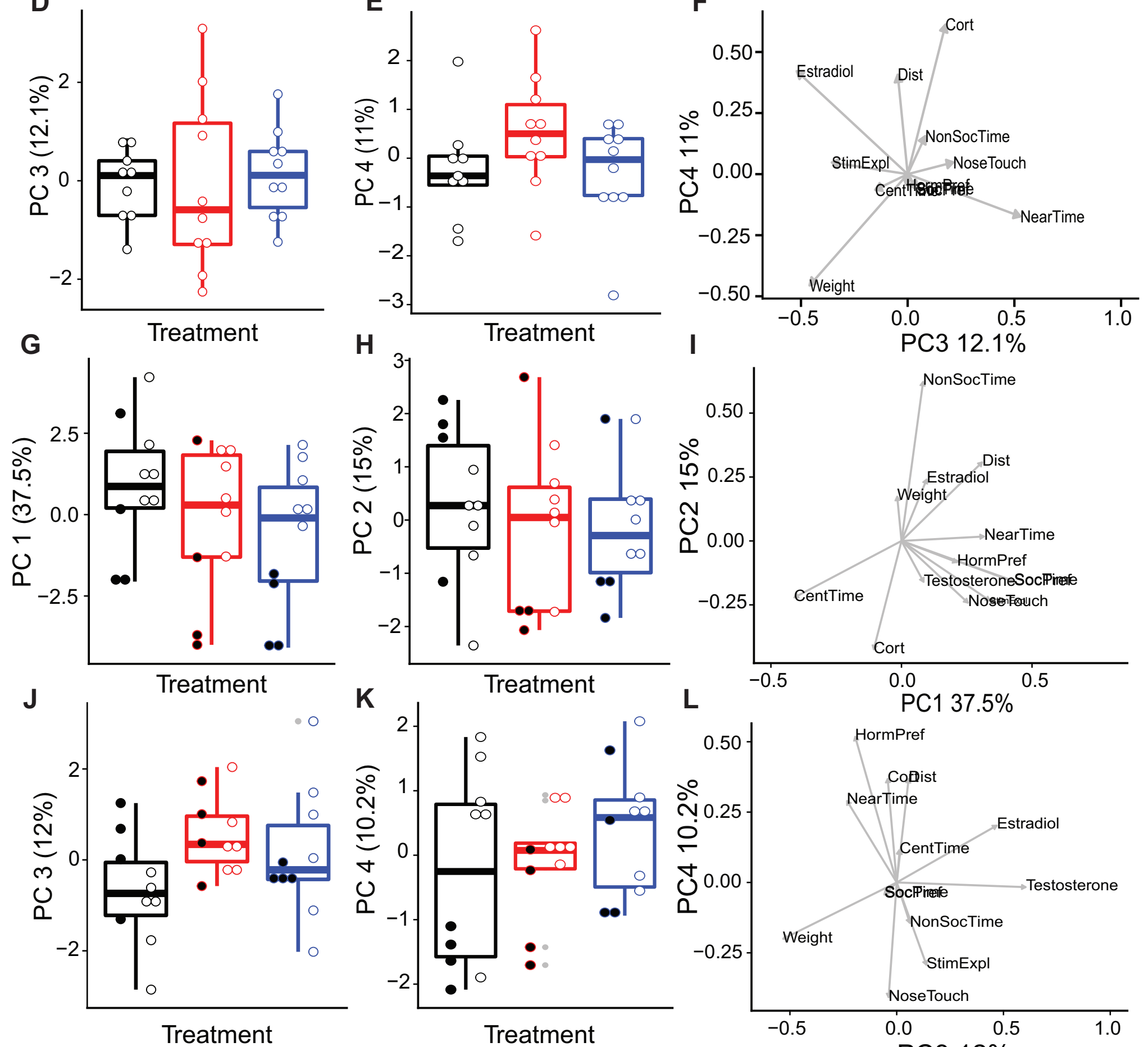

Treatment

Treatment

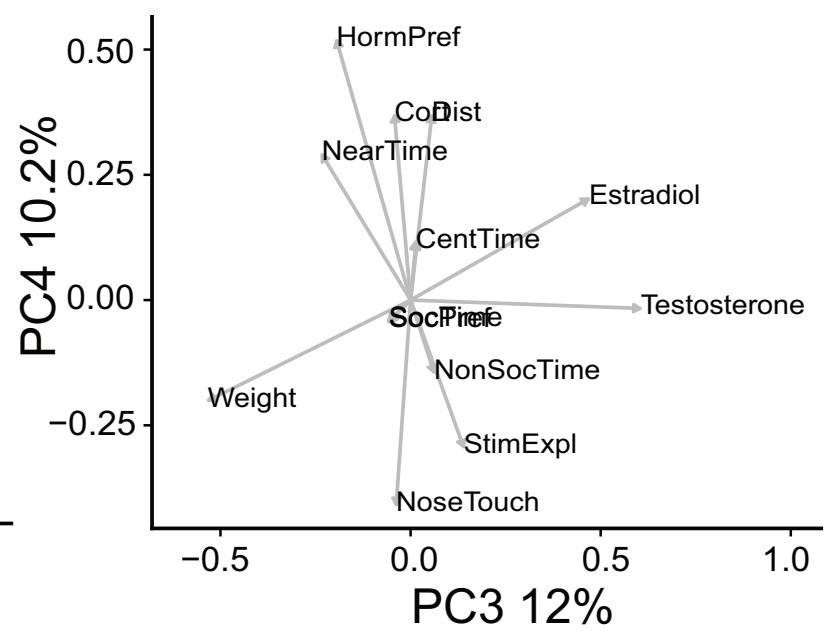


bioRxj AepMEAi: https://doi.org/10.1101/2020.10.12.335984; this version pBstPQAtober 12, 2020. The copyright holder for this preprint

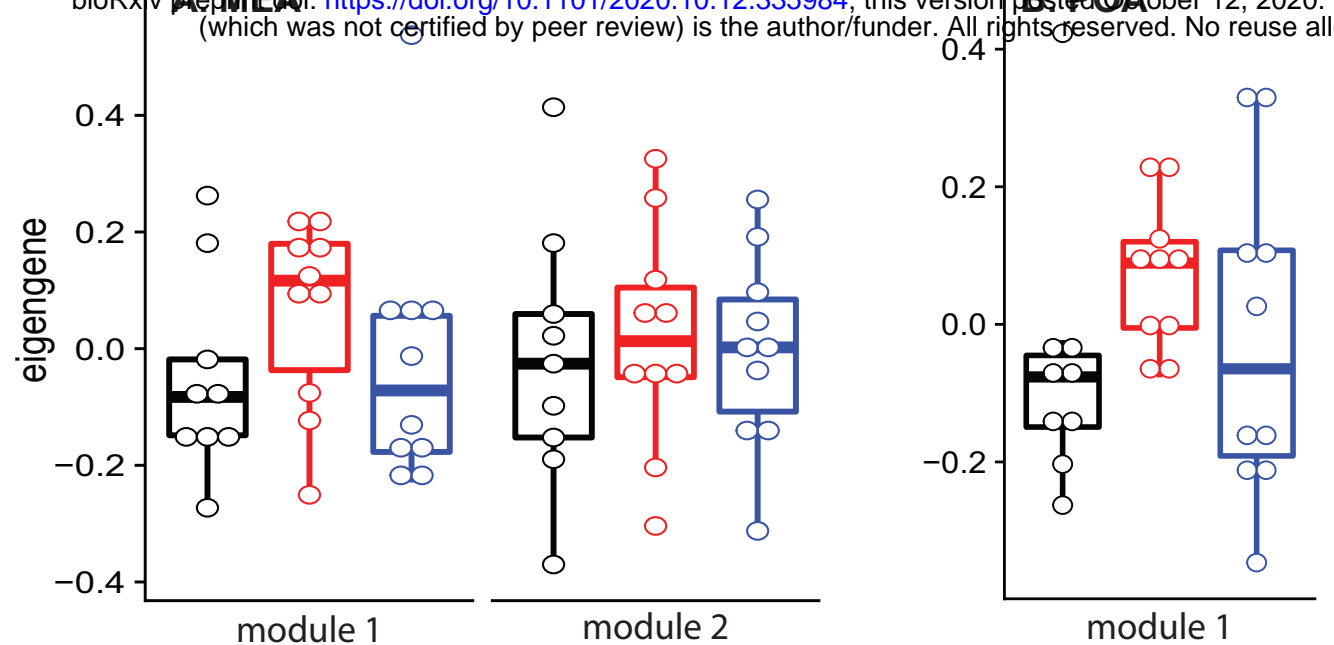

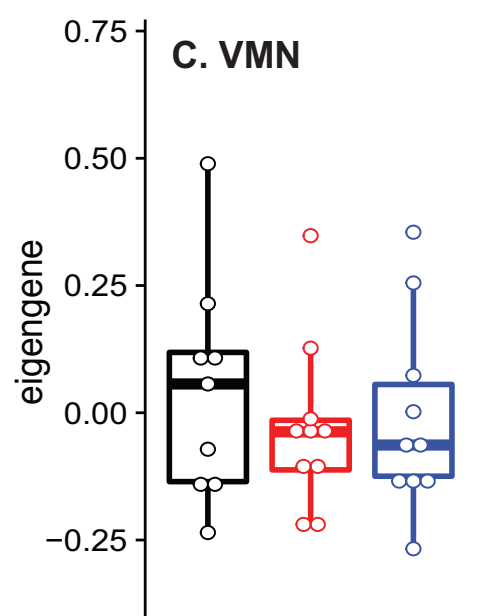

module 1

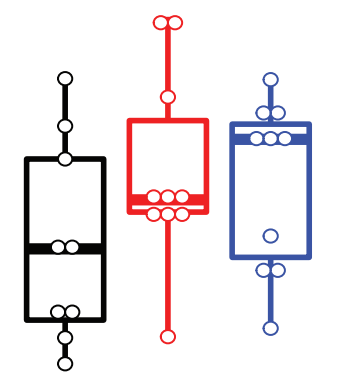

module 2

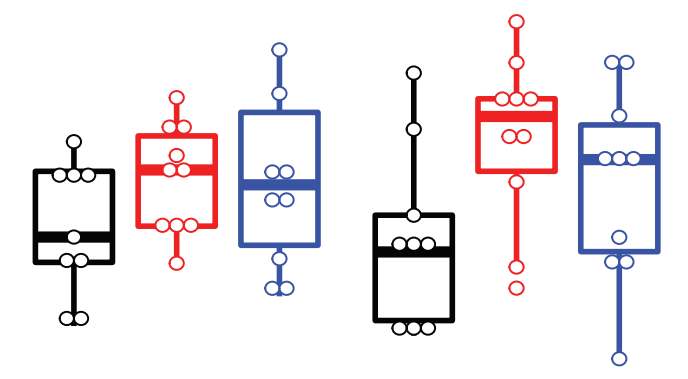

module 4

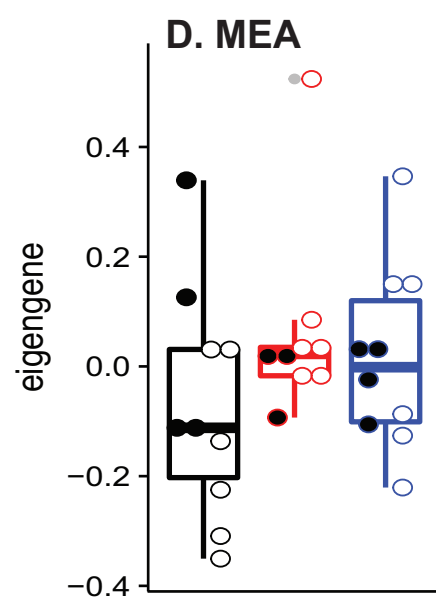

module 1
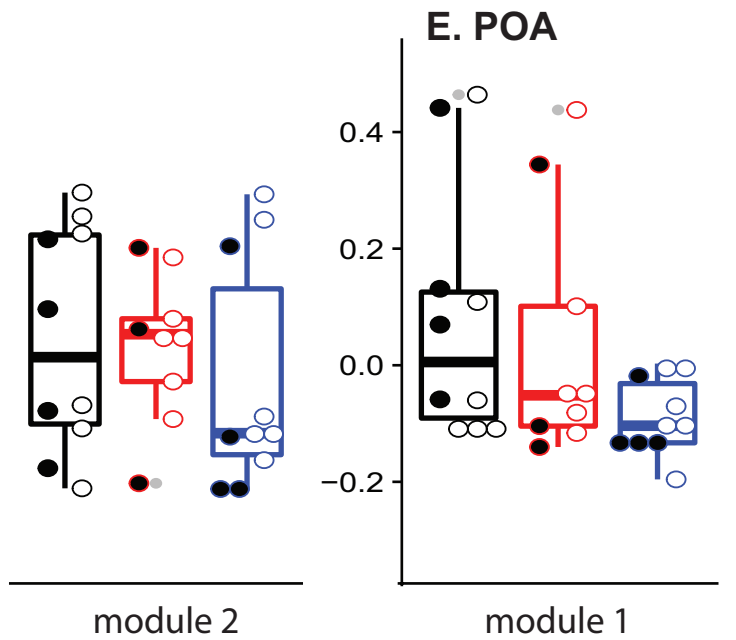

module 1

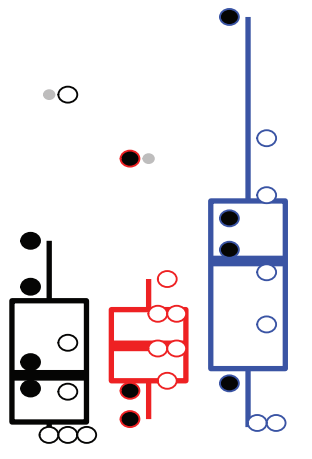

module 2

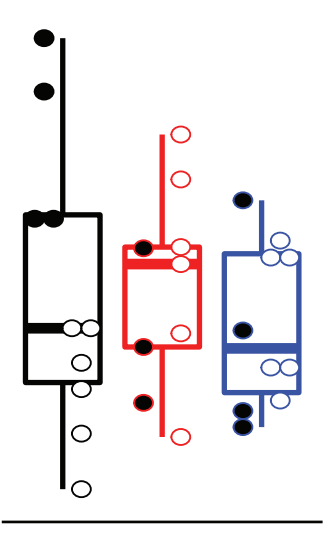

module 3

\section{F. VMN}
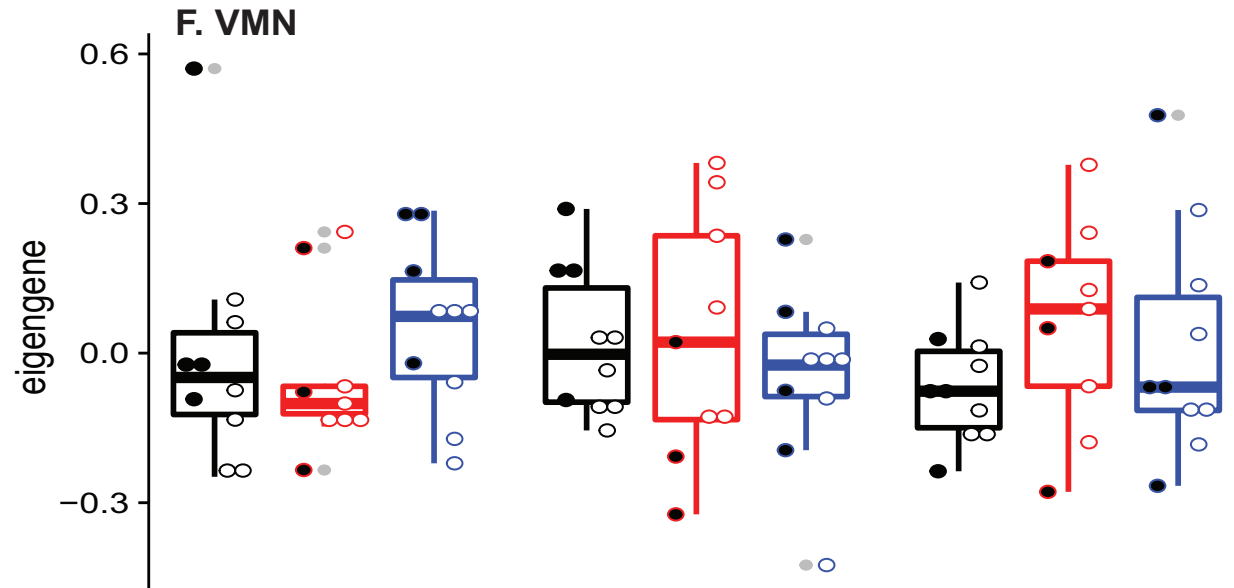

- 0 


\section{A. Female MeA: DMSO}

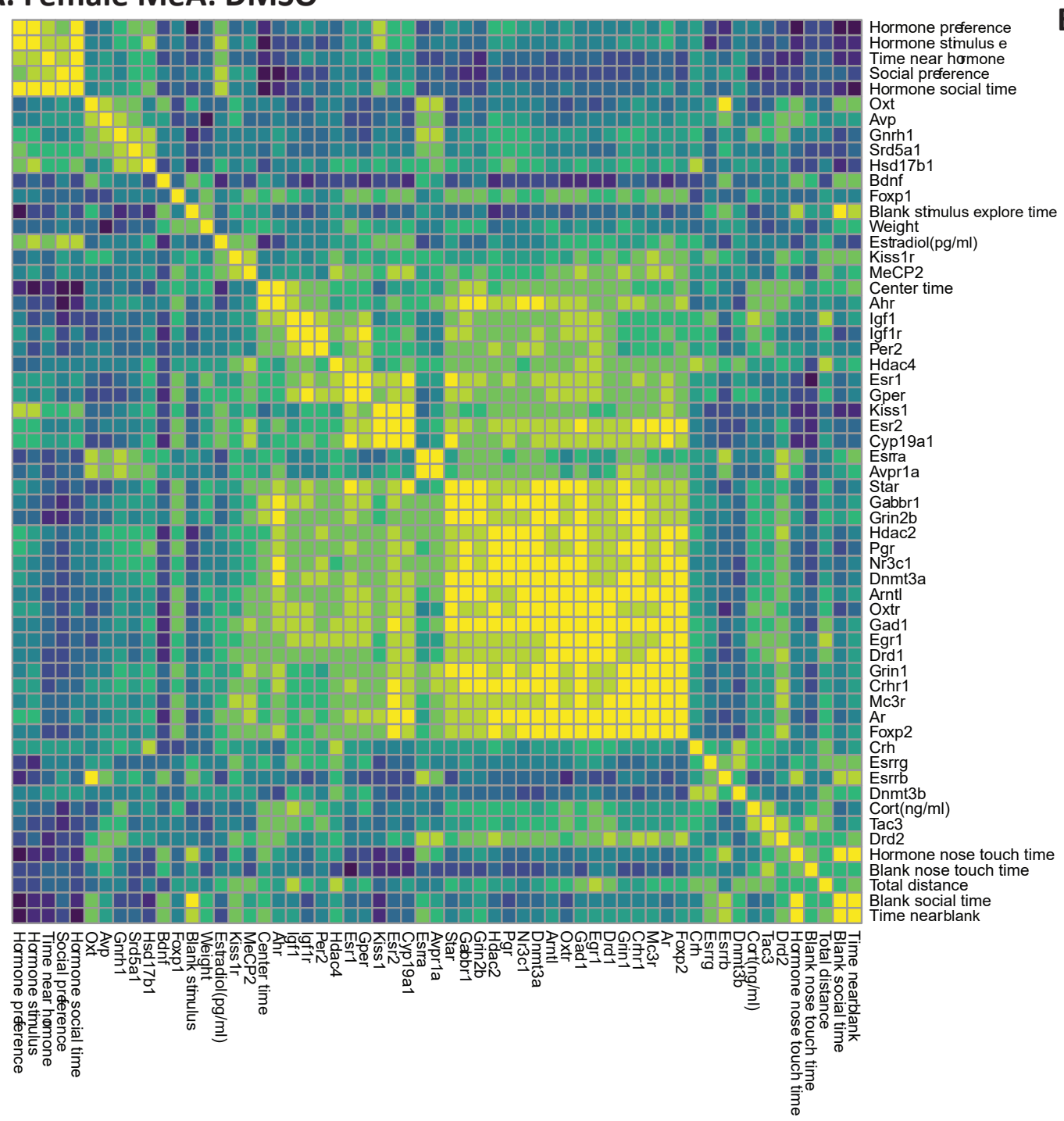

B. Female MeA: PCB

dis-integration

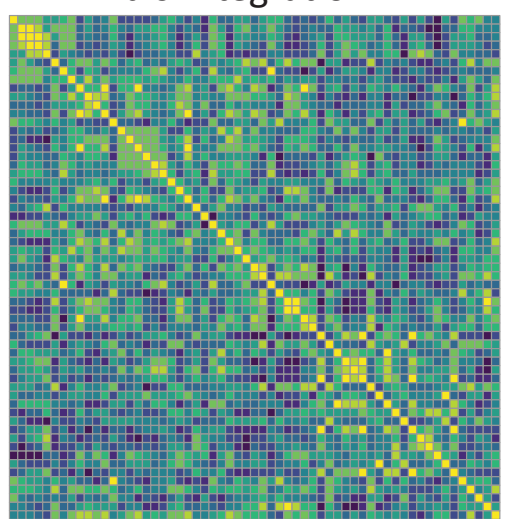

D. Female MeA: VIN dis-integration

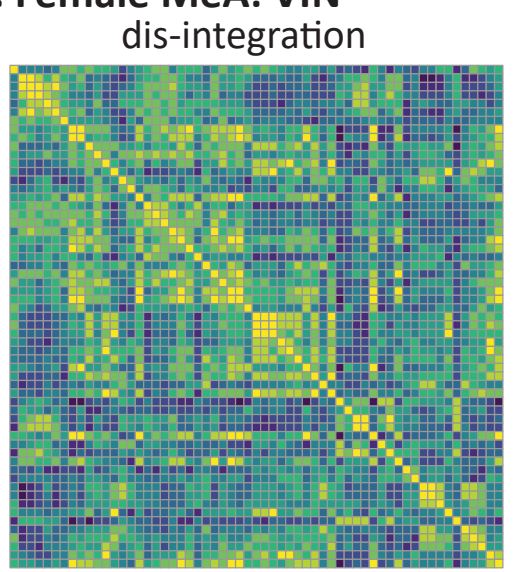

\section{Female MeA: PCB}

reconstitution

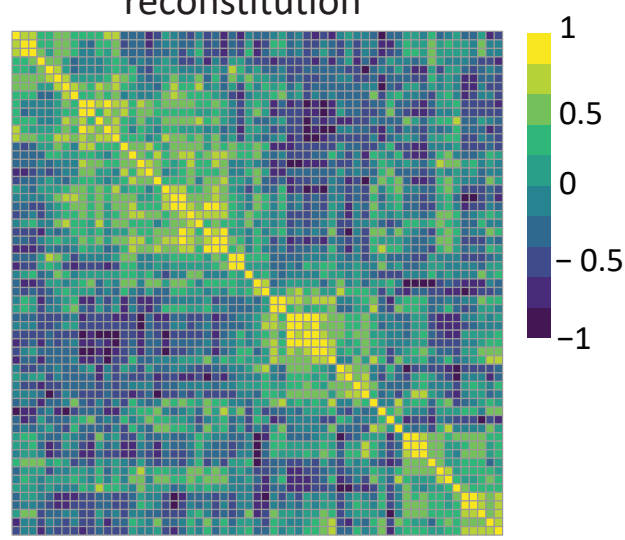

E. Female MeA: VIN

reconstitution

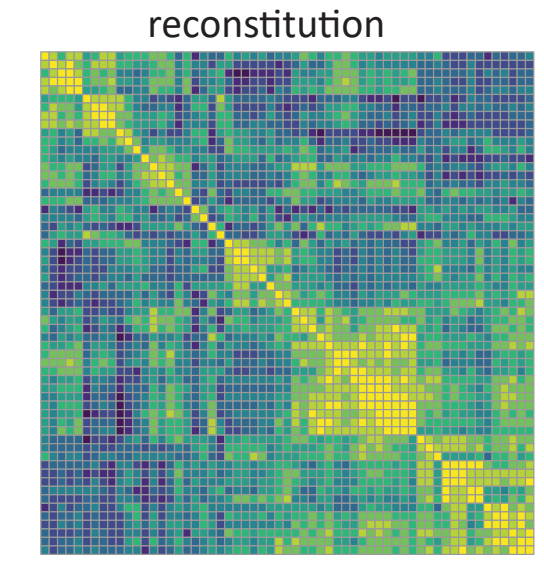




\section{F. Female POA: DMSO}

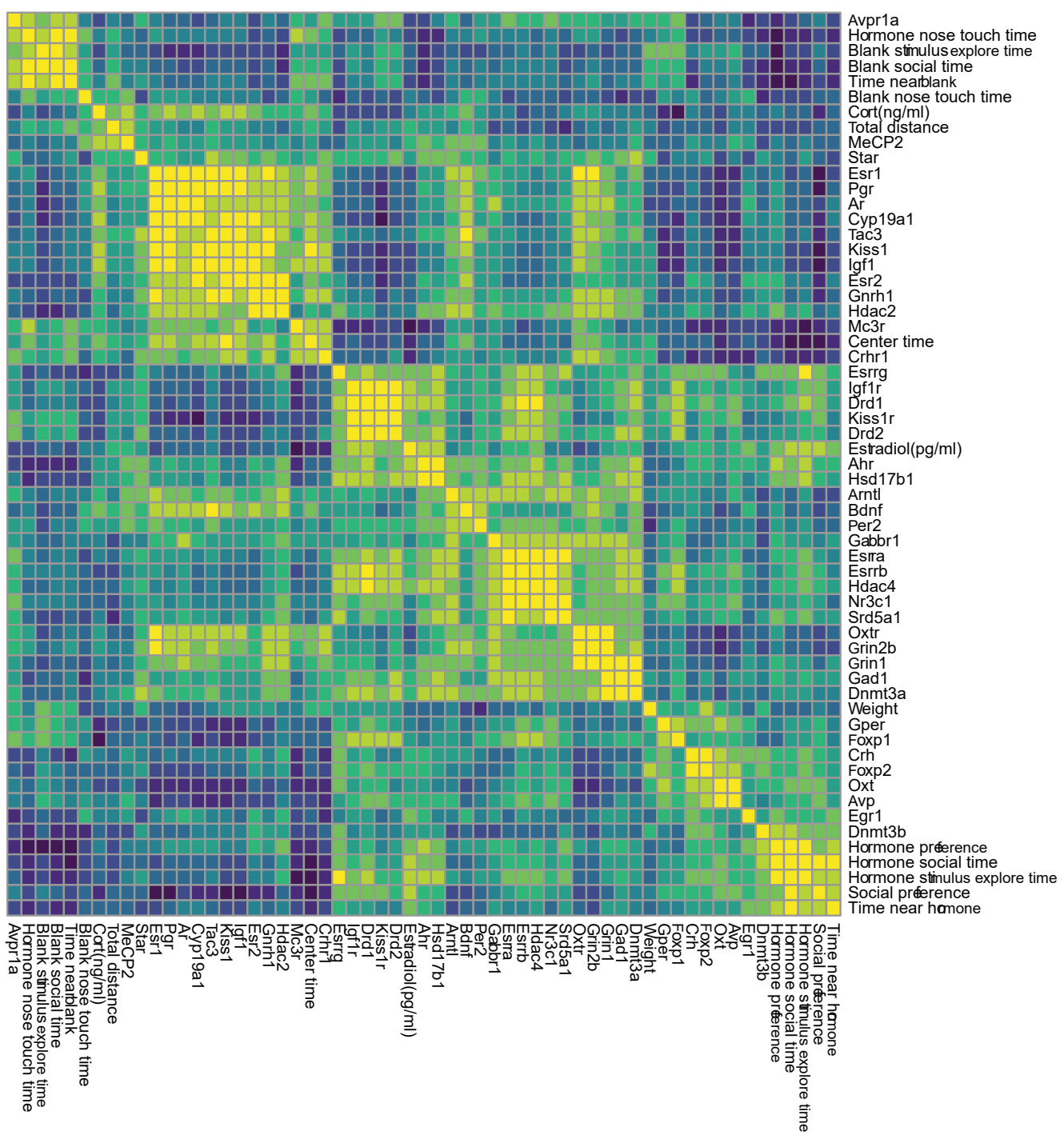

\section{G. Female POA: PCB}

dis-integration

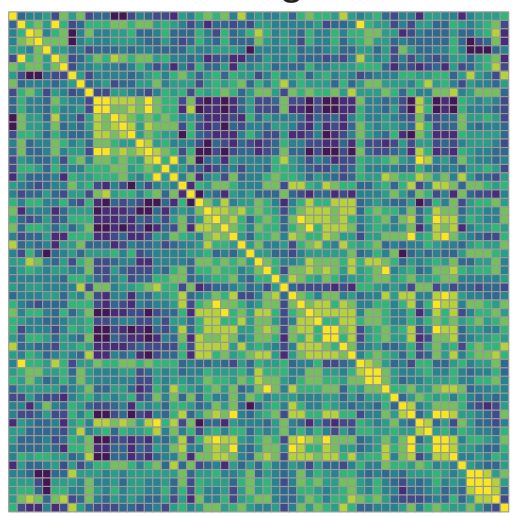

I. Female POA: VIN dis-integration

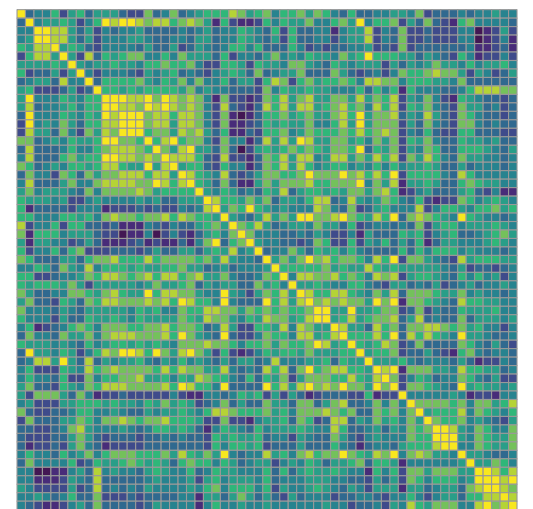

\section{H. Female POA: PCB}

reconstitution

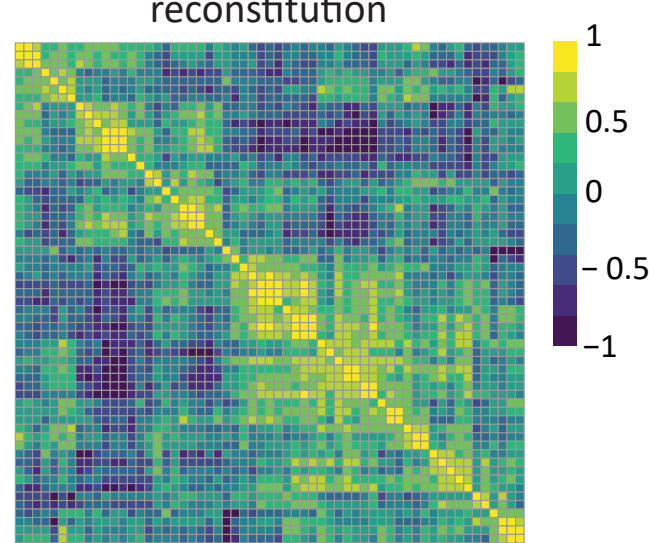

J. Female POA: VIN reconstitution

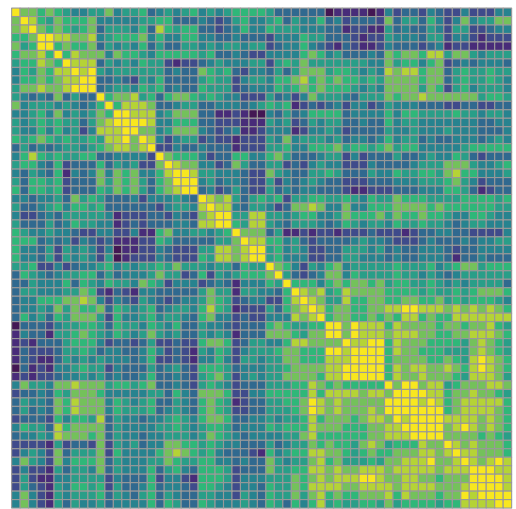
5 


\section{K. Female VMN: DMSO}

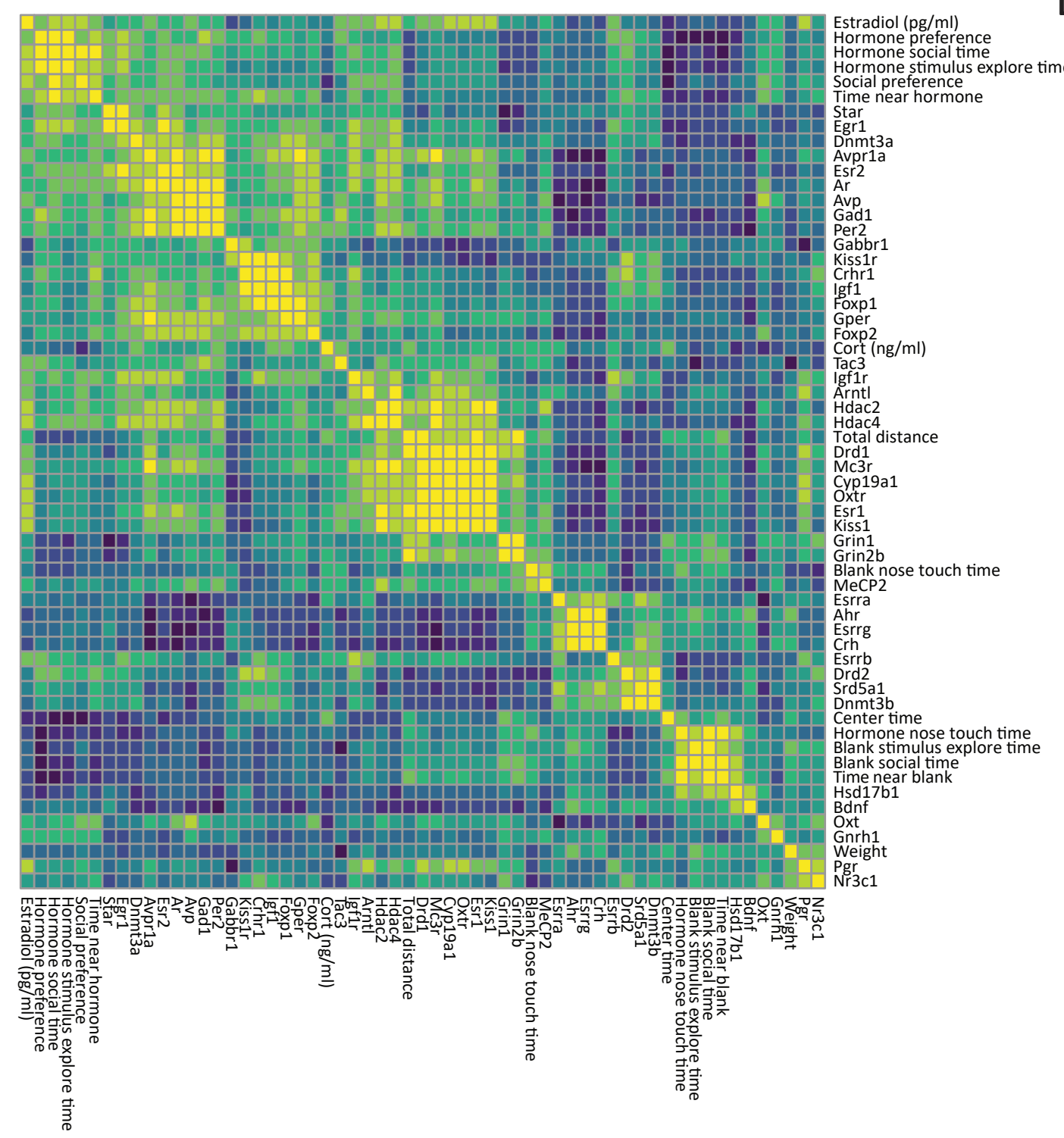

\section{Female VMN: PCB}

dis-integration

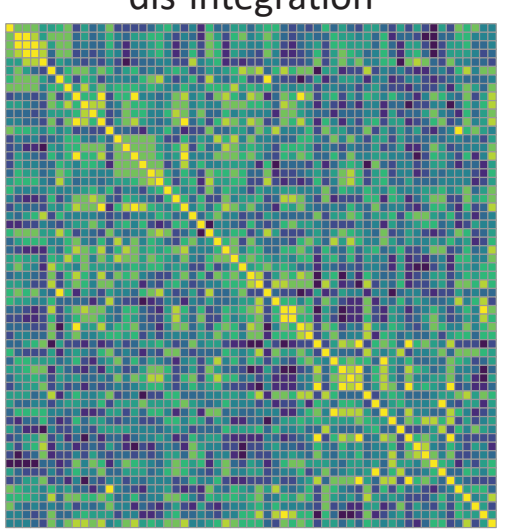

N. Female VMN: VIN dis-integration

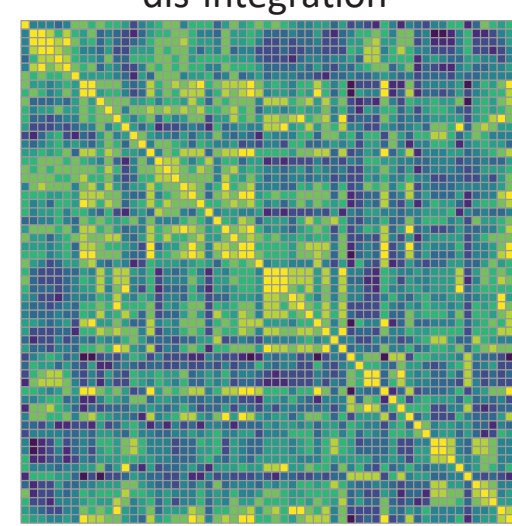

\section{Female VMN: PCB}

reconstitution

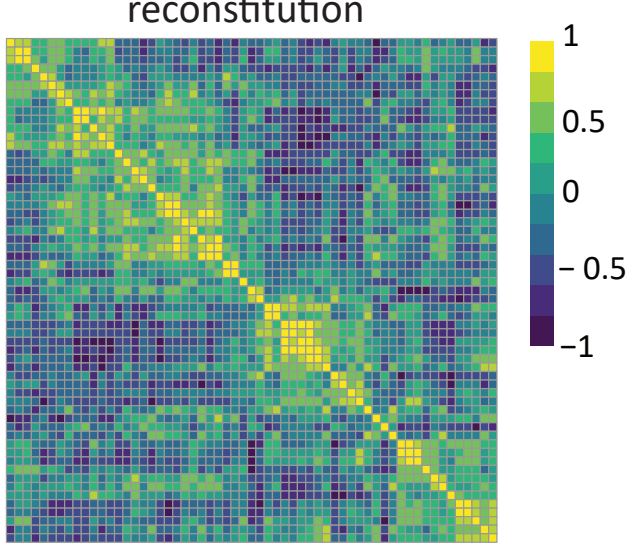

O. Female VMN: VIN reconstitution

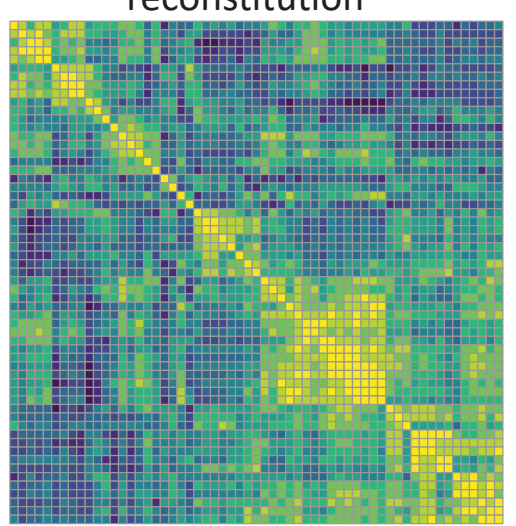
.5 


\section{P. Male MeA: DMSO}

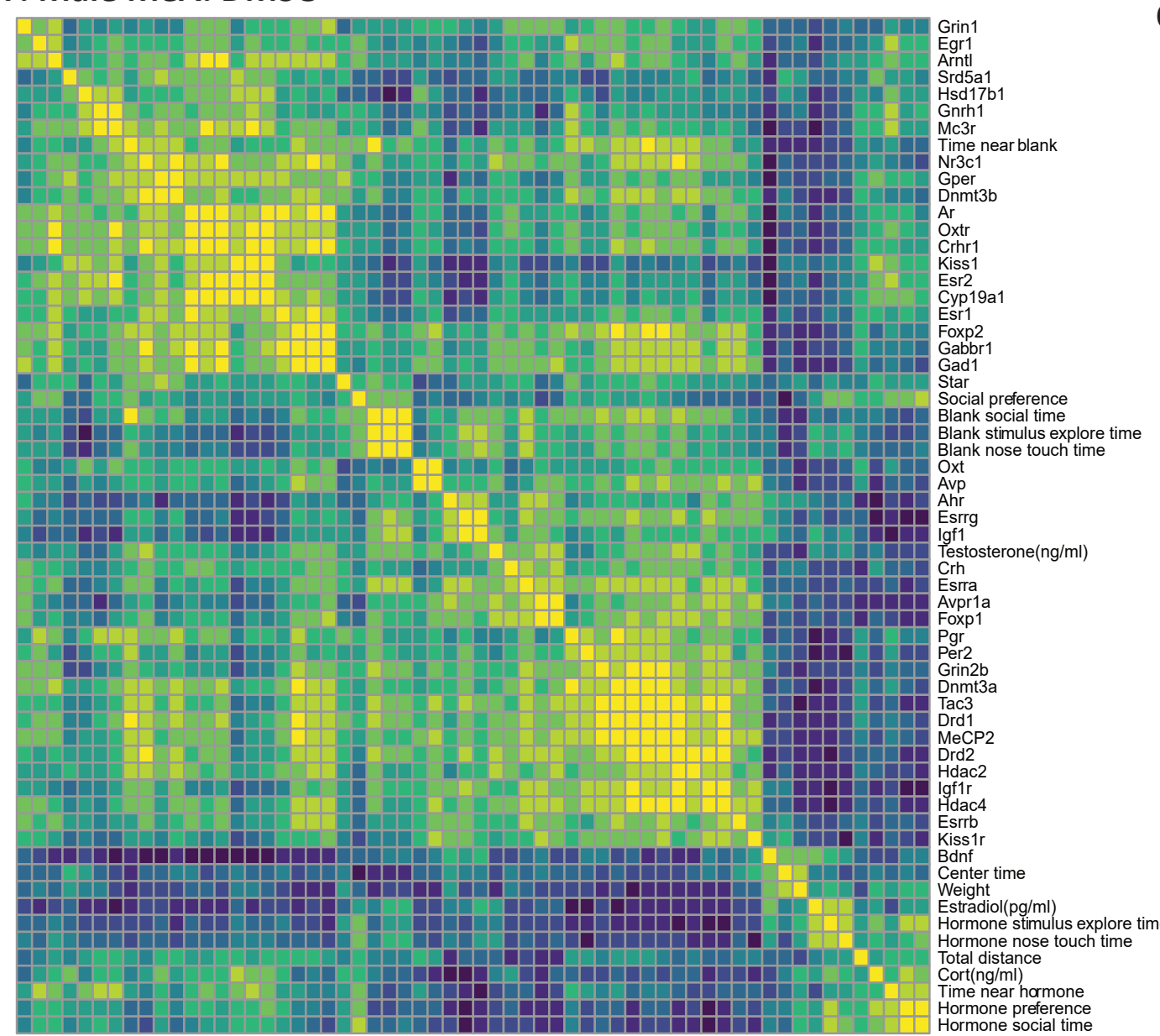

Q. Male MeA: PCB

dis-integration

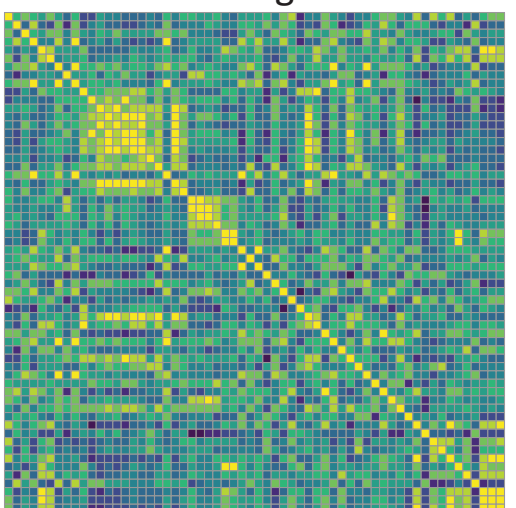

S. Male MeA: VIN

dis-integration

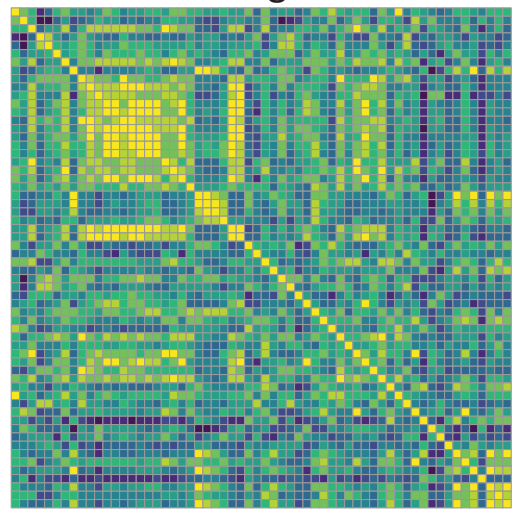

\section{R. Male MeA: PCB}

reconstitution

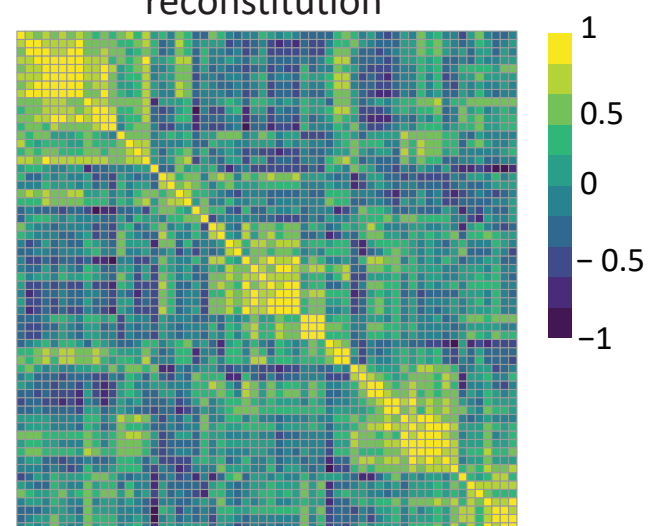

T. Male MeA: VIN

reconstitution

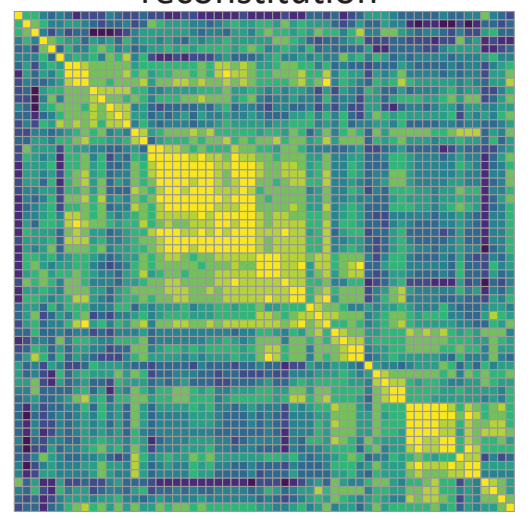

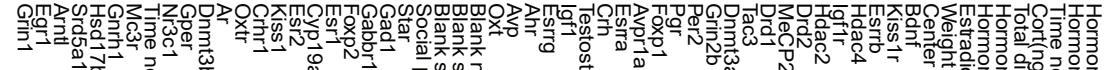

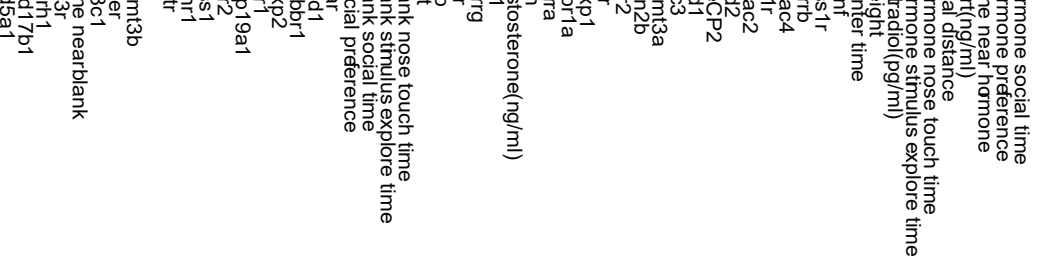




\section{U. Male VMN: DMSO}

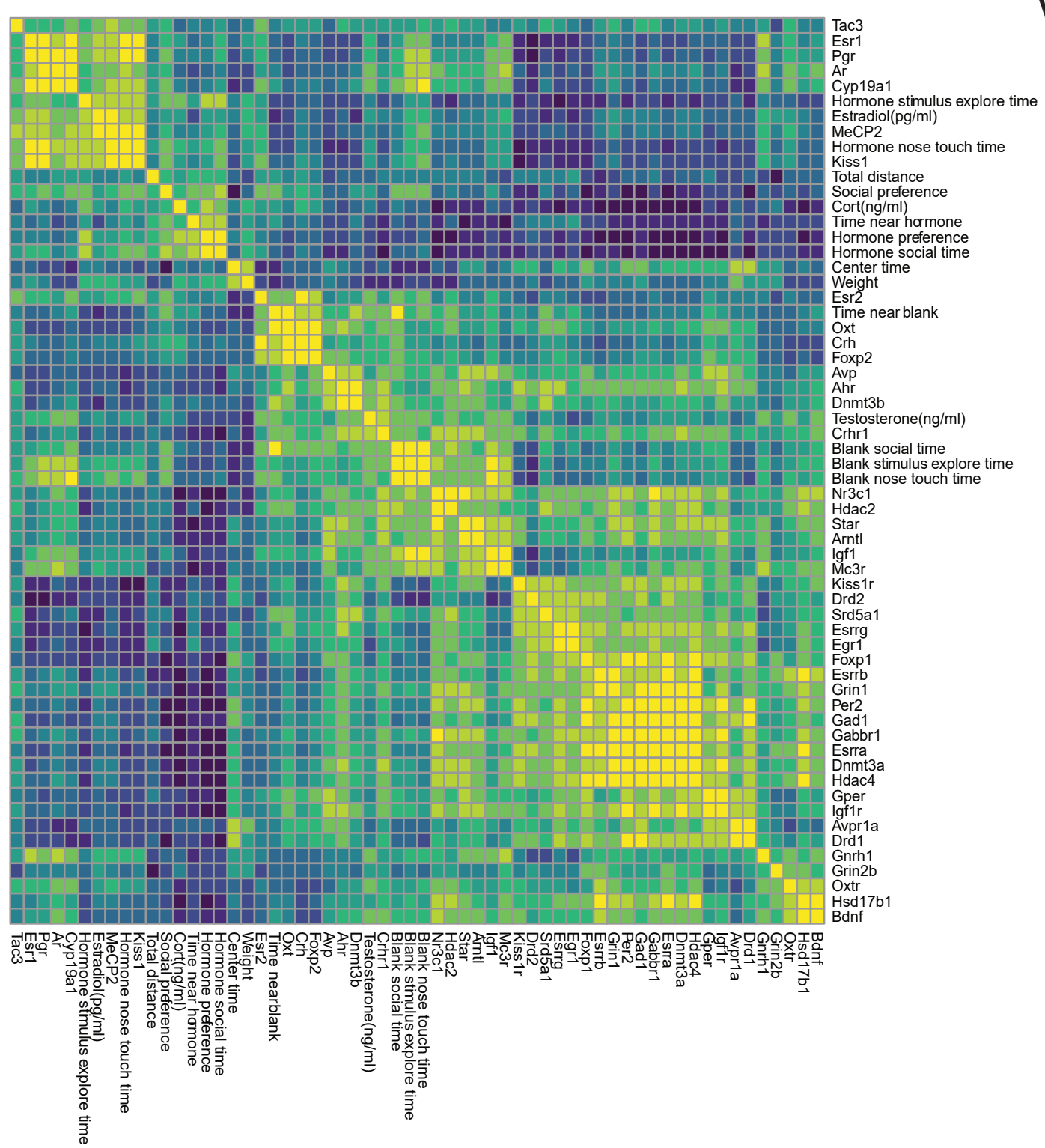

\section{Male VMN: PCB}

dis-integration

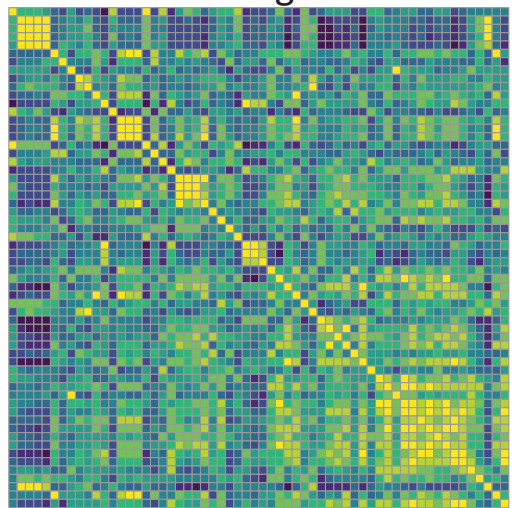

X. Male POA: VIN

dis-integration

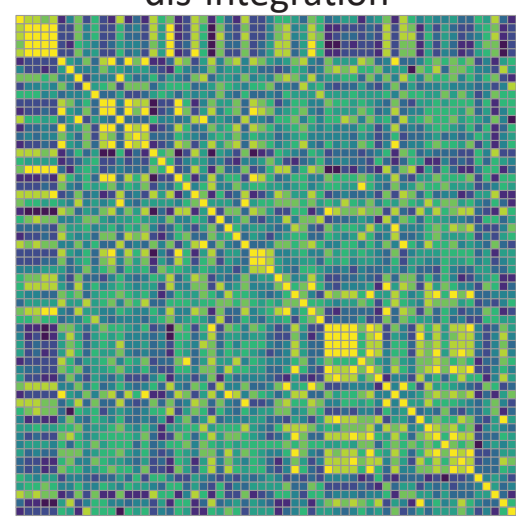

\section{W. Male POA: PCB}

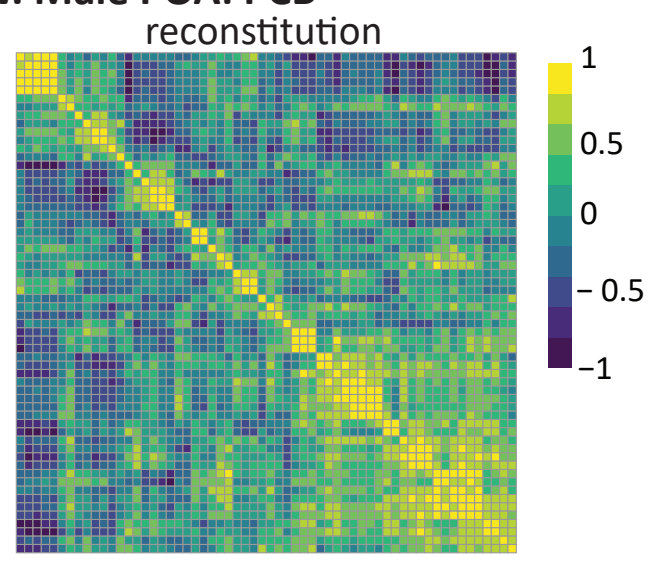

Y. Male POA: VIN

reconstitution

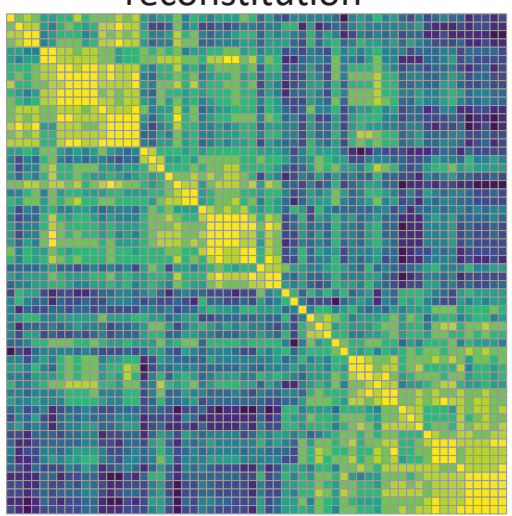

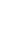




\section{Z. Male VMN: DMSO}

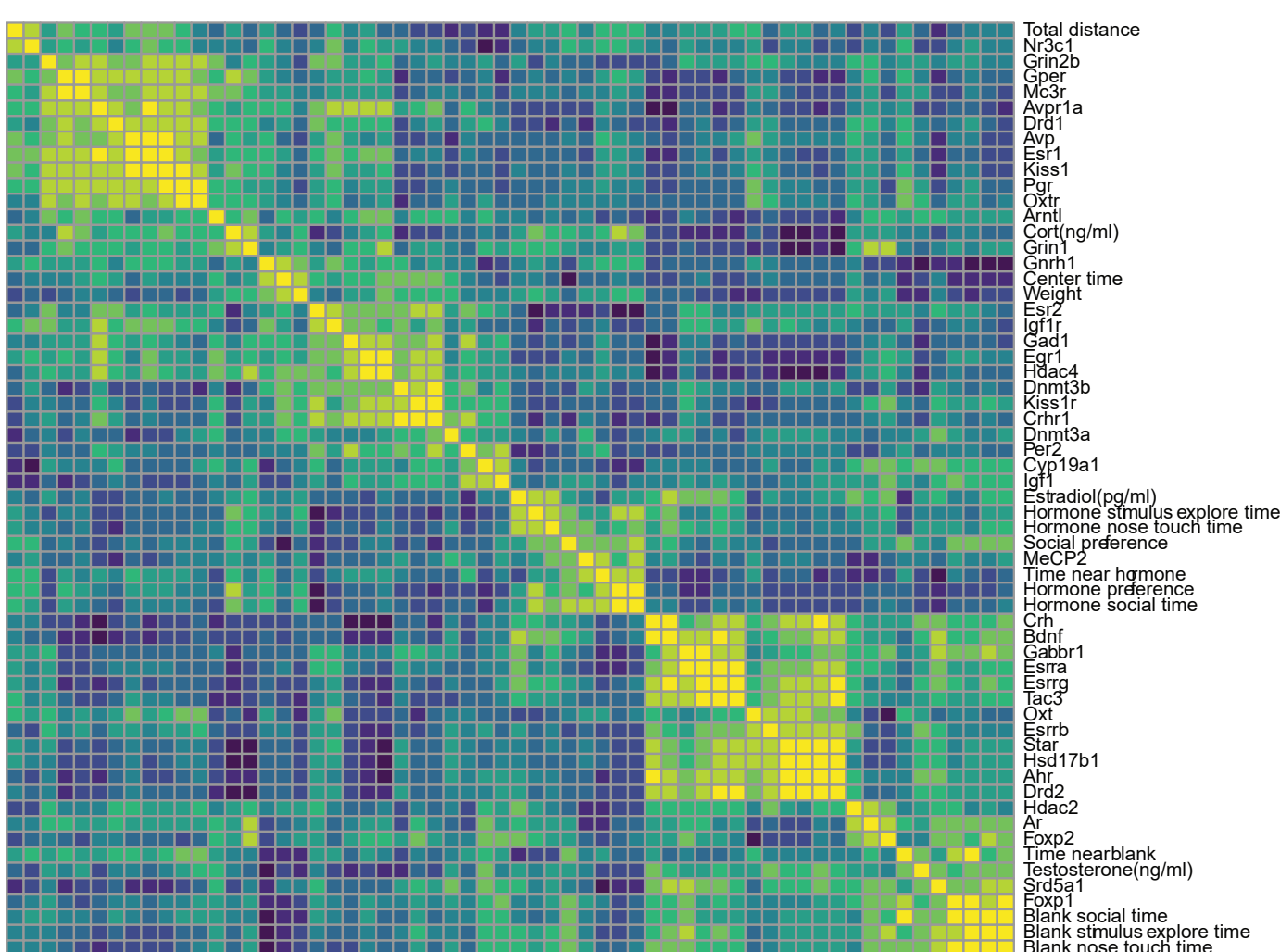

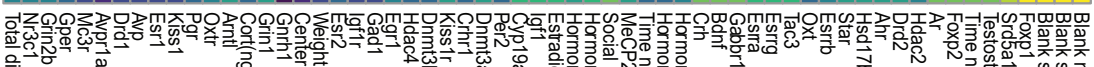

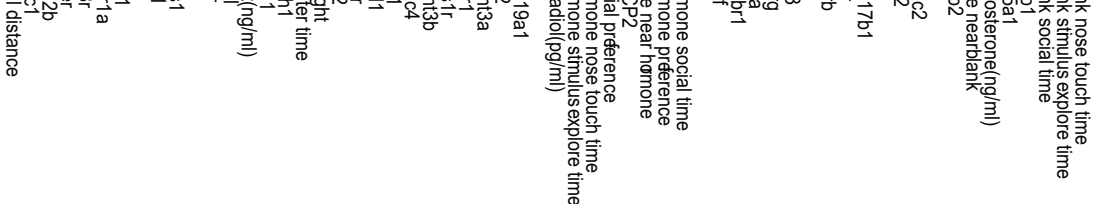

\section{AA. Male VMN: PCB}

dis-integration

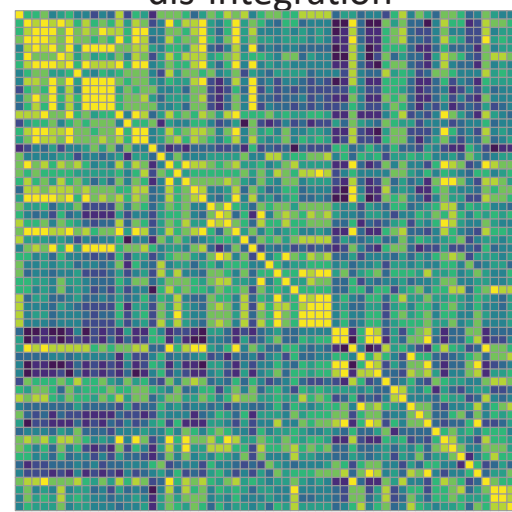

CC. Male VMN: VIN

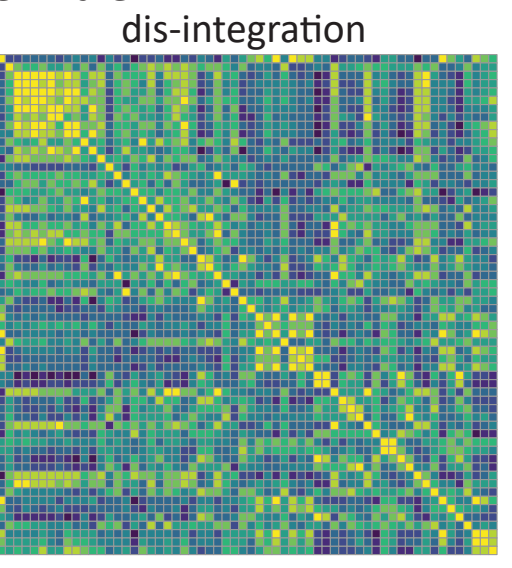

BB. Male VMN: PCB

reconstitution

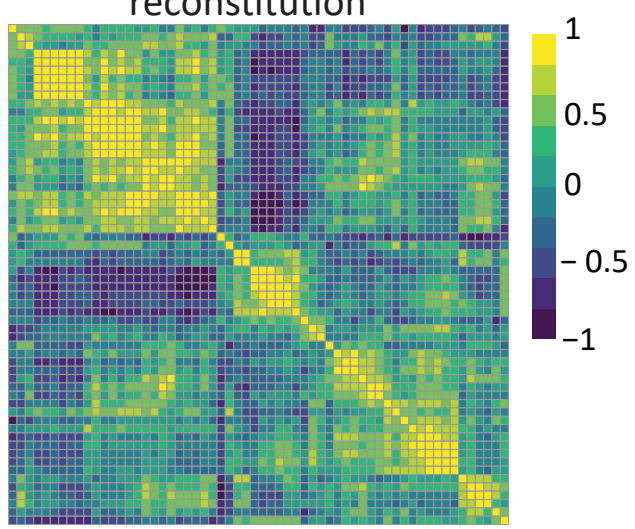

DD. Male VMN: VIN reconstitution

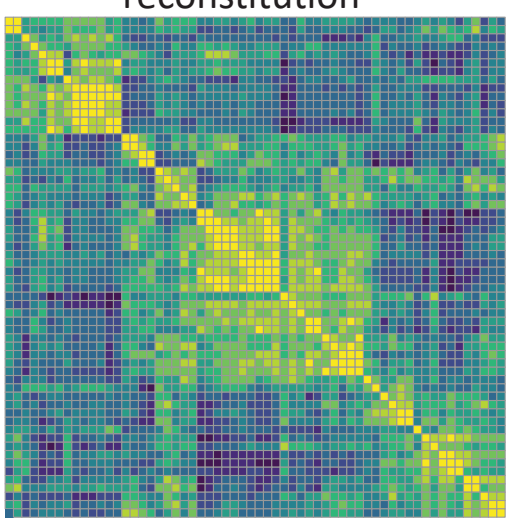


Supplementary Table 1. TLDA gene expression results

VMN-Female

DMSO

PCB

VIN

Esr1

Esr2

$\mathrm{Ar}$

Gper

Pgr

$\mathrm{Nr3c1}$

Ahr

Cyp19a1

Srd5a1

Star

Hsd17b1

Esrra

Esrrb

Esrrg

Oxt

Oxtr

Avp

Avpr1a

Kiss1

Kiss1r

Crh

Crhr1

Gnrh1

Bdnf

Igf1

$\operatorname{lgf} 1 \mathrm{r}$

Egr1

Mc3r

Tac3

Gabbr1

Drd1

Drd2

Grin1

Grin2b

Gad1

$\mathrm{MeCP} 2$

Dnmt3a

Dnmt3b

Hdac2

Hdac4

\begin{tabular}{rrrrrrrrr} 
Mean & SEM & $\mathrm{N}$ & Mean & SEM & $\mathrm{N}$ & Mean & SEM & $\mathrm{N}$ \\
\hline 1.39 & 0.41 & 9 & 2.16 & 0.37 & 10 & 1.63 & 0.29 & 10 \\
0.98 & 0.08 & 9 & 1.13 & 0.09 & 10 & 1.00 & 0.06 & 10
\end{tabular}

$\begin{array}{llll}0.89 & 0.11 & 9\end{array}$

$\begin{array}{lll}1.07 & 0.08 & 9\end{array}$

$\begin{array}{lll}1.55 & 0.55 & 9\end{array}$

$\begin{array}{lll}0.91 & 0.19 & 9\end{array}$

$\begin{array}{lll}1.04 & 0.10 & 9\end{array}$

$\begin{array}{lll}2.14 & 0.80 & 9\end{array}$

$\begin{array}{lll}1.21 & 0.15 & 9\end{array}$

$3.28 \quad 2.44 \quad 9$

$\begin{array}{lll}2.94 & 1.94 & 9\end{array}$

$\begin{array}{lll}1.02 & 0.07 & 9\end{array}$

$\begin{array}{lll}1.09 & 0.10 & 9\end{array}$

$\begin{array}{lll}0.95 & 0.12 & 9\end{array}$

$\begin{array}{lll}0.93 & 0.18 & 9\end{array}$

$\begin{array}{lll}2.44 & 1.25 & 9\end{array}$

$\begin{array}{lll}0.93 & 0.16 & 9\end{array}$

$\begin{array}{llll}0.83 & 0.13 & 9\end{array}$

$\begin{array}{lll}2.75 & 1.10 & 9\end{array}$

$\begin{array}{lll}1.01 & 0.11 & 9\end{array}$

$\begin{array}{lll}1.02 & 0.32 & 9\end{array}$

$\begin{array}{lll}1.05 & 0.11 & 9\end{array}$

$\begin{array}{lll}1.04 & 0.19 & 9\end{array}$

$\begin{array}{lll}1.03 & 0.11 & 9\end{array}$

$\begin{array}{lll}1.03 & 0.08 & 9\end{array}$

$\begin{array}{lll}1.13 & 0.07 & 9\end{array}$

$\begin{array}{lll}1.29 & 0.37 & 9\end{array}$

$\begin{array}{lll}1.23 & 0.32 & 9\end{array}$

$\begin{array}{lll}0.98 & 0.17 & 9\end{array}$

$\begin{array}{lll}0.84 & 0.11 & 9\end{array}$

$\begin{array}{lll}1.11 & 0.30 & 9\end{array}$

$\begin{array}{lll}1.05 & 0.13 & 9\end{array}$

$\begin{array}{lll}0.98 & 0.14 & 9\end{array}$

$\begin{array}{lll}1.05 & 0.18 & 9\end{array}$

$\begin{array}{lll}0.80 & 0.14 & 9\end{array}$

$\begin{array}{lll}1.01 & 0.07 & 9\end{array}$

$\begin{array}{llll}0.99 & 0.06 & 9\end{array}$

$\begin{array}{lll}0.92 & 0.08 & 9\end{array}$

$\begin{array}{lll}1.02 & 0.06 & 9\end{array}$

$\begin{array}{lll}0.99 & 0.07 & 9\end{array}$ $\begin{array}{lll}1.26 & 0.10 & 10\end{array}$

$\begin{array}{lll}1.24 & 0.07 & 10\end{array}$

$\begin{array}{lll}2.92 & 0.36 & 10\end{array}$

$\begin{array}{lll}1.47 & 0.08 & 10\end{array}$

$\begin{array}{lll}0.99 & 0.07 & 9\end{array}$

$\begin{array}{rrr}11.93 & 6.99 & 10\end{array}$

$\begin{array}{lll}1.06 & 0.12 & 10\end{array}$

$\begin{array}{lll}1.17 & 0.32 & 10\end{array}$

$\begin{array}{lll}1.63 & 0.50 & 10\end{array}$

$\begin{array}{lll}1.06 & 0.08 & 10\end{array}$

$\begin{array}{lll}1.09 & 0.15 & 10\end{array}$

$\begin{array}{lll}0.82 & 0.06 & 10\end{array}$

$\begin{array}{lll}5.74 & 2.23 & 10\end{array}$

$3.21 \quad 1.00 \quad 10$

$\begin{array}{lll}4.40 & 2.01 & 10\end{array}$

$\begin{array}{lll}1.20 & 0.11 & 10\end{array}$

$\begin{array}{lll}6.38 & 1.78 & 10\end{array}$

$\begin{array}{lll}1.05 & 0.12 & 10\end{array}$

$\begin{array}{lll}0.65 & 0.20 & 10\end{array}$

$\begin{array}{lll}1.26 & 0.11 & 10\end{array}$

$\begin{array}{lll}1.82 & 0.37 & 10\end{array}$

$\begin{array}{lll}0.80 & 0.11 & 10\end{array}$

$\begin{array}{lll}1.13 & 0.13 & 10\end{array}$

$\begin{array}{lll}1.20 & 0.07 & 10\end{array}$

$\begin{array}{lll}1.17 & 0.10 & 10\end{array}$

$\begin{array}{lll}2.26 & 0.29 & 10\end{array}$

$\begin{array}{lll}1.22 & 0.37 & 10\end{array}$

$\begin{array}{lll}1.11 & 0.07 & 10\end{array}$

$\begin{array}{lll}1.70 & 0.20 & 10\end{array}$

$\begin{array}{lll}1.15 & 0.13 & 10\end{array}$

$\begin{array}{lll}1.21 & 0.13 & 10\end{array}$

$\begin{array}{lll}1.31 & 0.20 & 10\end{array}$

$\begin{array}{lll}1.17 & 0.42 & 10\end{array}$

$\begin{array}{lll}1.05 & 0.07 & 10\end{array}$

$\begin{array}{lll}1.06 & 0.03 & 10\end{array}$

$\begin{array}{lll}0.98 & 0.08 & 10\end{array}$

$\begin{array}{lll}1.13 & 0.04 & 10\end{array}$

$\begin{array}{lll}1.18 & 0.07 & 10\end{array}$ $\begin{array}{lll}1.07 & 0.11 & 10\end{array}$

$\begin{array}{lll}1.16 & 0.11 & 10\end{array}$

$\begin{array}{lll}2.61 & 0.45 & 10\end{array}$

$\begin{array}{lll}1.50 & 0.12 & 10\end{array}$

$\begin{array}{lll}0.99 & 0.06 & 10\end{array}$

$\begin{array}{lll}2.96 & 0.97 & 10\end{array}$

$\begin{array}{lll}1.14 & 0.10 & 10\end{array}$

$\begin{array}{lll}2.83 & 1.72 & 10\end{array}$

$\begin{array}{lll}7.74 & 5.87 & 10\end{array}$

$\begin{array}{lll}1.05 & 0.13 & 10\end{array}$

$\begin{array}{lll}1.30 & 0.18 & 10\end{array}$

$\begin{array}{lll}0.86 & 0.07 & 10\end{array}$

$\begin{array}{lll}4.50 & 1.75 & 10\end{array}$

$\begin{array}{lll}2.39 & 0.91 & 10\end{array}$

$\begin{array}{lll}2.87 & 1.04 & 10\end{array}$

$\begin{array}{lll}1.10 & 0.14 & 10\end{array}$

$\begin{array}{lll}5.00 & 1.35 & 10\end{array}$

$\begin{array}{lll}1.09 & 0.12 & 10\end{array}$

$\begin{array}{lll}0.58 & 0.16 & 10\end{array}$

$\begin{array}{lll}1.14 & 0.12 & 10\end{array}$

$\begin{array}{lll}1.42 & 0.22 & 10\end{array}$

$\begin{array}{lll}1.03 & 0.19 & 10\end{array}$

$\begin{array}{lll}1.30 & 0.09 & 10\end{array}$

$\begin{array}{lll}1.26 & 0.07 & 10\end{array}$

$\begin{array}{lll}1.13 & 0.16 & 10\end{array}$

$\begin{array}{lll}1.63 & 0.31 & 10\end{array}$

$\begin{array}{lll}1.31 & 0.25 & 10\end{array}$

$\begin{array}{lll}1.10 & 0.07 & 10\end{array}$

$\begin{array}{lll}1.68 & 0.29 & 10\end{array}$

$\begin{array}{lll}0.99 & 0.12 & 10\end{array}$

$\begin{array}{lll}1.45 & 0.31 & 10\end{array}$

$\begin{array}{lll}1.29 & 0.11 & 10\end{array}$

$\begin{array}{lll}0.81 & 0.17 & 10\end{array}$

$\begin{array}{lll}0.97 & 0.06 & 10\end{array}$

$\begin{array}{lll}1.22 & 0.18 & 10\end{array}$

$\begin{array}{lll}1.08 & 0.11 & 10\end{array}$

$\begin{array}{lll}1.15 & 0.07 & 10\end{array}$

$\begin{array}{lll}1.24 & 0.11 & 10\end{array}$ 


\begin{tabular}{|c|c|c|c|c|c|c|c|}
\hline Foxp1 & 1.09 & 0.06 & 9 & 1.22 & 0.05 & 10 & 1.190 .06 \\
\hline Foxp2 & 1.10 & 0.22 & 9 & 1.50 & 0.23 & 10 & $1.32 \quad 0.14$ \\
\hline Per2 & 1.00 & 0.09 & 9 & 1.07 & 0.08 & 10 & 1.020 .04 \\
\hline Arntl & 1.00 & 0.06 & 9 & 1.01 & 0.03 & 10 & $0.99 \quad 0.04$ \\
\hline
\end{tabular}

\section{Esr1 \\ Esr2 \\ $\mathrm{Ar}$}

Gper

Pgr

Nr3c1

Ahr

Cyp19a1

Srd5a1

Star

Hsd17b1

Esrra

Esrrb

Esrrg

Oxt

Oxtr

Avp

Avpr1a

Kiss1

Kiss1r

Crh

Crhr1

Gnrh1

Bdnf

lgf1

$\lg 1 \mathrm{r}$

Egr1

Mc3r

Tac3

Gabbr1

Drd1

Drd2

Grin1

Grin2b

Gad1

\begin{tabular}{crrr} 
Mean & SEM & $\mathrm{N}$ & Mean \\
\hline 1.23 & 0.32 & 9 & 2.0
\end{tabular}

$\begin{array}{llll}0.98 & 0.07 & 9\end{array}$

$\begin{array}{lll}1.03 & 0.08 & 9\end{array}$

$\begin{array}{lll}1.01 & 0.05 & 9\end{array}$

$\begin{array}{lll}1.11 & 0.16 & 9\end{array}$

$\begin{array}{llll}0.97 & 0.04 & 9\end{array}$

$\begin{array}{lll}1.00 & 0.06 & 9\end{array}$

$\begin{array}{lll}1.23 & 0.26 & 9\end{array}$

$\begin{array}{lll}1.06 & 0.09 & 9\end{array}$

$\begin{array}{lll}1.02 & 0.07 & 9\end{array}$

$\begin{array}{lll}1.06 & 0.12 & 9\end{array}$

$\begin{array}{lll}0.98 & 0.08 & 9\end{array}$

$\begin{array}{lll}0.93 & 0.07 & 9\end{array}$

$\begin{array}{lll}0.99 & 0.07 & 9\end{array}$

$\begin{array}{lll}1.00 & 0.28 & 9\end{array}$

$\begin{array}{lll}0.98 & 0.06 & 9\end{array}$

$\begin{array}{lll}1.57 & 0.51 & 9\end{array}$

$\begin{array}{lll}1.07 & 0.12 & 9\end{array}$

$\begin{array}{lll}2.14 & 0.87 & 9\end{array}$

$\begin{array}{lll}1.04 & 0.07 & 9\end{array}$

$\begin{array}{lll}1.00 & 0.19 & 9\end{array}$

$\begin{array}{lll}1.03 & 0.06 & 9\end{array}$

$\begin{array}{lll}1.57 & 0.53 & 9\end{array}$

$\begin{array}{lll}1.06 & 0.08 & 9\end{array}$

$\begin{array}{lll}1.16 & 0.16 & 9\end{array}$

$\begin{array}{lll}1.01 & 0.07 & 9\end{array}$

$\begin{array}{lll}1.02 & 0.08 & 9\end{array}$

$\begin{array}{lll}1.04 & 0.11 & 9\end{array}$

$\begin{array}{lll}1.24 & 0.19 & 9\end{array}$

$\begin{array}{lll}1.00 & 0.04 & 9\end{array}$

$\begin{array}{lll}0.96 & 0.09 & 9\end{array}$

$\begin{array}{lll}1.00 & 0.11 & 9\end{array}$

$\begin{array}{lll}1.00 & 0.05 & 9\end{array}$

$\begin{array}{lll}1.04 & 0.06 & 9\end{array}$

$\begin{array}{lll}1.03 & 0.07 & 9\end{array}$

\section{$\begin{array}{lll}1.03 & 0.11 & 10\end{array}$}

$\begin{array}{lll}1.18 & 0.06 & 10\end{array}$

$\begin{array}{lll}1.08 & 0.08 & 10\end{array}$

$\begin{array}{lll}1.47 & 0.14 & 10\end{array}$

$\begin{array}{lll}1.01 & 0.03 & 10\end{array}$

$\begin{array}{lll}1.14 & 0.07 & 10\end{array}$

$\begin{array}{lll}1.51 & 0.16 & 10\end{array}$

$\begin{array}{lll}1.04 & 0.09 & 10\end{array}$

$\begin{array}{lll}1.09 & 0.07 & 10\end{array}$

$\begin{array}{lll}1.11 & 0.07 & 10\end{array}$

$\begin{array}{lll}0.97 & 0.10 & 10\end{array}$

$\begin{array}{lll}1.06 & 0.07 & 10\end{array}$

$\begin{array}{lll}0.97 & 0.04 & 10\end{array}$

$\begin{array}{lll}0.39 & 0.16 & 10\end{array}$

$\begin{array}{lll}1.06 & 0.06 & 10\end{array}$

$\begin{array}{lll}0.93 & 0.57 & 10\end{array}$

$\begin{array}{lll}1.10 & 0.07 & 10\end{array}$

$\begin{array}{lll}2.64 & 1.00 & 10\end{array}$

$\begin{array}{lll}1.15 & 0.10 & 10\end{array}$

$\begin{array}{lll}1.12 & 0.16 & 10\end{array}$

$\begin{array}{lll}1.07 & 0.06 & 10\end{array}$

$\begin{array}{lll}1.56 & 0.20 & 10\end{array}$

$\begin{array}{lll}1.47 & 0.12 & 10\end{array}$

$\begin{array}{lll}1.31 & 0.12 & 10\end{array}$

$\begin{array}{lll}1.07 & 0.07 & 10\end{array}$

$\begin{array}{lll}0.91 & 0.08 & 10\end{array}$

$\begin{array}{lll}0.93 & 0.03 & 10\end{array}$

$\begin{array}{lll}1.89 & 0.30 & 10\end{array}$

$\begin{array}{lll}1.00 & 0.03 & 10\end{array}$

$\begin{array}{lll}0.96 & 0.15 & 10\end{array}$

$\begin{array}{lll}1.02 & 0.11 & 10\end{array}$

$\begin{array}{lll}1.12 & 0.04 & 10\end{array}$

$\begin{array}{lll}4.26 & 2.18 & 10\end{array}$

$\begin{array}{lll}1.03 & 0.07 & 10\end{array}$ \begin{tabular}{crr} 
Mean & SEM & $\mathrm{N}$ \\
\hline 1.27 & 0.30 & 10
\end{tabular}

$\begin{array}{lll}0.78 & 0.11 & 10\end{array}$

$\begin{array}{lll}1.09 & 0.11 & 10\end{array}$

$\begin{array}{lll}1.03 & 0.07 & 10\end{array}$

$\begin{array}{lll}1.16 & 0.20 & 10\end{array}$

$\begin{array}{lll}0.98 & 0.04 & 10\end{array}$

$\begin{array}{lll}1.15 & 0.05 & 10\end{array}$

$\begin{array}{lll}1.02 & 0.29 & 10\end{array}$

$\begin{array}{lll}1.06 & 0.04 & 10\end{array}$

$\begin{array}{lll}1.09 & 0.11 & 10\end{array}$

$\begin{array}{lll}1.27 & 0.10 & 10\end{array}$

$\begin{array}{lll}1.01 & 0.05 & 10\end{array}$

$\begin{array}{lll}1.06 & 0.06 & 10\end{array}$

$\begin{array}{lll}1.26 & 0.13 & 10\end{array}$

$\begin{array}{lll}0.42 & 0.13 & 10\end{array}$

$\begin{array}{lll}0.99 & 0.07 & 10\end{array}$

$\begin{array}{lll}1.13 & 0.38 & 10\end{array}$

$\begin{array}{lll}1.25 & 0.12 & 10\end{array}$

$\begin{array}{lll}1.50 & 0.76 & 10\end{array}$

$\begin{array}{lll}1.17 & 0.04 & 10\end{array}$

$\begin{array}{lll}0.69 & 0.17 & 10\end{array}$

$\begin{array}{lll}1.06 & 0.07 & 10\end{array}$

$\begin{array}{lll}2.38 & 0.79 & 10\end{array}$

$\begin{array}{lll}1.24 & 0.11 & 10\end{array}$

$\begin{array}{lll}0.99 & 0.14 & 10\end{array}$

$\begin{array}{lll}1.05 & 0.04 & 10\end{array}$

$\begin{array}{lll}1.04 & 0.09 & 10\end{array}$

$\begin{array}{lll}0.94 & 0.08 & 10\end{array}$

$\begin{array}{lll}1.44 & 0.23 & 10\end{array}$

$\begin{array}{lll}1.02 & 0.04 & 10\end{array}$

$\begin{array}{lll}1.19 & 0.07 & 10\end{array}$

$\begin{array}{lll}1.17 & 0.11 & 10\end{array}$

$\begin{array}{lll}1.11 & 0.05 & 10\end{array}$

$\begin{array}{lll}2.60 & 1.53 & 10\end{array}$

$\begin{array}{lll}1.08 & 0.07 & 10\end{array}$ 


$\begin{array}{lccccccccc}\text { MeCP2 } & 0.97 & 0.07 & 9 & 0.91 & 0.06 & 10 & 0.91 & 0.04 & 10 \\ \text { Dnmt3a } & 0.98 & 0.06 & 9 & 1.10 & 0.07 & 10 & 1.10 & 0.05 & 10 \\ \text { Dnmt3b } & 1.04 & 0.05 & 9 & 0.98 & 0.11 & 10 & 1.20 & 0.12 & 10 \\ \text { Hdac2 } & 1.03 & 0.05 & 9 & 1.10 & 0.04 & 10 & 1.03 & 0.08 & 10 \\ \text { Hdac4 } & 0.94 & 0.05 & 9 & 1.00 & 0.04 & 10 & 1.02 & 0.03 & 10 \\ \text { Foxp1 } & 0.98 & 0.04 & 9 & 1.01 & 0.05 & 10 & 1.13 & 0.05 & 10 \\ \text { Foxp2 } & 0.98 & 0.16 & 9 & 0.85 & 0.13 & 10 & 0.70 & 0.10 & 10 \\ \text { Per2 } & 0.96 & 0.05 & 9 & 1.07 & 0.06 & 10 & 1.06 & 0.07 & 10 \\ \text { Arntl } & 0.98 & 0.04 & 9 & 0.98 & 0.03 & 10 & 0.98 & 0.04 & 10 \\ & & & & & & & & & \end{array}$

\section{Esr1 \\ Esr2 \\ $\mathrm{Ar}$}

Gper

Pgr

Nr3c1

Ahr

Cyp19a1

Srd5a1

Star

Hsd17b1

Esrra

Esrrb

Esrrg

Oxt

Oxtr

Avp

Avpr1a

Kiss1

Kiss1r

Crh

Crhr1

Gnrh1

Bdnf

lgf1

$\lg 1 \mathrm{r}$

Egr1

Mc3r

Tac3

Gabbr1

\begin{tabular}{cccc} 
Mean & SEM & N & Me \\
\hline 1.13 & 0.16 & 9 & \\
1.48 & 0.38 & 9 & \\
1.12 & 0.13 & 9 & \\
0.99 & 0.09 & 9 & \\
1.08 & 0.09 & 9 & \\
1.02 & 0.11 & 9 & \\
1.08 & 0.10 & 9 & \\
1.30 & 0.29 & 9 &
\end{tabular}

$\begin{array}{lll}1.01 & 0.15 & 9\end{array}$

$\begin{array}{lll}1.19 & 0.20 & 9\end{array}$

$\begin{array}{lll}0.97 & 0.11 & 9\end{array}$

$\begin{array}{lll}1.02 & 0.12 \quad 9\end{array}$

$\begin{array}{lll}1.04 & 0.13 & 9\end{array}$

$\begin{array}{lll}0.91 & 0.06 & 9\end{array}$

$\begin{array}{lll}3.15 & 1.37 \quad 9\end{array}$

$\begin{array}{lll}1.26 & 0.26 & 9\end{array}$

$\begin{array}{lll}1.32 & 0.38 & 9\end{array}$

$\begin{array}{lll}1.08 & 0.08 & 9\end{array}$

$\begin{array}{lll}1.06 & 0.32 & 9\end{array}$

$\begin{array}{lll}1.18 & 0.12 & 9\end{array}$

$\begin{array}{lll}0.95 & 0.10 & 9\end{array}$

$\begin{array}{lll}1.05 & 0.15 & 9\end{array}$

$\begin{array}{lll}1.42 & 0.31 \quad 8\end{array}$

$\begin{array}{lll}1.04 & 0.10 \quad 9\end{array}$

$\begin{array}{lll}0.98 & 0.07 & 9\end{array}$

$0.97 \quad 0.06 \quad 9$

$\begin{array}{lll}1.05 & 0.05 & 9\end{array}$

$\begin{array}{lll}1.56 & 0.45 \quad 9\end{array}$

$\begin{array}{lll}1.32 & 0.28 & 9\end{array}$

$\begin{array}{lll}1.06 & 0.06 \quad 9\end{array}$ $\begin{array}{ccc}\text { Mean } & \text { SEM } & \mathrm{N} \\ 1.21 & 0.16 & 10\end{array}$

$\begin{array}{lll}2.02 & 0.33 & 10\end{array}$

$\begin{array}{lll}1.22 & 0.07 & 10\end{array}$

$\begin{array}{lll}1.35 & 0.11 & 10\end{array}$

$\begin{array}{lll}1.15 & 0.08 & 10\end{array}$

$\begin{array}{lll}1.06 & 0.08 & 10\end{array}$

$\begin{array}{lll}1.19 & 0.06 & 10\end{array}$

$\begin{array}{lll}1.63 & 0.27 & 10\end{array}$

$\begin{array}{lll}1.01 & 0.16 & 10\end{array}$

$\begin{array}{lll}1.41 & 0.15 & 10\end{array}$

$\begin{array}{lll}1.00 & 0.12 & 10\end{array}$

$\begin{array}{lll}1.18 & 0.14 & 10\end{array}$

$\begin{array}{lll}1.13 & 0.11 & 10\end{array}$

$\begin{array}{lll}1.05 & 0.11 & 10\end{array}$

$\begin{array}{lll}1.83 & 0.70 & 10\end{array}$

$\begin{array}{lll}1.30 & 0.14 & 10\end{array}$

$\begin{array}{lll}0.92 & 0.35 & 10\end{array}$

$\begin{array}{lll}1.05 & 0.06 & 10\end{array}$

$\begin{array}{lll}2.85 & 0.45 & 10\end{array}$

$\begin{array}{lll}1.39 & 0.13 & 10\end{array}$

$\begin{array}{lll}1.09 & 0.11 & 10\end{array}$

$\begin{array}{lll}0.99 & 0.11 & 10\end{array}$

$\begin{array}{lll}2.09 & 0.18 & 10\end{array}$

$\begin{array}{lll}0.81 & 0.10 & 10\end{array}$

$\begin{array}{lll}1.04 & 0.08 & 10\end{array}$

$\begin{array}{lll}1.02 & 0.05 & 10\end{array}$

$\begin{array}{llll}0.90 & 0.04 & 10\end{array}$

$\begin{array}{lll}1.80 & 0.49 & 10\end{array}$

$\begin{array}{lll}0.80 & 0.10 & 10\end{array}$

$\begin{array}{lll}1.12 & 0.06 \quad 10\end{array}$ \begin{tabular}{rrr} 
Mean & SEM & $\mathrm{N}$ \\
\hline 0.93 & 0.16 & 10
\end{tabular}

$\begin{array}{lll}1.59 & 0.52 & 10\end{array}$

$\begin{array}{lll}1.10 & 0.10 & 10\end{array}$

$\begin{array}{lll}1.25 & 0.12 & 10\end{array}$

$\begin{array}{lll}1.02 & 0.05 & 10\end{array}$

$\begin{array}{lll}1.06 & 0.12 & 10\end{array}$

$\begin{array}{lll}1.17 & 0.03 & 10\end{array}$

$\begin{array}{lll}1.25 & 0.36 & 10\end{array}$

$\begin{array}{lll}1.07 & 0.12 & 10\end{array}$

$\begin{array}{lll}1.50 & 0.15 & 10\end{array}$

$\begin{array}{lll}1.32 & 0.16 & 10\end{array}$

$\begin{array}{lll}1.18 & 0.10 & 10\end{array}$

$\begin{array}{lll}1.08 & 0.08 & 10\end{array}$

$\begin{array}{lll}1.05 & 0.10 & 10\end{array}$

$\begin{array}{lll}4.78 & 1.72 & 10\end{array}$

$\begin{array}{lll}1.18 & 0.20 & 10\end{array}$

$\begin{array}{lll}1.69 & 0.64 & 10\end{array}$

$\begin{array}{lll}0.96 & 0.05 & 10\end{array}$

$\begin{array}{lll}1.68 & 1.12 & 10\end{array}$

$\begin{array}{lll}1.32 & 0.09 & 10\end{array}$

$\begin{array}{lll}1.06 & 0.12 & 10\end{array}$

$\begin{array}{lll}1.09 & 0.19 & 10\end{array}$

$\begin{array}{lll}1.89 & 0.36 & 10\end{array}$

$\begin{array}{lll}0.87 & 0.10 & 10\end{array}$

$\begin{array}{lll}1.09 & 0.10 & 10\end{array}$

$\begin{array}{llll}0.94 & 0.03 & 10\end{array}$

$\begin{array}{llll}1.00 & 0.06 & 10\end{array}$

$\begin{array}{lll}1.79 & 0.70 & 10\end{array}$

$\begin{array}{lll}1.26 & 0.21 & 10\end{array}$

$\begin{array}{lll}1.09 & 0.08 \quad 10\end{array}$ 


$\begin{array}{llll}\text { Drd1 } & 1.61 & 0.37 & 9 \\ \text { Drd2 } & 1.14 & 0.20 & 9 \\ \text { Grin1 } & 1.05 & 0.06 & 9 \\ \text { Grin2b } & 1.04 & 0.06 & 9 \\ \text { Gad1 } & 1.11 & 0.10 & 9 \\ \text { MeCP2 } & 1.04 & 0.06 & 9 \\ \text { Dnmt3a } & 1.00 & 0.09 & 9 \\ \text { Dnmt3b } & 0.98 & 0.12 & 9 \\ \text { Hdac2 } & 1.00 & 0.04 & 9 \\ \text { Hdac4 } & 0.98 & 0.06 & 9 \\ \text { Foxp1 } & 1.03 & 0.09 & 9 \\ \text { Foxp2 } & 1.61 & 0.47 & 9 \\ \text { Per2 } & 1.00 & 0.05 & 9 \\ \text { Arntl } & 1.07 & 0.10 & 9\end{array}$

VMN-Male

$\begin{array}{lll}1.38 & 0.26 & 10 \\ 0.89 & 0.23 & 10 \\ 1.06 & 0.04 & 10 \\ 1.02 & 0.06 & 10 \\ 1.08 & 0.09 & 10 \\ 1.17 & 0.09 & 10 \\ 1.10 & 0.08 & 10 \\ 1.05 & 0.13 & 10 \\ 1.12 & 0.06 & 10 \\ 1.04 & 0.04 & 10 \\ 1.10 & 0.11 & 10 \\ 1.39 & 0.35 & 10 \\ 1.07 & 0.08 & 10 \\ 1.07 & 0.05 & 10\end{array}$

PCB

$\begin{array}{lll}1.26 & 0.12 & 10 \\ 0.97 & 0.20 & 10 \\ 1.07 & 0.06 & 10 \\ 1.02 & 0.07 & 10 \\ 1.06 & 0.09 & 10 \\ 1.16 & 0.08 & 10 \\ 1.01 & 0.07 & 10 \\ 1.18 & 0.13 & 10 \\ 1.03 & 0.05 & 10 \\ 1.06 & 0.05 & 10 \\ 1.12 & 0.10 & 10 \\ 0.97 & 0.21 & 10 \\ 1.05 & 0.11 & 10 \\ 1.01 & 0.06 & 10\end{array}$

VIN

\begin{tabular}{lrrrrrrrrr} 
& Mean & SEM & $\mathrm{N}$ & Mean & SEM & $\mathrm{N}$ & Mean & SEM & $\mathrm{N}$ \\
\cline { 2 - 9 } Esr1 & 1.24 & 0.20 & 10 & 1.57 & 0.28 & 9 & 1.75 & 0.49 & 10 \\
Esr2 & 1.08 & 0.06 & 10 & 1.12 & 0.11 & 9 & 1.05 & 0.09 & 10 \\
Ar & 1.23 & 0.10 & 10 & 1.42 & 0.13 & 9 & 0.99 & 0.10 & 10 \\
Gper & 1.05 & 0.06 & 10 & 1.18 & 0.10 & 9 & 1.10 & 0.09 & 10 \\
Pgr & 1.66 & 0.22 & 10 & 2.08 & 0.29 & 9 & 2.47 & 0.56 & 10 \\
Nr3c1 & 1.15 & 0.10 & 10 & 1.36 & 0.09 & 9 & 1.34 & 0.15 & 10 \\
Ahr & 0.99 & 0.10 & 10 & 1.02 & 0.09 & 9 & 1.07 & 0.09 & 10 \\
Cyp19a1 & 23.68 & 14.16 & 10 & 3.89 & 1.13 & 9 & 4.81 & 1.47 & 10 \\
Srd5a1 & 1.18 & 0.08 & 10 & 1.17 & 0.09 & 9 & 1.53 & 0.19 & 10 \\
Star & 1.10 & 0.32 & 10 & 0.79 & 0.06 & 9 & 1.01 & 0.34 & 10 \\
Hsd17b1 & 3.79 & 2.73 & 10 & 0.87 & 0.14 & 9 & 1.00 & 0.20 & 10 \\
Esrra & 1.02 & 0.11 & 10 & 1.06 & 0.08 & 9 & 1.15 & 0.10 & 10 \\
Esrrb & 1.02 & 0.08 & 10 & 1.10 & 0.14 & 9 & 1.24 & 0.07 & 10 \\
Esrrg & 0.91 & 0.11 & 10 & 0.78 & 0.09 & 9 & 0.96 & 0.11 & 10 \\
Oxt & 5.07 & 2.16 & 10 & 1.42 & 0.49 & 9 & 4.67 & 2.35 & 10 \\
Oxtr & 2.09 & 0.50 & 10 & 4.13 & 1.52 & 9 & 3.63 & 1.15 & 10 \\
Avp & 4.54 & 1.89 & 10 & 5.56 & 3.72 & 9 & 2.77 & 0.70 & 10 \\
Avpr1a & 1.00 & 0.12 & 10 & 1.14 & 0.14 & 9 & 1.00 & 0.18 & 10 \\
Kiss1 & 1.41 & 0.59 & 10 & 2.39 & 1.02 & 9 & 3.52 & 1.21 & 10 \\
Kiss1r & 1.16 & 0.11 & 10 & 1.02 & 0.11 & 9 & 1.02 & 0.11 & 10 \\
Crh & 0.84 & 0.20 & 10 & 0.82 & 0.33 & 9 & 0.97 & 0.25 & 10 \\
Crhr1 & 1.13 & 0.10 & 10 & 1.10 & 0.13 & 9 & 1.04 & 0.10 & 10 \\
Gnrh1 & 0.86 & 0.08 & 10 & 1.46 & 0.21 & 9 & 1.52 & 0.30 & 10 \\
Bdnf & 0.91 & 0.17 & 10 & 1.00 & 0.24 & 9 & 1.10 & 0.19 & 10 \\
Igf1 & 1.07 & 0.09 & 10 & 1.11 & 0.14 & 9 & 1.15 & 0.10 & 10
\end{tabular}




$\begin{array}{llllllllll}\text { Igf1r } & 0.99 & 0.03 & 10 & 1.05 & 0.05 & 9 & 1.29 & 0.24 & 10 \\ \text { Egr1 } & 0.88 & 0.08 & 10 & 1.09 & 0.12 & 9 & 0.97 & 0.11 & 10 \\ \text { Mc3r } & 1.32 & 0.23 & 10 & 2.10 & 0.35 & 9 & 1.57 & 0.38 & 10 \\ \text { Tac3 } & 1.13 & 0.25 & 10 & 0.75 & 0.21 & 9 & 1.25 & 0.28 & 10 \\ \text { Gabbr1 } & 1.00 & 0.03 & 10 & 1.04 & 0.07 & 9 & 1.03 & 0.05 & 10 \\ \text { Drd1 } & 1.19 & 0.10 & 10 & 1.75 & 0.27 & 9 & 1.32 & 0.26 & 10 \\ \text { Drd2 } & 1.26 & 0.17 & 10 & 1.12 & 0.13 & 9 & 1.32 & 0.17 & 10 \\ \text { Grin1 } & 1.13 & 0.11 & 10 & 1.25 & 0.10 & 9 & 1.16 & 0.18 & 10 \\ \text { Grin2b } & 1.24 & 0.06 & 10 & 1.41 & 0.13 & 9 & 1.30 & 0.16 & 10 \\ \text { Gad1 } & 0.98 & 0.12 & 10 & 0.99 & 0.16 & 9 & 0.86 & 0.13 & 10 \\ \text { MeCP2 } & 1.05 & 0.05 & 10 & 0.99 & 0.09 & 9 & 1.02 & 0.06 & 10 \\ \text { Dnmt3a } & 0.90 & 0.10 & 10 & 1.02 & 0.08 & 9 & 0.96 & 0.06 & 10 \\ \text { Dnmt3b } & 1.10 & 0.11 & 10 & 0.89 & 0.11 & 9 & 0.92 & 0.08 & 10 \\ \text { Hdac2 } & 0.92 & 0.02 & 10 & 0.85 & 0.12 & 9 & 1.06 & 0.06 & 10 \\ \text { Hdac4 } & 0.88 & 0.09 & 10 & 1.08 & 0.09 & 9 & 1.04 & 0.09 & 10 \\ \text { Foxp1 } & 1.11 & 0.04 & 10 & 1.17 & 0.08 & 9 & 1.11 & 0.06 & 10 \\ \text { Foxp2 } & 1.63 & 0.14 & 10 & 1.60 & 0.24 & 9 & 1.12 & 0.16 & 10 \\ \text { Per2 } & 0.75 & 0.05 & 10 & 0.83 & 0.06 & 9 & 0.73 & 0.04 & 10 \\ \text { Arntl } & 0.92 & 0.02 & 10 & 0.95 & 0.05 & 9 & 0.89 & 0.05 & 10 \\ & & & & & & & & & \\ \text { PoA-Male } & \text { DMSO } & & \text { PCB } & & \text { VIN } & \end{array}$

\section{Esr1 \\ Esr2 \\ $\mathrm{Ar}$}

Gper

Pgr

$\mathrm{Nr3c1}$

Ahr

Cyp19a1

Srd5a1

Star

Hsd17b1

Esrra

Esrrb

Esrrg

Oxt

Oxtr

Avp

Avpr1a

Kiss1

Kiss1r

\begin{tabular}{rrrrrrrrr} 
Mean & SEM & $N$ & Mean & SEM & $N$ & Mean & SEM & $N$ \\
\hline 0.78 & 0.16 & 10 & 0.87 & 0.15 & 10 & 1.22 & 0.24 & 10 \\
0.79 & 0.12 & 10 & 0.75 & 0.05 & 10 & 0.85 & 0.11 & 10 \\
1.04 & 0.09 & 10 & 1.11 & 0.08 & 10 & 1.30 & 0.15 & 10 \\
1.16 & 0.06 & 10 & 1.10 & 0.08 & 10 & 1.06 & 0.04 & 10 \\
0.84 & 0.12 & 10 & 0.94 & 0.11 & 10 & 1.18 & 0.15 & 10 \\
1.03 & 0.05 & 10 & 1.03 & 0.02 & 10 & 1.06 & 0.02 & 10 \\
1.19 & 0.10 & 10 & 1.27 & 0.04 & 10 & 1.12 & 0.06 & 10 \\
1.29 & 0.35 & 10 & 1.54 & 0.26 & 10 & 2.01 & 0.43 & 10 \\
1.16 & 0.05 & 10 & 1.14 & 0.09 & 10 & 1.13 & 0.07 & 10 \\
1.13 & 0.12 & 10 & 1.01 & 0.08 & 10 & 1.15 & 0.10 & 10 \\
1.05 & 0.10 & 10 & 0.98 & 0.09 & 10 & 1.11 & 0.10 & 10 \\
1.05 & 0.11 & 10 & 1.05 & 0.06 & 10 & 0.96 & 0.07 & 10 \\
1.01 & 0.10 & 10 & 0.99 & 0.06 & 10 & 0.98 & 0.05 & 10 \\
1.28 & 0.11 & 10 & 1.12 & 0.13 & 10 & 1.05 & 0.10 & 10 \\
0.68 & 0.20 & 10 & 0.56 & 0.19 & 10 & 0.22 & 0.06 & 10 \\
0.87 & 0.08 & 10 & 0.93 & 0.04 & 10 & 1.01 & 0.06 & 10 \\
1.29 & 0.27 & 10 & 1.00 & 0.20 & 10 & 0.56 & 0.12 & 10 \\
1.17 & 0.08 & 10 & 1.15 & 0.08 & 10 & 1.08 & 0.11 & 10 \\
0.42 & 0.22 & 10 & 0.28 & 0.05 & 10 & 0.47 & 0.13 & 10 \\
1.30 & 0.07 & 10 & 1.34 & 0.10 & 10 & 1.24 & 0.07 & 10
\end{tabular}




$\begin{array}{llllllllll}\text { Crh } & 0.73 & 0.20 & 10 & 0.65 & 0.20 & 10 & 0.44 & 0.09 & 10 \\ \text { Crhr1 } & 1.07 & 0.07 & 10 & 1.05 & 0.06 & 10 & 1.05 & 0.05 & 10 \\ \text { Gnrh1 } & 1.17 & 0.12 & 10 & 0.83 & 0.19 & 10 & 1.13 & 0.20 & 10 \\ \text { Bdnf } & 1.06 & 0.08 & 10 & 1.11 & 0.08 & 10 & 1.10 & 0.05 & 10 \\ \text { Igf1 } & 0.80 & 0.08 & 10 & 0.90 & 0.08 & 10 & 0.90 & 0.09 & 10 \\ \text { Igf1r } & 1.05 & 0.09 & 10 & 1.01 & 0.06 & 10 & 0.94 & 0.05 & 10 \\ \text { Egr1 } & 0.76 & 0.07 & 10 & 0.93 & 0.08 & 10 & 0.89 & 0.11 & 10 \\ \text { Mc3r } & 0.78 & 0.06 & 10 & 0.95 & 0.07 & 10 & 0.99 & 0.02 & 10 \\ \text { Tac3 } & 0.90 & 0.07 & 10 & 0.78 & 0.08 & 10 & 1.03 & 0.12 & 10 \\ \text { Gabbr1 } & 1.06 & 0.07 & 10 & 1.08 & 0.04 & 10 & 0.92 & 0.10 & 10 \\ \text { Drd1 } & 1.19 & 0.16 & 10 & 1.23 & 0.11 & 10 & 0.91 & 0.09 & 10 \\ \text { Drd2 } & 1.12 & 0.11 & 10 & 0.93 & 0.11 & 10 & 0.89 & 0.11 & 10 \\ \text { Grin1 } & 1.09 & 0.07 & 10 & 1.13 & 0.04 & 10 & 1.06 & 0.05 & 10 \\ \text { Grin2b } & 2.19 & 1.19 & 10 & 1.83 & 0.78 & 10 & \mathbf{5 . 2 2} & \mathbf{4 . 1 1} & 10 \\ \text { Gad1 } & 1.05 & 0.09 & 10 & 1.05 & 0.05 & 10 & 1.02 & 0.06 & 10 \\ \text { MeCP2 } & 1.05 & 0.18 & 10 & 0.92 & 0.06 & 10 & 0.85 & 0.04 & 10 \\ \text { Dnmt3a } & 1.09 & 0.08 & 10 & 1.09 & 0.05 & 10 & 1.06 & 0.05 & 10 \\ \text { Dnmt3b } & 1.29 & 0.07 & 10 & 1.22 & 0.09 & 10 & 1.09 & 0.11 & 10 \\ \text { Hdac2 } & 0.99 & 0.05 & 10 & 1.03 & 0.04 & 10 & 1.02 & 0.06 & 10 \\ \text { Hdac4 } & 1.01 & 0.07 & 10 & 0.99 & 0.04 & 10 & 0.94 & 0.03 & 10 \\ \text { Foxp1 } & 1.16 & 0.06 & 10 & 1.18 & 0.05 & 10 & 1.07 & 0.06 & 10 \\ \text { Foxp2 } & 0.75 & 0.16 & 10 & 0.64 & 0.13 & 10 & 0.50 & 0.06 & 10 \\ \text { Per2 } & 0.93 & 0.07 & 10 & 1.02 & 0.07 & 10 & 0.95 & 0.07 & 10 \\ \text { Arntl } & 0.97 & 0.04 & 10 & 1.00 & 0.03 & 10 & 0.98 & 0.03 & 10 \\ & & & & & & & & & \\ \text { MEA-Male } & \mathbf{D M S O} & & & \mathbf{P C B} & & & \text { VIN }\end{array}$

\section{Esr1 \\ Esr2 \\ Ar}

Gper

Pgr

Nr3c1

Ahr

Cyp19a1

Srd5a1

Star

Hsd17b1

Esrra

Esrrb

Esrrg

Oxt

\begin{tabular}{cccrrrrrr} 
Mean & SEM & $\mathrm{N}$ & Mean & SEM & $\mathrm{N}$ & Mean & SEM & $\mathrm{N}$ \\
\hline 1.27 & 0.16 & 10 & 1.24 & 0.12 & 10 & 1.07 & 0.14 & 10 \\
2.69 & 0.54 & 10 & 2.43 & 0.33 & 10 & 2.21 & 0.47 & 10 \\
1.29 & 0.15 & 10 & 1.26 & 0.10 & 10 & 1.21 & 0.15 & 10 \\
1.08 & 0.08 & 10 & 0.97 & 0.09 & 10 & 0.95 & 0.10 & 10 \\
1.32 & 0.12 & 10 & 1.17 & 0.09 & 10 & 1.02 & 0.09 & 10 \\
0.91 & 0.07 & 10 & 0.93 & 0.08 & 10 & 0.89 & 0.07 & 10 \\
1.03 & 0.08 & 10 & 1.25 & 0.08 & 10 & 1.11 & 0.08 & 10 \\
2.30 & 0.43 & 10 & 2.20 & 0.34 & 10 & 1.84 & 0.36 & 10 \\
0.84 & 0.11 & 10 & 1.01 & 0.12 & 10 & 1.04 & 0.18 & 10 \\
1.24 & 0.11 & 10 & 1.30 & 0.11 & 10 & 1.14 & 0.11 & 10 \\
0.81 & 0.10 & 10 & 0.79 & 0.09 & 10 & 0.88 & 0.10 & 10 \\
0.84 & 0.08 & 10 & 1.01 & 0.06 & 10 & 0.99 & 0.11 & 10 \\
0.83 & 0.07 & 10 & 0.94 & 0.06 & 10 & 1.05 & 0.11 & 10 \\
0.86 & 0.11 & 10 & 0.89 & 0.06 & 10 & 0.87 & 0.08 & 10 \\
2.12 & 0.56 & 10 & 2.32 & 0.77 & 10 & 1.40 & 0.54 & 10
\end{tabular}




$\begin{array}{llllllllll}\text { Oxtr } & 1.91 & 0.27 & 10 & 2.02 & 0.23 & 10 & 1.72 & 0.35 & 10 \\ \text { Avp } & 1.31 & 0.35 & 10 & 1.20 & 0.33 & 10 & 1.01 & 0.43 & 10 \\ \text { Avpr1a } & 0.96 & 0.09 & 10 & 1.05 & 0.06 & 10 & 1.06 & 0.05 & 10 \\ \text { Kiss1 } & 6.08 & 1.57 & 10 & 5.84 & 1.22 & 10 & 4.94 & 0.97 & 10 \\ \text { Kiss1r } & 1.01 & 0.08 & 10 & 1.24 & 0.09 & 10 & 1.12 & 0.12 & 10 \\ \text { Crh } & 0.81 & 0.08 & 10 & 0.89 & 0.10 & 10 & 0.81 & 0.10 & 10 \\ \text { Crhr1 } & 1.08 & 0.15 & 10 & 0.92 & 0.09 & 10 & 1.11 & 0.15 & 10 \\ \text { Gnrh1 } & 2.14 & 0.43 & 10 & 1.87 & 0.18 & 10 & 1.46 & 0.22 & 10 \\ \text { Bdnf } & 0.76 & 0.07 & 10 & 0.84 & 0.07 & 10 & 1.01 & 0.13 & 10 \\ \text { Igf1 } & 0.90 & 0.08 & 10 & 1.06 & 0.08 & 10 & 0.77 & 0.07 & 10 \\ \text { Igf1r } & 0.87 & 0.06 & 10 & 0.90 & 0.06 & 10 & 0.86 & 0.05 & 10 \\ \text { Egr1 } & 0.86 & 0.06 & 10 & 0.85 & 0.04 & 10 & 0.89 & 0.05 & 10 \\ \text { Mc3r } & 1.37 & 0.40 & 10 & 1.27 & 0.39 & 10 & 1.26 & 0.22 & 10 \\ \text { Tac3 } & 0.75 & 0.12 & 10 & 0.67 & 0.05 & 10 & 0.87 & 0.16 & 10 \\ \text { Gabbr1 } & 0.99 & 0.06 & 10 & 1.08 & 0.06 & 10 & 1.03 & 0.06 & 10 \\ \text { Drd1 } & 1.08 & 0.19 & 10 & 0.94 & 0.08 & 10 & 0.94 & 0.19 & 10 \\ \text { Drd2 } & 0.63 & 0.09 & 10 & 0.72 & 0.12 & 10 & 0.69 & 0.10 & 10 \\ \text { Grin1 } & 1.01 & 0.04 & 10 & 1.11 & 0.04 & 10 & 1.11 & 0.04 & 10 \\ \text { Grin2b } & 0.87 & 0.07 & 10 & 1.08 & 0.06 & 10 & 1.03 & 0.08 & 10 \\ \text { Gad1 } & 1.04 & 0.11 & 10 & 1.08 & 0.07 & 10 & 1.03 & 0.09 & 10 \\ \text { MeCP2 } & 1.06 & 0.09 & 10 & 1.05 & 0.09 & 10 & 0.87 & 0.07 & 10 \\ \text { Dnmt3a } & 0.84 & 0.07 & 10 & 0.94 & 0.05 & 10 & 0.89 & 0.06 & 10 \\ \text { Dnmt3b } & 1.00 & 0.10 & 10 & 1.05 & 0.06 & 10 & 0.87 & 0.11 & 10 \\ \text { Hdac2 } & 1.07 & 0.06 & 10 & 1.02 & 0.03 & 10 & 1.06 & 0.06 & 10 \\ \text { Hdac4 } & 0.82 & 0.04 & 10 & 0.91 & 0.03 & 10 & 0.92 & 0.04 & 10 \\ \text { Foxp1 } & 1.01 & 0.04 & 10 & 1.16 & 0.06 & 10 & 1.00 & 0.08 & 10 \\ \text { Foxp2 } & 1.37 & 0.29 & 10 & 0.81 & 0.20 & 10 & 0.99 & 0.34 & 10 \\ \text { Per2 } & 0.83 & 0.07 & 10 & 0.79 & 0.05 & 10 & 0.87 & 0.03 & 10 \\ \text { Arntl } & 0.98 & 0.07 & 10 & 0.92 & 0.04 & 10 & 0.95 & 0.04 & 10\end{array}$

bolded numbers indicate significantly different from DMSO after adjusting for m 
Supplementary Table 2. Sex differences in gene expression results

VMN

Esr1
Esr2
Ar

Gper

Pgr

$\mathrm{Nr3c1}$

Ahr

Cyp19a1

Srd5a1

Star

Hsd17b1

Esrra

Esrrb

Esrrg

Oxt

Oxtr

Avp

Avpr1a

Kiss1

Kiss1r

Crh

Crhr1

Gnrh1

Bdnf

lgf1

Igf1 $r$

Egr1

Mc3r

Tac3

Gabbr1

Drd1

Drd2

Grin1

Grin2b

Gad1

$\mathrm{MeCP} 2$

Dnmt3a

Dnmt3b

Hdac2

Hdac4
Females

\begin{tabular}{|c|c|c|c|c|c|c|c|}
\hline Mean & SEM & $\mathrm{N}$ & & & SEM & & \\
\hline 1.39 & 0.41 & & 9 & 1.24 & & 0.20 & 10 \\
\hline 0.98 & 0.08 & & 9 & 1.08 & & 0.06 & 10 \\
\hline 0.89 & 0.11 & & 9 & 1.23 & & 0.10 & 10 \\
\hline 1.07 & 0.08 & & 9 & 1.05 & & 0.06 & 1( \\
\hline 1.55 & 0.55 & & 9 & 1.66 & & 0.22 & 10 \\
\hline 0.91 & 0.19 & & 9 & 1.15 & & 0.10 & 10 \\
\hline 1.04 & 0.10 & & 9 & 0.99 & & 0.10 & 10 \\
\hline
\end{tabular}

2.14

0.79

0.15

2.44

1.94

0.07

0.10

0.11

0.18

1.25

0.16

0.13

1.10

0.11

0.32

0.11

0.19

0.10

0.08

0.07

0.36

0.32

0.16

0.11

0.30

0.13

0.14

0.18

0.14

0.07

0.06

0.08

0.06

0.07
Males

23.68

1.18

1.10

3.79

1.02

1.02

0.91

5.07

2.09

4.54

1.00

1.41

1.16

0.84

1.13

0.86

0.91

1.07

0.99

0.88

1.32

1.13

1.00

1.19

1.26

1.13

1.24

0.98

1.05

0.90

1.10

0.92

0.88
$14.16 \quad 10$

$0.08 \quad 10$

$0.32 \quad 10$

$2.73 \quad 10$

$0.11 \quad 10$

$0.08 \quad 10$

$0.11 \quad 10$

$2.16 \quad 10$

$0.50 \quad 10$

$1.89 \quad 10$

$0.12 \quad 10$

$0.59 \quad 10$

$0.11 \quad 10$

$0.20 \quad 10$

$0.10 \quad 10$

$0.08 \quad 10$

$0.17 \quad 10$

$0.09 \quad 10$

$0.03 \quad 10$

$0.08 \quad 10$

$0.23 \quad 10$

$0.25 \quad 10$

$0.03 \quad 10$

$0.10 \quad 10$

$0.17 \quad 10$

$0.11 \quad 10$

$0.06 \quad 10$

$0.12 \quad 10$

$0.05 \quad 10$

$0.10 \quad 10$

$0.11 \quad 10$

$0.02 \quad 10$

$0.09 \quad 10$ 


$\begin{array}{lllllll}\text { Foxp1 } & 1.09 & 0.06 & 9 & 1.11 & 0.04 & 10 \\ \text { Foxp2 } & 1.10 & 0.22 & 9 & 1.63 & 0.14 & 10 \\ \text { Per2 } & 1.00 & 0.09 & 9 & 0.75 & 0.05 & 10 \\ \text { Arntl } & 1.00 & 0.06 & 9 & 0.92 & 0.02 & 10\end{array}$

POA

Females

Males

\begin{tabular}{|c|c|c|c|c|c|c|}
\hline & Mean & SEM & $\mathrm{N}$ & Mean & SEM & v \\
\hline Esr1 & 1.23 & 0.32 & 9 & 0.78 & 0.16 & 10 \\
\hline Esr2 & 0.98 & 0.07 & 9 & 0.79 & 0.12 & 10 \\
\hline $\mathrm{Ar}$ & 1.03 & 0.08 & 9 & 1.04 & 0.09 & 10 \\
\hline Gper & 1.01 & 0.05 & 9 & 1.16 & 0.06 & 10 \\
\hline Pgr & 1.11 & 0.16 & 9 & 0.84 & 0.12 & 10 \\
\hline $\mathrm{Nr} 3 \mathrm{c} 1$ & 0.97 & 0.04 & 9 & 1.03 & 0.05 & 10 \\
\hline Ahr & 1.00 & 0.06 & 9 & 1.19 & 0.10 & 10 \\
\hline Cyp19a1 & 1.23 & 0.26 & 9 & 1.29 & 0.35 & 10 \\
\hline Srd5a1 & 1.06 & 0.09 & 9 & 1.16 & 0.05 & 10 \\
\hline Star & 1.02 & 0.07 & 9 & 1.13 & 0.12 & 10 \\
\hline Hsd17b1 & 1.06 & 0.12 & 9 & 1.05 & 0.10 & 10 \\
\hline Esrra & 0.98 & 0.08 & 9 & 1.05 & 0.11 & 10 \\
\hline Esrrb & 0.93 & 0.07 & 9 & 1.01 & 0.10 & 10 \\
\hline Esrrg & 0.99 & 0.07 & 9 & 1.28 & 0.11 & 10 \\
\hline Oxt & 1.00 & 0.28 & 9 & 0.68 & 0.20 & 10 \\
\hline Oxtr & 0.98 & 0.06 & 9 & 0.87 & 0.08 & 10 \\
\hline Avp & 1.57 & 0.51 & 9 & 1.29 & 0.27 & 10 \\
\hline Avpr1a & 1.07 & 0.12 & 9 & 1.17 & 0.08 & 10 \\
\hline Kiss 1 & 2.14 & 0.87 & 9 & 0.42 & 0.22 & 10 \\
\hline Kiss1r & 1.04 & 0.07 & 9 & 1.30 & 0.07 & 10 \\
\hline Crh & 1.00 & 0.19 & 9 & 0.73 & 0.20 & 10 \\
\hline Crhr1 & 1.03 & 0.06 & 9 & 1.07 & 0.07 & 10 \\
\hline Gnrh1 & 1.57 & 0.53 & 9 & 1.17 & 0.12 & 10 \\
\hline Bdnf & 1.06 & 0.08 & 9 & 1.06 & 0.08 & 10 \\
\hline lgf1 & 1.16 & 0.16 & 9 & 0.80 & 0.08 & 10 \\
\hline $\lg 1 \mathrm{r}$ & 1.01 & 0.07 & 9 & 1.05 & 0.09 & 10 \\
\hline Egr1 & 1.02 & 0.08 & 9 & 0.76 & 0.07 & 10 \\
\hline $\mathrm{Mc} 3 \mathrm{r}$ & 1.04 & 0.11 & 9 & 0.78 & 0.06 & 10 \\
\hline Tac3 & 1.24 & 0.19 & 9 & 0.90 & 0.07 & 10 \\
\hline Gabbr1 & 1.00 & 0.04 & 9 & 1.06 & 0.07 & 10 \\
\hline Drd1 & 0.96 & 0.09 & 9 & 1.19 & 0.16 & 10 \\
\hline Drd2 & 1.00 & 0.11 & 9 & 1.12 & 0.11 & 10 \\
\hline Grin1 & 1.00 & 0.05 & 9 & 1.09 & 0.07 & 10 \\
\hline Grin2b & 1.04 & 0.06 & 9 & 2.19 & 1.19 & 10 \\
\hline Gad1 & 1.03 & 0.07 & 9 & 1.05 & 0.09 & 10 \\
\hline MeCP2 & 0.97 & 0.07 & 9 & 1.05 & 0.18 & 10 \\
\hline Dnmt3a & 0.98 & 0.06 & 9 & 1.09 & 0.08 & 10 \\
\hline
\end{tabular}




$\begin{array}{lllllll}\text { Dnmt3b } & 1.04 & 0.05 & 9 & 1.29 & 0.07 & 10 \\ \text { Hdac2 } & 1.03 & 0.05 & 9 & 0.99 & 0.05 & 10 \\ \text { Hdac4 } & 0.94 & 0.05 & 9 & 1.01 & 0.07 & 10 \\ \text { Foxp1 } & 0.98 & 0.04 & 9 & 1.16 & 0.06 & 10 \\ \text { Foxp2 } & 0.98 & 0.16 & 9 & 0.75 & 0.16 & 10 \\ \text { Per2 } & 0.96 & 0.05 & 9 & 0.93 & 0.07 & 10 \\ \text { Arntl } & 0.98 & 0.04 & 9 & 0.97 & 0.04 & 10\end{array}$

MEA

Females

Males

\begin{tabular}{lcccccc} 
& \multicolumn{2}{c}{$\mathrm{N}$} & \multicolumn{2}{c}{ Mean } & SEM & $\mathrm{N}$ \\
\cline { 2 - 6 } Esr1 & 1.13 & 0.16 & 9 & 1.27 & 0.16 & 10 \\
Esr2 & 1.48 & 0.38 & 9 & 2.69 & 0.54 & 10 \\
Ar & 1.12 & 0.13 & 9 & 1.29 & 0.15 & 10 \\
Gper & 0.99 & 0.09 & 9 & 1.08 & 0.08 & 10 \\
Pgr & 1.08 & 0.09 & 9 & 1.32 & 0.12 & 10 \\
Nr3c1 & 1.02 & 0.11 & 9 & 0.91 & 0.07 & 10 \\
Ahr & 1.08 & 0.10 & 9 & 1.03 & 0.08 & 10 \\
Cyp19a1 & 1.30 & 0.29 & 9 & 2.30 & 0.43 & 10 \\
Srd5a1 & 1.01 & 0.15 & 9 & 0.84 & 0.11 & 10 \\
Star & 1.19 & 0.20 & 9 & 1.24 & 0.11 & 10 \\
Hsd17b1 & 0.97 & 0.11 & 9 & 0.81 & 0.10 & 10 \\
Esrra & 1.02 & 0.12 & 9 & 0.84 & 0.08 & 10 \\
Esrrb & 1.04 & 0.13 & 9 & 0.83 & 0.07 & 10 \\
Esrrg & 0.91 & 0.06 & 9 & 0.86 & 0.11 & 10 \\
Oxt & 3.15 & 1.37 & 9 & 2.12 & 0.56 & 10 \\
Oxtr & 1.26 & 0.26 & 9 & 1.91 & 0.27 & 10 \\
Avp & 1.32 & 0.38 & 9 & 1.31 & 0.35 & 10 \\
Avpr1a & 1.08 & 0.08 & 9 & 0.96 & 0.09 & 10 \\
Kiss1 & $\mathbf{1 . 0 6}$ & $\mathbf{0 . 3 2}$ & $\mathbf{9}$ & $\mathbf{6 . 0 8}$ & $\mathbf{1 . 5 7}$ & 10 \\
Kiss1r & 1.18 & 0.12 & 9 & 1.01 & 0.08 & 10 \\
Crh & 0.95 & 0.10 & 9 & 0.81 & 0.08 & 10 \\
Crhr1 & 1.05 & 0.15 & 9 & 1.08 & 0.15 & 10 \\
Gnrh1 & 1.42 & 0.31 & 8 & 2.14 & 0.43 & 10 \\
Bdnf & 1.04 & 0.10 & 9 & 0.76 & 0.07 & 10 \\
Igf1 & 0.98 & 0.07 & 9 & 0.90 & 0.08 & 10 \\
Igf1r & 0.97 & 0.06 & 9 & 0.87 & 0.06 & 10 \\
Egr1 & 1.05 & 0.05 & 9 & 0.86 & 0.06 & 10 \\
Mc3r & 1.56 & 0.45 & 9 & 1.37 & 0.40 & 10 \\
Tac3 & 1.32 & 0.28 & 9 & 0.75 & 0.12 & 10 \\
Gabbr1 & 1.06 & 0.06 & 9 & 0.99 & 0.06 & 10 \\
Drd1 & 1.61 & 0.37 & 9 & 1.08 & 0.19 & 10 \\
Drd2 & 1.14 & 0.20 & 9 & 0.63 & 0.09 & 10 \\
Grin1 & 1.05 & 0.06 & 9 & 1.01 & 0.04 & 10 \\
Grin2b & 1.04 & 0.06 & 9 & 0.87 & 0.07 & 10
\end{tabular}




$\begin{array}{lllllll}\text { Gad1 } & 1.11 & 0.10 & 9 & 1.04 & 0.11 & 10 \\ \text { MeCP2 } & 1.04 & 0.06 & 9 & 1.06 & 0.09 & 10 \\ \text { Dnmt3a } & 1.00 & 0.09 & 9 & 0.84 & 0.07 & 10 \\ \text { Dnmt3b } & 0.98 & 0.12 & 9 & 1.00 & 0.10 & 10 \\ \text { Hdac2 } & 1.00 & 0.04 & 9 & 1.07 & 0.06 & 10 \\ \text { Hdac4 } & 0.98 & 0.06 & 9 & 0.82 & 0.04 & 10 \\ \text { Foxp1 } & 1.03 & 0.09 & 9 & 1.01 & 0.04 & 10 \\ \text { Foxp2 } & 1.61 & 0.47 & 9 & 1.37 & 0.29 & 10 \\ \text { Per2 } & 1.00 & 0.05 & 9 & 0.83 & 0.07 & 10 \\ \text { Arntl } & 1.07 & 0.10 & 9 & 0.98 & 0.07 & 10\end{array}$

bolded numbers indicate significant sex difference after adjusting for multiple comparisons 
Supplementary Table 3. Gene co-expression, social interaction, and preference across treatments.

\begin{tabular}{|c|c|c|c|c|c|c|}
\hline \multicolumn{7}{|l|}{ Females } \\
\hline & & Coefficient & Estimate & t-value & p-value & adj.p-value \\
\hline \multirow{6}{*}{ MEA } & \multirow{3}{*}{ Treatment } & DMSO & -0.00718 & -0.106 & 0.916 & 0.999 \\
\hline & & PCB & 0.018466 & 0.294 & 0.772 & 0.988 \\
\hline & & VIN & -0.00386 & -0.061 & 0.952 & 1.000 \\
\hline & Behavior & PC2 & 0.047341 & 0.837 & 0.411 & 0.796 \\
\hline & \multirow{2}{*}{ t x Behavior } & $P C B \times P C 2$ & -0.10677 & -1.41 & 0.172 & 0.432 \\
\hline & & VIN $x$ PC2 & -0.04574 & -0.706 & 0.488 & 0.866 \\
\hline \multirow{6}{*}{ POA } & \multirow{3}{*}{ Treatment } & DMSO & -0.0431 & -0.736 & 0.469 & 0.850 \\
\hline & & PCB & 0.0741 & 1.356 & 0.188 & 0.465 \\
\hline & & VIN & -0.03248 & -0.591 & 0.56 & 0.915 \\
\hline & Behavior & PC2 & 0.07305 & 1.487 & 0.151 & 0.388 \\
\hline & \multirow{2}{*}{ t x Behavior } & $\mathrm{PCB} \times \mathrm{PC2}$ & -0.03153 & -0.48 & 0.636 & 0.952 \\
\hline & & VIN $x$ PC2 & -0.01544 & -0.274 & 0.786 & 0.990 \\
\hline \multirow{6}{*}{ VMN } & \multirow{3}{*}{ Treatment } & DMSO & -0.11861 & -2.086 & 0.0483 & 0.138 \\
\hline & & PCB & 0.088936 & 1.678 & 0.1069 & 0.288 \\
\hline & & VIN & 0.003025 & 0.057 & 0.9552 & 1.000 \\
\hline & Behavior & PC2 & -0.06209 & -1.303 & 0.2056 & 0.499 \\
\hline & \multirow{2}{*}{ t x Behavior } & $P C B \times P C 2$ & -0.02727 & -0.427 & 0.6731 & 0.965 \\
\hline & & VIN $x$ PC2 & 0.066164 & 1.212 & 0.238 & 0.558 \\
\hline
\end{tabular}

\begin{tabular}{|c|c|c|c|c|c|c|}
\hline \multicolumn{7}{|l|}{ Males } \\
\hline & & Coefficient & Estimate & t-value & p-value & adj. p-value \\
\hline \multirow{6}{*}{ MEA } & \multirow{3}{*}{ Treatment } & DMSO & 0.053823 & 0.912 & 0.371 & 0.604 \\
\hline & & PCB & 0.025393 & 0.415 & 0.682 & 0.899 \\
\hline & & VIN & -0.00613 & -0.098 & 0.923 & 0.994 \\
\hline & Behavior & PC2 & 0.060819 & 1.492 & 0.149 & 0.276 \\
\hline & \multirow{2}{*}{ t x Behavior } & $\mathrm{PCB} \times \mathrm{PC4}$ & -0.06123 & -0.649 & 0.523 & 0.772 \\
\hline & & $V I N \times P C 4$ & -0.14916 & -2.068 & 0.05 & 0.098 \\
\hline \multirow{6}{*}{ VMN } & \multirow{3}{*}{ Treatment } & DMSO & -0.05868 & -1.101 & 0.28241 & 0.485 \\
\hline & & PCB & 0.06015 & 1.088 & 0.28776 & 0.493 \\
\hline & & VIN & 0.07725 & 1.37 & 0.18378 & 0.334 \\
\hline & Behavior & PC4 & 0.03216 & 0.873 & 0.39148 & 0.630 \\
\hline & \multirow{2}{*}{ t x Behavior } & $\mathrm{PCB} \times \mathrm{PC4}$ & -0.01304 & -0.153 & 0.87977 & 0.986 \\
\hline & & $V I N \times P C 4$ & -0.19943 & -3.06 & 0.00554 & 0.011 \\
\hline
\end{tabular}

Bolded numbers indicate significant effects $(p<0.05)$ and italicized numbers indicate a trend $(p<0.1)$ after adjusting for multiple comparisons. 